$$
\begin{gathered}
\text { UNIVERSIDADE DE SÃO PAULO } \\
\text { FACULDADE DE ODONTOLOGIA DE RIBEIRÃO PRETO } \\
\text { Departamento de Materiais Dentários e Prótese }
\end{gathered}
$$

\title{
"Análise da liberdade rotacional de pilares para prótese unitária de hexágono externo submetidos à ciclagem mecânica"
}




\section{"Análise da liberdade rotacional de pilares para prótese unitária de hexágono externo submetidos à ciclagem mecânica"}

Dissertação apresentada à Faculdade de Odontologia de Ribeirão Preto da Universidade de São Paulo - USP, para concorrer ao Título de Mestre em Odontologia

Área de concentração: Reabilitação Oral.

Orientadora: Profa. Dra. Rossana Pereira de Almeida Antunes 
AUTORIZO A REPRODUÇÃO E DIVULGAÇÃO TOTAL OU PARCIAL DESTE TRABALHO, POR QUALQUER MEIO CONVENCIONAL OU ELETRÔNICO, PARA FINS DE ESTUDO E PESQUISA, DESDE QUE CITADA A FONTE.

FICHA CATALOGRÁFICA

Piantino, Marcela Caffarena Junqueira

Análise da liberdade rotacional de pilares para prótese unitária de hexágono externo submetidos à ciclagem mecânica. Ribeirão Preto, 2010.

150 p. : il. ; $30 \mathrm{~cm}$

Dissertação de Mestrado, apresentada à Faculdade de Odontologia de Ribeirão Preto/USP. Área de concentração: Reabilitação Oral.

Orientadora: Antunes, Rossana Pereira de Almeida

1. Implante dental de hexágono externo. 2. Restaurações implanto-suportadas unitárias. 3. Liberdade Rotacional. 4. Ciclagem mecânica. 5. Torque. 6. Afrouxamento de parafuso. 
Nome: PIANTINO, Marcela Caffarena Junqueira

Título: Análise da liberdade rotacional de pilares para prótese unitária de hexágono externo submetidos à ciclagem mecânica. Ribeirão Preto, 2010.

Dissertação apresentada à Faculdade de Odontologia de Ribeirão Preto da Universidade de São Paulo para obtenção do título de Mestre em Reabilitação Oral.

Aprovado em: ___ I I 2010

\section{Banca Examinadora}

Prof. Dr. Instituição:

Julgamento: Assinatura:

Prof. Dr. Instituição:

Julgamento: Assinatura:

Prof. Dr. Instituição:

Julgamento: Assinatura: 
Dedicatóría 


\section{$\mathcal{A} \mathcal{D E U S}$}

Senhor! $\mathcal{P} \mathcal{A} I$ bondoso, paciente, amável, persistente e determinado... Obrigada Meu $\mathcal{P} \mathcal{A I}$ por toda força, luz, sabedoria, amor e coragem.... Obrigada por nunca desistir de mim e estar sempre ao meu lado!

\section{AOS MEUS PASS DELCIDES F AURORA}

Louvo ao $\mathcal{P} \mathcal{A} I$ infinitamente céu por ter me agraciado com pais tão maravilhosos e abençoados. Pai e $\mathcal{M}$ ãe, vocês sempre foram e sempre serão minha fortaleza e meu porto seguro. Graças aos seus empenho, amor, renúncia, carinho, afeto e luta, muita luta, hoje, estou aqui conquistando mais uma vitóría. Amor puro que se renova e se intensifica a cada minuto, estando juntos ou distantes! Obrigada por serem exemplos em minha vida, de amizade, amor, companheirísmo, entrega, persistêncía, idoneidade, fé e esperança... A vocês, todo meu amor, respeito, gratidão, carinho, amizade, apoío.... Obrigada exatamente por tudo e muito mais... Amo demais vocês!!!

\section{$\mathcal{A O} \mathcal{M E U} \mathcal{E S P O S O} \mathcal{T H} \mathcal{H} \mathcal{L} \mathcal{E S}$}

Meu grande amor, o que dizer de você? São poucas as palavras que tenho para descrever tão profundo $e$ intenso sentimento... Primeiramente, agradeço novamente a Deus, sempre maravilhoso e que me abençoou com a sua presença, de forma tão especial... Para começar, sou grata pelos momentos de paciência, compreensão e de renúncia à minha presença... pelos muitos momentos de companheirismo, ensinamentos, entrega e especialmente por todo o apoio e suporte durante toda nossa vida juntos e, príncipalmente durante a pós-graduação! Você é o meu acalento, me dá todo o amor e 
sustento de que precíso... com você os dias são maís azuís e o seu sorríso ilumina e alegra minha vida!!! Obrigada por tudo! Orgulho-me de ser sua esposa e de tê-lo como meu marido, amigo, companheiro e futuro papai dos nossos filhos! $\mathcal{E}$ u o amo demais!

$\mathcal{A}$ você o título de Co-mestre.....

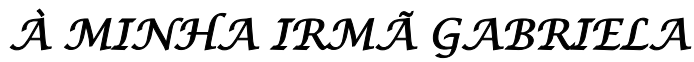

Mana querida, você sempre foi e sempre será meu exemplo de determinação, dedicação e coragem! Seu amor, carinho e amizade, são essenciais em minha vida! Amo você por tudo o que você é e significa! Minha estrela que Gritha a cada dia mais, sempre serei sua eterna fã, número 1!!! Tenho muito orgulho de ser sua irmä! Obrígada por ser a minha maninha tão amada e especial!

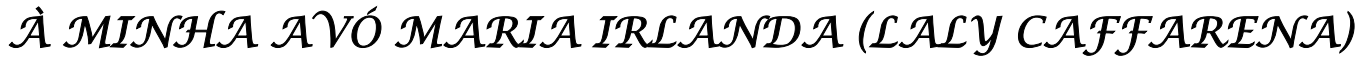

Vó querída, quanta saudade... Meu exemplo de amor, dedicação e superação... Quantos maravíthosos e inesqueciveis momentos passamos juntas!! Obrigada por todo o amor que sempre dedicou a mim, com tanto carinho, zelo, afeto e amizade... A sua alegría de viver contagiava a todos em sua volta...

Peço a Deus que permita a sua presença eterna perto de mím... Obrigada por tudo e por todo o amor!!! Amo demais a senhora, sua presença carnal faz muita falta, embora saiba que estaremos sempre juntas e que sempre poderei contar com você !!! Sua benção e proteção. 


\section{AOS MMEUS SOGROS GALENO e PRISCILA}

Deus continua sendo infinitamente bondoso comigo... me apresentou a uma familia especial... Especial no jeito de ser, "meio louco", alegre, sincero, carinhoso, divertido e um jeito $\mathcal{A} \mathcal{M} \mathcal{A} \mathcal{R}$, de ser... Obrigada a vocês pelo carinho, por todo amor e alegría com que me receberam, por serem pais presentes, persistentes e determinados... Grata pela paciência e doação! Pelo exemplo de sabedoria, cultura, honestidade e amor! Amo vocês e tenho orgutho de ser mais um membro desta família tão especial!

\section{$\mathcal{M I \mathcal { N H } \mathcal { A }} \mathcal{F} \mathcal{A M} I ́ L I \mathcal{A}$}

Posso dizer que, o que hoje sou, se deve um pouco a cada um de vocês.... Por isso agradeço de coração o amor, carinho, atenção e ensinamentos de vocês. Minha gratidão aos meus padrinhos, tíos e tías, primos e primas, aos meus cunhados: Gustavo e Cláudio. Grata Eliana e Claúdio por nos presentear com um lindo sobrinho. Obrígada a todos, por todo apoío e dedicação.

Obrigada por acreditarem em mim e me darem forças em todos os momentos.... 
Agradecimentos Especiais 


\section{À Profa. Dra. Rossana Pereira de Almeida Antunes}

Obrigada pelo carinho com que sempre me tratou desde os tempos de graduação quando, com seu jeitinho meigo e simpático me recebeu como orientada. Grata pelos ensinamentos, compreensão, paciência e disponibilidade. A sua luz e alegría são contagiantes e permitem um ambiente tranqüilo, prazeroso e aconchegante para se trabalhar. $\mathcal{A}$ tranqüilidade com que orienta, de forma capaz, objetiva, honesta e justa são virtudes e devem ser tomadas como exemplo.

Agradeço também por acreditar em mim, pela amizade, apoío, carinho e dedicação.

\section{Ao Prof. Dr. Rícardo Faría Ribeíro}

Professor Ricardo, obrigada por tantas dúvidas solucionadas e pela forma didática e suave de ensinar. Também pelos ensinamentos e o apoio, desde a época da graduação até hoje, na finalização da pósgraduação. Por ser tão atencioso e prestativo, eu quero expressar minha gratidão. O senhor é um grande exemplo!

À Profa. Dra. María da Glóría Chíarello, por estar sempre pronta a ajudar e a estender as mãos. Pelo carinho, atenção e conhecimentos que me passou durantes todos estes anos, com alegria, entusiasmo e muita dedicação, obrigada. Você é uma professora exemplar, digna de minha admiração! 


\section{À Dra. Elíana Teshima}

Dra. Eliana (Li) muito obrigada pelo carinho, disponibilidade e atenção nos momentos mais exaustivos da fase de elaboração da dissertação. Grata pela amizade e companheirismo. Você é como uma irmã e um exemplo de determinação!

\section{Ao meu marido Thales}

Thales, minha gratidão pelas idéias, questionamentos e discussões, que foram extremamente importantes para lapidação do meu conhecimento e desta forma, permitir a elaboração deste trabalho. Obrigada pela imensa ajuda em todas as etapas desta dissertação e por ser um companheiro tão carinhoso e especial.

\section{Ao Prof. Wirley Gonçalves Assunção}

Por ter me recebido em um momento de desespero, pela paciência e tranqüilidade em ensinar, pela disponibilidade imediata em ajudar e fornecer informação, meus agradecimentos.

Ȧ Adriana Cláudia Lapría Faría Queiroz, por ser a pessoas mais solicita e prestativa que conheço. Obrigada por toda ajuda e por sua dedicação na fase experimental e estatística do meu trabalho. Você é expressão de carinho e amizade!

À engenheira Ana Paula Macedo, pela troca de informação, por toda a ajuda no desenvolvimento laboratorial e estatístico dessa dissertação. Obrigada pelo companheirismo e amizade, carinho e dedicação. A sua ajuda foi indispensável para a conclusão deste trabalho! 
Agradecimentos 
À Faculdade de Odontología de Ríbeirão Preto, da Universidade de São Paulo, representada pelo seu Diretor Prof. Dr. Osvaldo Luiz Bezzon e Vice-Diretor na pessoa do Prof. Dr. Valdemar Mallet da Rocha Barros.

À Capes pelo apoío fínanceiro para realização desta pesquísa.

Ao curso de pós-graduação em Reabilitação Oral, na pessoa da Prof. Dra. Fernanda Panzerí Pires-de-Souza atual coordenadora, obrigada pelo carinho com que sempre me atendeu e pelos seus ensinamentos.

Aos professores do curso de pós-graduação em Reabilitação Oral da FORP-USP e, muitos dos quais tive o orgutho de ser aluna desde a graduação. Grata pela teimosia e dedicação em ensinar.

Aos docentes e funcionáríos do Departamento de Materíais Dentáríos e Prótese na pessoa da Profa. Dra. Helena de Freitas Oliveira Paranhos, chefe do departamento onde foi realizado este trabalho e que nunca mediram esforços em viabilizar nossas pesquisas.

À Profa. Dra. Iara Augusta Orsí, pelo empenho em conseguir os materiais para que fosse possivel a realização deste trabalho, pela dedicação e apoío.

丸̀ Profa. Dra. Cláudía Helena Lovato da Sílva, obrígada pelo carinho, dedicação, paciêncía e seriedade na luta pelo ensinar. $\mathcal{A}$ senhora é um exemplo de professora! Pela oportunidade de ser sua aluna no $\mathcal{P} \mathcal{A} \mathcal{E}$, meus agradecimentos. 
À Profa. Dra. Andréa Cândido Reís, pelo apoío e incentivo nos momentos em que precisei de um ombro amigo. Continue sempre sendo carinhosa, meiga e um exemplo de professora e de como se deve ensinar.

À Profa. Dra. Alma Blásida C. E. B. Catírse, professora tenho enorme carinho e admiração pela senhora. Obrigada por ser um exemplo na forma de ensinar, com tanto carinho, amor e dedicação. Minha gratídão pela amizade e apoío.

Ao prof. Dr. Valdemar Mallet da Rocha Barros, por ter acreditado em mim, ter me apoíado e aceitado como orientada no início do segundo ano da graduação. Grata pelos ensinamentos e amizade.

Aos amigos e colegas de pós-graduação, Ana Paula Farína, Daniella Rivera, Fábio Aguiar, Jerônimo Manço, Keíco Sano, Rômulo R. Régis e Wendel Teixeira pela amizade, paciência, momentos inesqueciveis na sala de aula e conhecimentos compartilhados.

Às minhas grandes e eternas amigas, Ana Paula Terossí De Godoi e Lariça Barbosa Raimundo, vocês são especiaís em minha vida. Construímos uma históría, repleta de risos, alegria, partilha, dedicação, carinho e amizade. Amigas "fithotas" que recebia em nossa casa para conversarmos, trabalharmos, estudarmos e por fim... darmos gostosas risadas e claro... novas receitas culinárias! Obrigada pelo apoio, amizade e carinho de vocês! 
À empresa $\mathcal{N}$ eodent $₫$ pela doação dos materiais, indispensáveis ao desenvolvimento desta pesquísa.

Aos amigos $\mathcal{E} d s o n$ Volta e Ricardo Antunes, obrigada pelo apoio e todo auxilio que me deram no desenvolvimento das pesquisas desde a graduação.

Aos técnicos do Caboratório de apoio clinico Fernando Schiavetto e Eduardo Destito pelo carinho e disponibilidade em ajudar.

Aos amigos e técnicos do Laboratório do Departamento de Materiais Dentários e Prótese, José de Godoy Filho, Lício Firmino Júnior, Marcelo Aparecido Vieira e Paulo Sérgío Ferreira, obrigada pela amizade, respeito, carinho e competência com que me atenderam e ajudaram durante toda a graduação e especialmente, pós-graduação. Grata por dividirem comigo os ensinamentos e serem tão solicitos.

Aos técnícos do Laboratório do Departamento de Materiais Dentários e Prótese, Odair Rosa Síva e Paulo César Teodoro, obrígada pela atenção e dedicação do trabalho de vocês!

Às secretarias do Departamento de Materiais Dentários $e$ Prótese, Regiane Damasceno e Ana Paula Xavier pela amizade, respeito, carinho e disponibilidade. Grata por todo apoí e paciência, vocês são muito queridas por mím! 
Às secretarias da pós-graduação, Regiane Crístina Moí Sacílotto e Isabel Cristina Galino Sola pela paciência e pronta disponibilidade em colaborar com o processo burocrátíco da pós-graduação. Obrígada por toda ajuda, compreensão e carinho.

Aos amigos e colegas de profissão Diogo Cruvinel e Cássio Nascimento, pela disposição em ajudar e por estarem sempre dispostos a compartilhar confecimento.

À querída amiga María Luiza Piantino e sua línda famílía, pelos momentos de descontração, alegría, companheirismo. Obrígada pelas frequentes e prazerosas caronas, pelo carinho e amizade.

Aos queridos "padinho e madinha" Evaldo e Liliane, pelo carinho, amizade, dedicação, compreensão e pelo amor de vocês! Minha gratidão por serem tão especiaís comigo e terem me recebido tão bem na família de vocês! Saíbam que os admiro muito! Grata por tudo!

$\mathcal{A}$ querida e eterna amiga Mariana $\mathcal{P}$. Desjardins, pelas palavras de incentivo, carinho e príncipalmente de amizade. Você é uma irmã para mim. Minha eterna gratídão pela sua amizade e dedicação! Torço muito por você!

Aos amigos e amigas Natalina Rocha, Taíana Días, Daniela Campos, Heloísa Helena, Isabel Dourado e Thiago de Moraís, Fayla Bosso, Helóisa e André Faría, Fabiola Xavier, Tatiane Carvalho, grandes e queridos amigos! Obrígada por serem tão pacientes $e$ compreensivos com minha, ou melhor, nossa ausência e pelos momentos alegres, felizes, dificeis, tristes, enfim... Grata simplesmente por serem nossos amigos. 
Às inesquecíveis e carinhosas primas, Patrícía Caffarena e Ana Caroline Caffarena, obrigada pela amizade, dedicação e pelos momentos felizes.

Aos amigos, Flávío Carriço, Ingríd Machado, Marina Xavier e Fabrício Mundim, Ana Luiza Felippini e Amanda Peracini, pela companhia e momentos compartilhados nos corredores e sala de estudo da pós-graduação.

Aos amigos da Biologia Oral Ríchard Honorato, Bruno Toledo, Marcelo Palinkas, Fernando Maeda e Paulo Batista por compartitharem ensinamentos e momentos de alegría e nervosismo.

$\mathcal{A}$ todos que de alguma forma colaboraram para a realização deste trabalho, meu muito obrigada! 
Resumo 
PIANTINO, M. C. J. Análise da liberdade rotacional de pilares para prótese unitária de hexágono externo submetidos à ciclagem mecânica. 2010. 150f. Dissertação (Mestrado) Faculdade de Odontologia de Ribeirão Preto, Universidade de São Paulo, Ribeirão Preto, 2010.

A estabilidade da prótese na junção parafusada está diretamente relacionada ao seu grau de adaptação e assentamento bem como à pré-carga que é gerada para unir os componentes. O afrouxamento e/ ou fratura do parafuso do pilar e também a desadaptação rotacional na interface implante/ pilar têm sido relatados como os maiores problemas encontrados em reabilitações unitárias parafusadas, em especial áreas de pré-molares e molares. Desta forma, o objetivo deste estudo foi avaliar a liberdade rotacional (LR) de 20 pilares protéticos tipo UCLA calcináveis (10 totalmente plásticos e $10 \mathrm{com}$ a base usinada em Tilite - Neodent Implante Osteointegrável), fundidos em liga de $\mathrm{NiCr}$ e Tilite, respectivamente, sobre 10 implantes de hexágono externo (Hexágono Externo, HE - Neodent Implante Osteointegrável) para próteses unitárias e, também o torque de afrouxamento do parafuso do pilar, submetidos à ciclagem mecânica. Um dispositivo foi fabricado para medir os ângulos de liberdade rotacional entre os hexágonos de implante e pilar em três diferentes tempos: antes e após o processo de fundição e depois da ciclagem mecânica. Os grupos foram classificados de acordo com as leituras de LR: (1) pilares novos + implantes novos; (2) pilares fundidos + implantes novos; (3) pilares fundidos + implantes, ambos ciclados; (4) outros pilares novos + implantes ciclados e (5) os mesmos pilares após fundição + implantes ciclados. Foram medidas as distâncias entre os lados e vértices do hexágono externo dos implantes e interno dos pilares. Para a realização da ciclagem mecânica, foi utilizada uma máquina de ensaio cuja carga média aplicada foi de $120 \mathrm{~N}$ em sentido axial, com componente oblíquo, a uma freqüência de 101 ciclos por minuto $(1,8 \mathrm{~Hz})$, durante 500.000 ciclos. O torque de aperto dos parafusos de fixação foi de $32 \mathrm{~N} . c m$ e o de afrouxamento mensurado após fadiga. Atestada a normalidade da amostra aplicou-se o teste $\mathrm{t}$ de Student para comparações em par $(p<0,05)$. Os resultados encontrados foram: para LR (em graus): Grupo Tilite - (1) 2,930 \pm 0,273; (2) 4,506 2 2,448; (3) 5,126 2 2,885; (4) 3,229 \pm 0,235; (5) 2,813 \pm 0,406; Grupo NiCr: (1) 4,684 \pm 0,788; (2) 3,21 $\pm 1,370$; (3) 3,818 \pm 1,904; (4) 6,029 \pm 0,503; (5) 4,421 \pm 2,499. A análise estatística revelou que não houve significância entre nenhuma das diferentes leituras de LR tanto para os pilares do grupo $\mathrm{NiCr}$ quanto para os do Tilite; todavia, quando a comparação foi 
feita entre os pilares, houve diferença estatística significativa para as leituras (1) e (4), com maiores valores para os pilares plásticos calcináveis. $O$ destorque para o grupo $\mathrm{NiCr}$ foi de $13,26 \pm 4,32 \mathrm{~N}$.cm com perda de torque de $41,44 \%$ e, para o grupo Tilite de $13,72 \pm 7,36 \mathrm{~N} . \mathrm{cm}$ e perda de torque de $42,88 \%$. Houve expressiva perda de torque para ambos os grupos, porém não houve diferença estatística na comparação entre as ligas. A quantidade de ciclos aplicada não foi suficiente para alterar de forma significativa a LR nos conjuntos implante/ pilar quando avaliados para cada tipo de liga. A aplicação de cargas cíclicas alterou de forma significativa as dimensões dos implantes.

Palavras-chave: Implante dental de hexágono externo. Restaurações implantosuportadas unitárias. Liberdade rotacional. Ciclagem mecânica. Torque. Afrouxamento de parafuso. 
Abstract 
PIANTINO, M. C. J. Evaluation of abutment rotational freedom of external hexagon single implant restorations after mechanical cycling. 2010. 150f. Dissertação (Mestrado) Faculdade de Odontologia de Ribeirão Preto, Universidade de São Paulo, Ribeirão Preto, 2010.

Prosthesis stability is related to misfit and screw joint preload. The screw loosening or fracture and rotational misfit have been related as the major problems in screwed single implant restorations, especially in molar or premolar areas. The aim of this study was to evaluate the rotational freedom and detorque of 20 UCLA type abutment (10 plastic and 10 machined abutments) cast in $\mathrm{NiCr}$ and $\mathrm{NiCrTi}$ alloys respectively, over 10 external hexagon implants submitted to mechanical cycling. A device was made to measure the rotational freedom between the implant hexagon and abutment in three different times: before and after the cast procedure and after the mechanical cycling. Groups were classified according the rotational misfit register: (1) new abutments + new implants; (2) cast abutments + new implants; (3) cycled cast abutments + cycled implants; (4) new abutments + cycled implants, and, (5) cast abutments + cycled implants. Measurements were made in the sides and vertices of external hexagon of the implants and internal hexagon of the abutments. Specimens were positioned with $30^{\circ}$ of inclination in relation to the vertical axis in an eletromechanical machine for mechanical cycling $\left(5.0 \times 10^{5}\right.$ cycles) using $120 \mathrm{~N}$ axial load and $1.8 \mathrm{~Hz}$ of frequence. The abutment screws were tightened to a torque of $32 \mathrm{~N} . \mathrm{cm}$ and the detorque measurement was registered after mechanical cycling. The rotational freedom results were: NiCrTi groups - (1) $2.930 \pm$ 0.273 ; (2) $4.506 \pm 2.448$; (3) $5.126 \pm 2.885$; (4) $3.229 \pm 0.235$; (5) $2.813 \pm 0.406$; and NiCr groups - (1) $4.684 \pm 0.788$; (2) $3.21 \pm 1.370$; (3) $3.818 \pm 1.904$; (4) $6.029 \pm 0.503$; (5) $4.421 \pm 2.499$. Statistical analysis $(p<0.05)$ showed that there is not significance among the different rotational freedom of $\mathrm{NiCrTi}$ or $\mathrm{NiCr}$ abutments; but there is statistically significant difference between (1) and (4) with higher values to the plastic abutments. Detorque of $\mathrm{NiCr}$ group was $13.26 \pm 4.32 \mathrm{~N} . \mathrm{cm}(-41.44 \%)$ and to the $\mathrm{NiCrTi}$ group was $13.72 \pm 7.36 \mathrm{~N} . \mathrm{cm}(-42.88 \%)$ but there is not statistically significant difference between the alloys. The mechanical cycling did not statistically influence the rotational freedom in the abutment/implant system when evaluated to each alloy but influenced the implant dimension.

Key words: External hexagon implant. Single-implant restorations. Rotational freedom. Mechanical cycling. Torque. Screw loosening. 
Lista de Simbolos e Abreviaturas 
$\%$ - Porcentagem

$<$ Menor

\pm - mais ou menos

- - Graus

${ }^{\circ} \mathrm{C}$ - Graus Celsius

$25 x$ - 25 vezes

3I - empresa de implantes - Implant Innovation Inc.

Al - Alumínio

AR - Anti-rotacional

C - Carbono

CAD I CAM - (Computer Assisted Designed/Computer Assisted Machined), tecnologia de fresagem de estruturas.

cm - centímetro

Co - Cobalto

$\mathrm{CoCr}$ - Cobalto-Cromo

$\mathrm{Cr}$ - Cromo

DP (ou dp) - Desvio padrão

EUA - Estados Unidos da América, em inglês (USA)

Fe - Ferro

GPa - Giga Pascal

gr - Grama

HE - Hexágono externo

HI - Hexágono Interno

Hz - Hertz

ìm - Micrometro

Kg - Quilograma

MEV - em inglês (SEM)- microscopia eletrônica de varredura.

min - Minuto

mm - Milímetro

Mo - Molibdênio

MPa - Mega Pascal

N - Newtons

n - Quantidade da amostra

N.cm - Newton / centímetro 
$\mathrm{Na}$ - Sódio

$\mathrm{Ni}$ - Níquel

$\mathrm{NiCr}$ - Níquel-Cromo

P - Nível de significância

Psi - libra por polegada quadrada

rpm - Rotações por minuto

Si - Silício

Ti - Titânio

UCLA - Pilar em plástico calcinável para prótese utilizado diretamente sobre o implante - em inglês (University California Los Angeles)

W - Tungstênio

$\mu \mathrm{m}$ - Micrometro 
Sumárío 
2 - REVISÃO DA LITERATURA

2.1 - Conexão parafusada implante - pilar protético: propriedades e características.

2.2 - O pilar UCLA

2.3 - Perda de torque de aperto e desajuste rotacional em próteses unitárias implanto suportadas

4 - MATERIAL E MÉTODO. .74

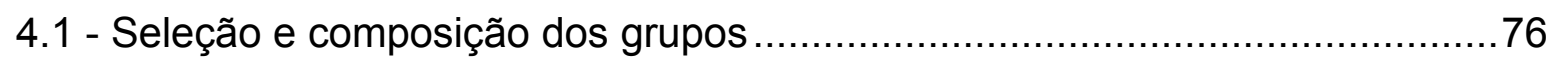

4.2 - Dimensões dos hexágonos dos implantes e pilares protéticos ……..............77

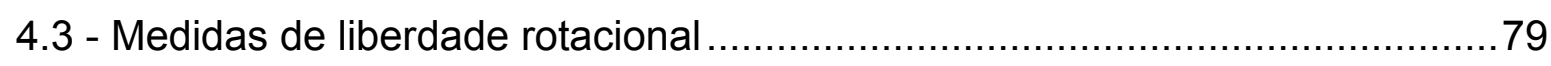

4.3.1 - Medida dos ângulos de liberdade rotacional experimental .....................82

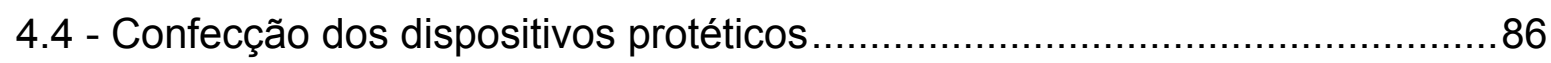

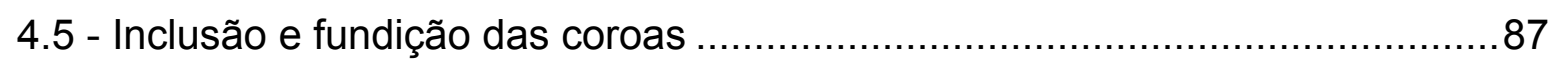

4.6 - Desinclusão e acabamentos das coroas protéticas ......................................92

4.7 - Preparo dos corpos-de-prova para simulação de fadiga mecânica ................92

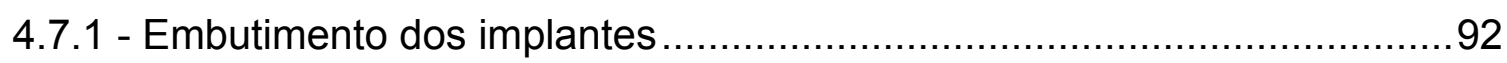

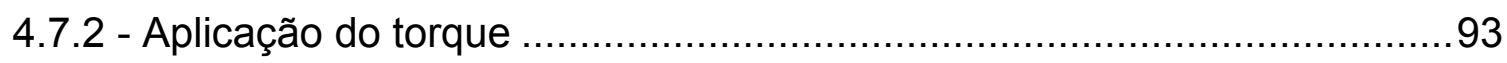

4.7.3 - Posicionamento dos corpos-de-prova na máquina de simulação de fadiga mecânica (MSFM) ........................................................................94

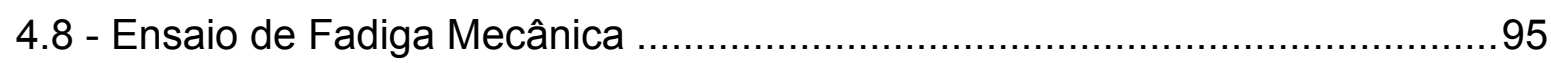

4.9 - Medida do torque de afrouxamento ou destorque .....................................97

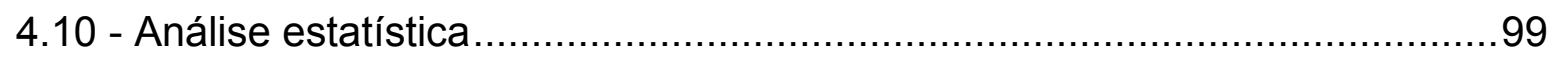

5 - RESULTADOS

5.1 - Dimensões dos hexágonos dos Implantes e pilares UCLA .........................101

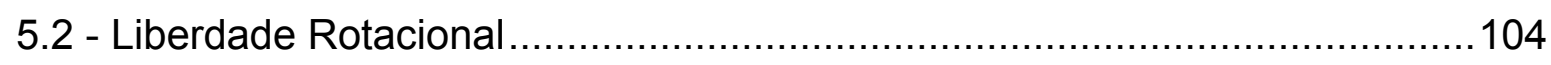

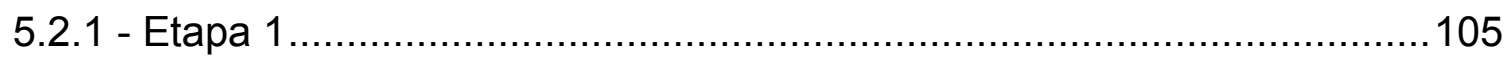

5.2.2 - Segunda etapa: comparação da Liberdade Rotacional entre as ligas

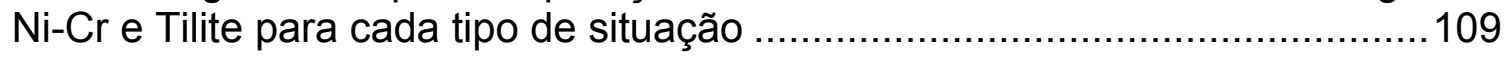

5.3 - Torque de afrouxamento ou destorque................................................112 


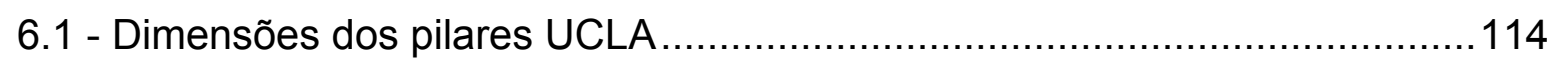

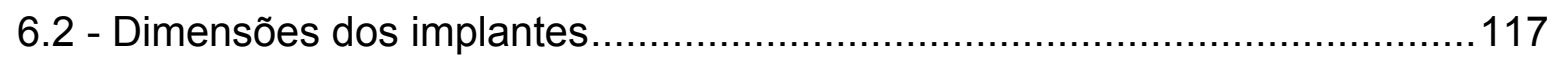

6.3 - Medidas de Liberdade (desadaptação) Rotacional da interface implante /

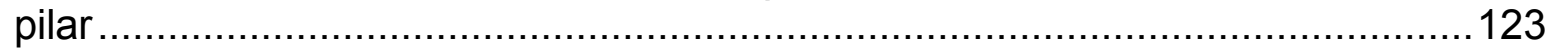

6.4 - Medidas de destorque ou torque de afrouxamento .................................128

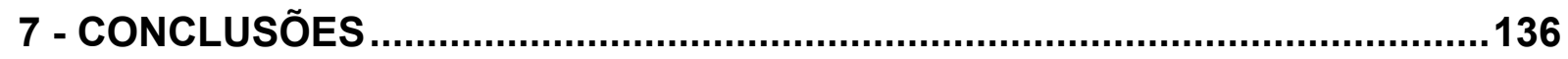

REFERÊNCIAS

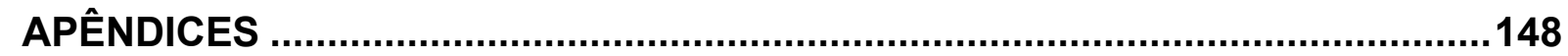




$$
1 \text { - Introdução }
$$


A perda de elementos dentais atribui conseqüências indesejáveis para a saúde do complexo estomatognático, podendo gerar problemas como desequilíbrios funcionais, estéticos e de ordem psico-social, nestes indivíduos (ADELL et al., 1981). A busca por alternativas para reabilitar os espaços ausentes na cavidade oral, através da substituição por análogos artificiais, é histórica e se tornou um grande desafio na área de saúde oral, fato que acabou por impulsionar o desenvolvimento e aprimoramento de técnicas e procedimentos restauradores.

A osseointegração, termo dado à união direta, estrutural e funcional entre o osso hospedeiro vital, organizado e implantes de óxidos de titânio possui um processo dinâmico que pode sofrer remodelação de acordo com a carga mastigatória aplicada. Ela foi descoberta, acidentalmente, por Brånemark e seus colegas em 1952 e, com isso fez vislumbrar a possibilidade de mais uma alternativa de tratamento, surgindo, desta forma, a implantodontia moderna. Em 1977, Brånemark et al. relataram os princípios da osseointegração de implantes de titânio em tecido ósseo e sua aplicação clínica na reabilitação de pacientes desdentados, com conseqüente restabelecimento da função mastigatória. Visando a osseointegração em humanos, em 1965 foram colocados os primeiros implantes, cujo desenho da plataforma possuía um encaixe no formato de hexágono externo com a função de, inicialmente, servir como um mecanismo de transferência de torque rotacional usado durante a colocação cirúrgica do implante e, posteriormente, em reabilitações unitárias, utilizado como um índex protético e mecanismo antirotacional. (BRÅNEMARK et al., 1977, 1983; ADELL et al., 1981; BINON, 1995, 2000). Após a realização de intensos e extensos estudos experimentais e clínicos, os resultados obtidos foram de grande importância para o reconhecimento da técnica, oferecendo previsibilidade e longevidade para o tratamento (HAAS et al, 1995).

Os primeiros protocolos de tratamento com implantes osseointegrados baseavam-se na reabilitação de mandíbulas totalmente edêntulas, em pacientes considerados por Brånemark como "inválidos orais", obtendo-se altos índices de sucesso (ALBREKTSSON, 1988; ADELL et al., 1990). Com isso, surgiu grande interesse no uso de implantes em pacientes com desdentamentos parciais e em reposições unitárias. A extensão ao uso de implantes osseointegrados para reposições de elementos unitários ausentes é, segundo Schmitt e Zarb (1993), uma opção prudente de tratamento, uma vez que segue o objetivo de tratar os pacientes 
sem causar danos irreversíveis, além de evitar problemas causados por outros procedimentos alternativos como, por exemplo, desgastes em estrutura dental hígida para próteses parciais fixas (SCHWARTZ-ARAD; SAMET; SAMET, 1999; EKFELDT, CARLSSON; BÖRJESSON, 1994 e BECKER, BECKER, 1995). Além disso, possibilita a preservação óssea no local onde irá receber o implante evitando reabsorção atrófica do rebordo edêntulo. Segundo Sones (1989) o sucesso da reabilitação protética tem maior significância do que somente o sucesso da osseointegração do implante.

A prótese sobre implante pode ser feita de duas maneiras distintas: através da conexão de um componente protético diretamente à cabeça do implante, sendo a prótese confeccionada sobre a estrutura de um pilar que é conectado à cabeça do implante por meio de um parafuso; ou através de um componente intermediário, o qual após estar conectado à cabeça do implante, também por meio de um parafuso, poderá receber a prótese construída sobre uma infra-estrutura que agora se adapta sobre ele, através de um segundo parafuso ou mesmo por um agente cimentante (BUTIGNON, 2007).

Quando dois componentes são conectados por um parafuso, essa unidade é denominada junta parafusada e em prótese sobre implante, exemplo clássico deste tipo de junção, um componente é o implante e o outro o pilar. O objetivo principal de apertar um parafuso é gerar adequada força de travamento entre as duas peças, de forma que permaneçam unidas e, que seja capaz de prevenir e resistir à separação das partes constituintes, deslocamento ou ainda ao afrouxamento quando expostas à vibração e à ação de repetidas cargas cíclicas externas, ou seja, conseguir estabilidade adequada na junção parafusada (BINON, 2000a; NAKAMURA; CONTIN; PICHLER, 2006). Essa estabilidade é considerada uma função da précarga, que é conseguida quando, após a aplicação do torque de aperto, uma força compressiva (tensão) é gerada no parafuso enquanto este se encaixa em seu local de assentamento dentro do pilar e as roscas macho e fêmea se encaixam dentro do corpo do implante. No processo de apertar o parafuso, ele se alonga e pressiona as duas partes juntas criando uma força de travamento. Essa tensão (força) criada no parafuso é chamada de pré-carga e é gerada pela aplicação do torque (BURGUETE et al., 1994; DIXON et al., 1995; BINON, 2000a; KHRAISAT et al., 2004a; KHRAISAT et al., 2004b). 
O sucesso da junção está diretamente relacionado ao alongamento do parafuso do pilar ou à pré-carga conseguida a partir do torque de aperto e sua manutenção por todo o período funcional. Se o parafuso afrouxa e a pré-carga cai ou diminui abaixo de um limite crítico, a estabilidade da união estará comprometida podendo levar a uma potencial falha clínica (BURGUETE et al., 1994; CIBIRKA et al., 2001; HAACK et al., 1995).

Existem vários tipos de componentes protéticos, e suas indicações levam em conta a necessidade do caso (próteses múltiplas ou unitárias), o tipo de região (anterior ou posterior), necessidade estética, quantidade de espaço interoclusal e posicionamento e inclinação dos implantes (LEWIS ET al., 1988a; LEWIS; LLAMAS; AVERA, 1992). O pilar UCLA foi desenvolvido pela Universidade da Califórnia - Los Angeles, na década de 80 trazendo como principal característica a eliminação do pilar intermediário. Originalmente, o pilar UCLA era plástico, que devia ser encerado e fundido em liga de metal, nos moldes da restauração final desejada. Este modelo persiste até o presente momento, porém, atualmente dá-se preferência para os pilares cujas bases já venham prontas e usinadas de fábrica, visando a diminuição da interferência do processo de fundição na adaptação destes pilares (KANO et al., 2007; VIGOLO; MAJZOUB; CORDIOLI, 2000). Ele foi criado com o intuito de solucionar problemas como distância interoclusal limitada, angulação e distância interproximal entre implantes, além de agregar benefícios na estética da prótese. Primeiramente foi desenvolvido para próteses múltiplas e, posteriormente, para próteses unitárias com a incorporação de um desenho com característica antirotacional, no formato de hexágono, para encaixar na cabeça do implante. Esta abordagem foi especialmente benéfica para pacientes com edentulismos parciais e também útil na fabricação de algumas barras para overdenture (LEWIS; LLAMAS; AVERA, 1992).

Visando a estabilidade e o sucesso da prótese implanto-suportada, uma condição essencial é que haja adequada adaptação entre as peças e que esta, seja passiva. Na literatura não há consenso a respeito de uma definição clara e precisa de adaptação passiva, mas considera-se que ela ocorre quando a prótese é conectada sem que tensões sejam geradas no sistema e, ainda, que ela deve ser avaliada em 3 eixos: vertical, horizontal e angular, devendo a prótese estar livre de báscula ou interfaces verticais e horizontais (ASSUNÇÃO et al., 2010; WHITE, 1993). Do ponto de vista mecânico, a passividade das próteses é fundamental para 
a estabilidade dos componentes, já que evidências demonstram que a falta de passividade pode ser a causa da alta taxa de complicações mecânicas relatadas, especialmente de afrouxamento de parafusos (BINON, 2000a; KOHAVI, 1993). Avaliações da adaptação marginal de componentes protéticos mostram que os mesmos apresentam certo grau de desajuste que pode variar conforme o fabricante e que os procedimentos laboratoriais necessários à confecção da prótese tendem a aumentar o desajuste marginal (BINON, 1995; BYRNE et al., 1998; MA; NICHOLLS; RUBENSTEIN, 1997).

O assentamento entre os componentes também pode influenciar a estabilidade da conexão. Após o aperto do parafuso de retenção, as microrugosidades entre as superfícies de contato começam a se regularizar, diminuindo a distância entre os componentes e promovendo uma folga entre os mesmos, o que pode resultar em afrouxamento dos parafusos (BINON, 2000a). Carr; Brunski e Hurley (1996) observaram uma redução de cerca de $30 \%$ nos valores de pré-carga para componentes submetidos à fundição.

Múltiplos são os fatores que podem resultar em instabilidade da junta parafusada: pré-carga inadequada, desenho da prótese ou do parafuso, pobre adaptação do componente protético, sedimentação de superfícies microrugosas e carga excessiva (BINON et al., 1996, 2000a).

BINON (1996, 2000a, 2000b) verificou que, entre outros fatores, o desajuste entre o pilar (abutment) e implante são causas de falhas do parafuso de retenção daí a importância da adaptação passiva entre as interfaces, que pode eliminar a situação de desajuste entre os hexágonos. Porém, como essa passividade total é difícil de ser conseguida, os fabricantes de implantes tem tentado resolver este problema por meio de desenhos com características anti-rotacionais, para se conseguir o maior grau de adaptação possível entre o componente protético e o implante, visando a manutenção do tratamento reabilitador unitário por tempo ideal. Para May et al., (1997) o encaixe dos hexágonos tem dupla função, que é localizar e alinhar o pilar ao implante e servir como um mecanismo anti-rotacional.

As desadaptações podem ser classificadas como: vertical, horizontal, angular e rotacional (ASSUNÇÃO et al., 2010) e desajustes de $10 \mu \mathrm{m}$ são capazes de sobrecarregar os parafusos que passam a ser utilizados para fechar a interface comprometendo a estabilidade da conexão (SAKAGUCHI; BORGENSEN, 1993). A 
falta de adaptação dos componentes pode alterar a pré-carga inicial, colocando os parafusos sob tensão e reduzindo o seu tempo de fadiga.

A desadaptação rotacional tem sido considerada um dos maiores fatores relacionados à falha da junção parafusada (BINON; McHUGH, 1996; KANO et al., 2007; GARINE et al., 2007). A estabilidade protética também está diretamente relacionada ao desajuste rotacional dos componentes, isto significa que quanto menor o desajuste rotacional, maior é a área de contato entre os hexágonos e, conseqüentemente, maior é a resistência do parafuso ao afrouxamento (BINON, 1996; BINON; McHUGH, 1996). Conexões com desajuste rotacional inferior a $2^{\circ}$ são mais estáveis ao ser submetidas a cargas cíclicas e, para evitar a falha precoce dos parafusos, o desajuste rotacional entre implante e intermediário não deve exceder $5^{\circ}$ (BINON, 1998).

A falha da junção parafusada é definida pela mobilidade do pilar resultante do afrouxamento do parafuso de pilar, fratura do parafuso ou do implante. (BINON, 1998). Em próteses unitárias, o problema mecânico mais encontrado relacionado à falência dessas próteses implanto-suportadas, foi a falha dos parafusos que pode variar de $6 \%$ a $48 \%$, especialmente o afrouxamento e/ou fratura dos parafusos dos pilares (EKFELDT; CARLSSON; BÖRJESSON, 1994; GOODACRE, et al., 2003; HASS et al., 1995; JEMT; LEKHOLM; GRONDAHL, 1990; SONES, 1989).

Já a prevenção de fraturas dos parafusos de pilar inicia com a garantia de adaptação passiva da estrutura metálica e cuidadoso equilíbrio da oclusão. Outros fatores de importância a serem considerados são a quantidade de reabsorção da crista óssea, o comprimento e a quantidade de implantes, o arco antagonista, a angulação dos implantes e hábitos parafuncionais. (SONES, 1989)

Em restaurações implanto-suportadas unitárias, os pilares UCLA são uma solução bastante utilizada, uma vez que, a técnica utilizada para a confecção da prótese é bastante simples e o custo, mais baixo. Além do mais, com os pilares de base pronta ou usinada, a literatura tem demonstrado melhores resultados de adaptação. Diante do exposto, o objetivo deste presente trabalho foi verificar a desadaptação (liberdade) rotacional de pilares UCLA, antes e após fundição, submetidos à ciclagem mecânica, além de avaliar a quantidade de perda do torque após a simulação de fadiga. 
2 - Revísão da Literatura 
Para tornar a leitura mais organizada e didática, a revisão foi divida em itens: conexão parafusada implante - pilar protético: propriedades e características, o pilar UCLA e perda do torque de aperto e desajuste rotacional em próteses unitárias implanto-suportadas.

\section{1 - Conexão parafusada implante - pilar protético: propriedades e características}

Adell et al. (1981), analisaram 2.768 implantes instalados em 371 pacientes edêntulos, com a proposta de fazer uma sumária revisão dos materiais, métodos e resultados de 15 anos de acompanhamento longitudinal dos tratamentos com implantes osseointegrados de maxilares edêntulos. Por variados motivos, os reais valores que compõem o material deste trabalho são: 1997 implantes instalados que formaram 146 próteses maxilares e 172 próteses mandibulares em 284 pacientes que permaneceram com acompanhamento do tempo proposto. No período de 5 a 9 anos, $81 \%$ dos implantes da maxila e $91 \%$ da mandíbula permaneceram estáveis. Em relação às próteses, $89 \%$ na maxila e $100 \%$ na mandíbula estavam estáveis. Durante a cicatrização e o primeiro ano após a conexão da prótese, o valor médio de perda óssea foi $1,5 \mathrm{~mm}$. Em cada ano subseqüente observaram a perda de apenas $0,1 \mathrm{~mm}$. Fraturas foram observadas em 69 implantes, as quais eram freqüentemente associadas com perda acelerada do osso marginal. Outras complicações mecânicas foram fraturas de próteses, parafusos de pilares e de próteses. As próteses sobre implantes mostraram-se estética, fonética e funcionalmente adequadas para restaurar o sistema mastigatório de pacientes edêntulos por até mesmo mais de 15 anos. Os resultados clínicos encontrados pelos autores preencheram e até excederam as exigências estabelecidas na Conferência de Harvard de 1978 padrão de exigência vigente na época - dos procedimentos de sucesso da implantação dentária. Ainda, segundo os autores, o tratamento com próteses sobre implantes osseointegrados implica não somente em uma reabilitação oral como também em um considerável impacto na situação psicossocial do paciente, que antes sofria com o desdentamento total compensado por próteses inadequadas.

Schmitt e Zarb (1993) testaram a eficácia de coroas protéticas sobre implantes unitários para repor perdas dentárias unitárias. Eles acompanharam 32 pacientes que foram tratados com 40 implantes unitários, sendo 28 implantes 
colocados na maxila (27 na região anterior e somente um na região posterior) e 12 na mandíbula (todos em região posterior). Nos dados coletados, todos os implantes mantiveram-se em função, sob aplicação de carga, variando em período de 1,4 a 6,6 anos. Os implantes estavam clinicamente assintomáticos, imóveis, e radiograficamente livres de qualquer tipo de morbidade. Ainda, nenhuma reclamação de desconforto ou algum outro sintoma foi relatado pelos pacientes, sendo todos os implantes considerados osseointegrados de acordo com os critérios de sucesso desses autores. As manutenções exigidas foram mínimas e consistiram somente em apertamento do parafuso da coroa. Estes resultados sugerem que a técnica de osseointegração pode ser adaptada para o uso em pacientes com perda de dentes unitários, com bom prognóstico.

A estabilidade da união entre a restauração protética e o implante é um dos critérios mais importantes para se conseguir sucesso nas restaurações implantosuportadas unitárias. A união entre implante e pilar é uma conexão entre duas partes seguradas por meio de parafuso, cuja função é criar uma força de travamento entre o implante e o pilar que seja suficiente para resistir às cargas externas (Binon et al.,2000a). A força de aperto exercida sobre o parafuso é denominada torque e este, quando aplicado, desenvolve uma força compressiva de travamento entre as partes, chamada de pré-carga, responsável por manter os componentes unidos. Quando algum tipo de desadaptação está presente, e a interface pilar/ implante não está precisamente alinhada, parte do torque aplicado é dissipado para tentar alinhar os componentes. Na junção parafusada, a aplicação de um torque adequado assim como a tolerância de adaptação entre o hexágono externo do implante com o hexágono interno dos pilares, têm sido sugeridos como os dois maiores fatores da instabilidade da união parafusada.

Com o objetivo de medir o torque necessário para afrouxar os parafusos de diferentes sistemas anti-rotacionais da conexão implante/pilar, para a restauração de implantes unitários, após função simulada (aplicação de carga mastigatória), foi que Bredding et al. (1993) realizaram um estudo comparando três diferentes combinações pilar / implante em dois diferentes períodos de tempo. Um selante adesivo também foi testado para determinar seu efeito no torque necessário para afrouxar os parafusos sob as mesmas condições experimentais. Para isso, foram avaliadas as seguintes conexões: (1) Implante Calciteck integral Omnilock com desenho de octógono interno e pilar anti-rotacional Integral Omnilock (Calcitek); (2) 
Implante Bio-Vent com hexágono interno e pilar anti-rotacional Hex-lock (Dentsply / Core-Vent); e (3) Implante Minimatic com hexágono externo e pilares anti-rotacionais unitários do mesmo sistema. Sobre cada pilar foi encerado um dente com forma de pré-molar, reproduzindo-se dez réplicas para cada sistema, as quais foram fundidas em liga metálica. Os implantes foram fixados em blocos de resina acrílica autopolimerizável com o auxílio de um delineador e, em um período de 24 horas após o embutimento, os parafusos dos pilares de um grupo pré-teste, constituído de quatro combinações pilar / implante de cada sistema, foram apertados com um torque de 22,6N.cm, utilizando-se um torquímetro (Tohnichi). Esta medida foi realizada novamente após dez minutos, para minimizar o relaxamento embutido. Dois minutos depois, o torque necessário para afrouxar os parafusos foi registrado como o valor de destorque imediato. Os parafusos foram novamente apertados, seguindo a mesma seqüência e, após 4 horas e 25 minutos, o torque necessário para afrouxar os parafusos foi novamente obtido, sendo registrado como destorque. Este procedimento foi realizado para verificar a existência de um relaxamento adicional entre os componentes, o que resultaria em um valor de destorque menor. Assim, o destorque inicial foi calculado pela diferença entre o destorque (após 4 horas e 25 minutos) e o destorque imediato, sendo que esta medida foi utilizada como grupo controle ou grupo pré-teste.

Três grupos testes foram analisados, observando-se a diferença entre os valores de torque de afrouxamento do grupo pré-teste e os valores de torque de afrouxamento de cada grupo. (1) O grupo 1 foi constituído de cinco combinações de cada sistema, das quais duas amostras eram pertencentes ao grupo pré-teste. Os parafusos foram apertados como no grupo pré teste, e em cada pilar uma coroa foi cimentada com um cimento resinoso, sendo que uma hora após a cimentação, uma força de $6 \mathrm{~kg}$ foi aplicada a uma distância de $1,5 \mathrm{~mm}$ do longo eixo do parafuso. Cada amostra recebeu carga vertical e lateral por 16.667 ciclos ou 3 horas e 25 minutos ou o equivalente a 1 mês de função mastigatória. Como já foi dito, após a aplicação destas forças foi registrado o torque necessário para afrouxar o parafuso, sendo as medidas comparadas com as do grupo pré-teste. (2) O grupo 2 foi constituído de cinco amostras de cada sistema, também com duas provenientes do grupo pré-teste, sendo a única diferença com o grupo anterior, a utilização de um selante adesivo (Ceka Bond), aplicado nas roscas do parafuso do pilar, antes do aperto. Feito isso, após 12 horas de permanência das amostras em temperatura ambiente, os mesmos 
procedimentos do grupo anterior foram realizados. (3) O grupo 3, as cinco amostras de cada sistema, que tinham tido o adesivo aplicado, foram reapertadas $\mathrm{e}$ submetidas a 100.002 ciclos ou 19,5 horas (equivalente a 6 meses de função mastigatória) e como nos grupos anteriores, registrado o torque necessário para afrouxamento dos parafusos. Os resultados não mostraram diferença entre o destorque imediato e o destorque após 4 horas e 15 minutos, assim como não houve nenhuma diminuição significante no torque requerido para afrouxar os parafusos, dos sistemas com octógono interno (Calcitek Omnilock) e hexágono externo (Minimatic), após os períodos estudados (1 e 6 meses de simulação intraoral). As amostras com hexágono interno (sistema Core-Vent), entretanto, exibiram uma diminuição significante na quantidade de torque de afrouxamento dos parafusos após o teste de carga cíclica referente a um mês, mas não com 6 meses de simulação. A adição do selante adesivo (Ceka Bond) aumentou significativamente a quantidade de torque necessária para afrouxar os parafusos apenas do sistema de hexágono interno.

Burguete et al. (1994) realizaram uma revisão a respeito das características de aperto (torque) para uniões parafusadas em implantes osseointegrados, na qual os maiores objetivos foram definir a quantidade de torque desejado a ser aplicado e também identificar o melhor método para se conseguir tal situação. Segundo os autores, o objetivo de apertar uma união parafusada é conseguir uma ótima précarga que irá maximizar a resistência à fadiga, permitindo um grau de proteção considerável contra o afrouxamento.

Segundo Bickford o mecanismo de afrouxamento dos parafusos ocorre em duas etapas. Inicialmente, forças externas aplicadas a uma união parafusada, como ocorre durante a mastigação, levam a uma efetiva erosão da pré-carga nesta junção. O parafuso, nessa situação, funcionaria como uma mola, esticada pela pré-carga pela qual esse estiramento é mantido por forças de fricção de suas roscas. Qualquer força externa, seja ela axial ou transversal, que cause uma pequena quantidade de deslizamento entre as roscas, sem interessar quão pequeno seja, libera um pouco da tensão desse estiramento e uma pequena quantidade de pré-carga é perdida. Nesse momento, quanto maior a pré-carga na união, maior será a resistência ao afrouxamento, isso porque as forças de fricção entre as roscas são maiores e uma grande quantidade de forças externas será requerida para causar deslizamento entre elas. Na segunda etapa do afrouxamento, a pré-carga está abaixo de um valor 
crítico, o que deixa a união entre as roscas menos intensa a ponto de qualquer ação de força externa ou vibração, causar o desrosqueamento do parafuso. Uma vez atingido esse estágio, a união parafusada torna-se mais susceptível à abertura e, consequentemente, a falhas.

Outro fator importante, relacionado ao fato da seleção de um adequado nível de aperto, diz respeito à fadiga do parafuso. Se um parafuso é apertado até se obter uma união firme, ou seja, significando que todas as regiões da união estão em contato, todas as cargas provenientes do meio externo de certa forma atuarão para separar essa união. Entretanto, enquanto o torque de aperto é aumentado acima do nível de união das partes, a pré-carga aumenta e o parafuso irá gradualmente receber proteção adicional contra as cargas externas. Essa proteção é um beneficio adicional contra a fadiga do parafuso até o ponto em que o total de carga recebida pelo parafuso (pré-carga mais as cargas recebidas do meio externo) seja aproximadamente igual à resistência do parafuso. Quando o nível de carga é excedido, a resistência à fadiga do parafuso diminui drasticamente.

Para os autores, o relacionamento entre a pré-carga e o torque no parafuso depende do coeficiente de fricção entre as roscas, da geometria delas e das propriedades dos materiais envolvidos, sendo o primeiro fator de maior relevância. $O$ coeficiente de fricção depende da dureza do material, do polimento da superfície, da quantidade e propriedade do lubrificante e da velocidade do aperto. Ele aumenta conforme a dureza do material e a rugosidade de superfície. Da mesma forma quando diminui a quantidade de lubrificante aumenta o coeficiente de fricção. Segundo os autores, para manter uma velocidade de aperto dentro dos limites, é aconselhável o uso de um controlador de torque eletrônico.

Os autores relatam a existência de 3 métodos para se apertar um parafuso: 1por meio do uso de um torquímetro, 2- de um medidor de ângulo, onde se observa a deformação angular necessária do parafuso para seu aperto, ou 3- por meio do uso de um torquímetro associado a um medidor de ângulo, o que tornaria a aplicação de torque mais precisa. Os autores sugerem o desenvolvimento de um dispositivo capaz de transmitir adequado torque aos parafusos, avaliando a quantidade de graus necessária para o aperto dos mesmos, uma vez que um medidor de ângulos pode ser capaz de identificar um problema de falta de adaptação passiva entre os componentes, tornando-se um elemento de diagnóstico da adaptação. 
Wie (1995) realizou um estudo no qual descreve um seleto grupo de complicações encontradas no primeiro registro de acompanhamento clínico após o tratamento de pacientes total e parcialmente edêntulos com próteses implantosuportadas na Faculdade de Odontologia da Universidade de Oslo. Foram incluídos neste trabalho, 56 pacientes com 240 implantes do sistema Brånemark, que foram examinados 2 a 4 meses depois dos implantes serem levados em função e foi realizado um protocolo para coletar informações sobre as condições do tratamento. Os exames incluíam o registro da higiene oral, alterações patológicas em tecido mole e duro, o tipo de material usado nas superfícies de contato oclusal, o esquema oclusal utilizado, além das falhas técnicas e mecânicas. Segundo o autor, duas hipóteses têm sido propostas para explicar a falha das próteses implanto-retidas, são elas: a teoria da placa (placa induzindo gengivite) e a teoria de carga (concentração de estresse). Mesmo implantes que estejam inicialmente osseointegrados, se tiverem um excesso de carga aplicada sobre eles, podem resultar em microfraturas ósseas e um movimento relativo, levando, desta forma, à reabsorção óssea ao redor dos implantes. Além disso, o tipo de material das superfícies oclusais, o grau de extensão dos dispositivos protéticos, a localização do implante em relação à qualidade e volume ósseo e o tipo de esquema oclusal, têm sido associados aos limites de tolerância de carga da entidade prótese-implante. Os materiais utilizados para contato das superfícies oclusais foram: resina acrílica, ligas de ouro e cerâmica e, nas arcadas antagonistas, os padrões foram: esmalte/ dentina, metal, cerâmica, materiais plásticos e próteses totais com dentes em acrílico. Cerca de $83 \%$ dos implantes localizavam-se na região anterior da maxila e da mandíbula e a taxa de sucesso para os implantes individuais, neste estudo, foi de $94 \%$, o que está dentro dos níveis aceitáveis para os sistemas de implantes osseointegráveis. Todos os tipos de sobreestruturas, exceto as próteses unitárias de CeraOne, foram desaparafusadas para inspeção dos implantes e da mobilidade da junção parafusada. $O$ índice de placa e as complicações de tecidos moles foram baixos e não puderam ser associados à perda precoce dos implantes. Quanto ao esquema oclusal, o preferido foi função em grupo $(53,4 \%)$, seguido de função canina $(37 \%)$ e, por último, articulação balanceada (9\%). Durante o período entre o carregamento permanente (funcionamento) e o primeiro registro de acompanhamento, 14 parafusos de pilares e 7 parafusos de ouro afrouxaram. A maioria dos parafusos soltos $(22 \%)$ foram encontrados nas próteses fixas implanto- 
suportadas com superfícies oclusais plásticas ocluídas com próteses totais com dentes de acrílico no arco antagonista. Os parafusos que falharam foram distribuídos em 14 pacientes, significando que $25 \%$ dos pacientes experimentaram este tipo de complicação depois do tratamento protético executado, precisando de reparos e serviços extras. A porcentagem encontrada neste estudo para afrouxamento da junção parafusada foi de $9 \%$. Portanto, as razões para as falhas são consideradas iatrogênicas e poderiam ser evitadas se, medidas como a construção de uma oclusão funcional equilibrada, um método mais previsível de apertamento dos parafusos e materiais mais confiáveis e resistentes para parafusos suportarem melhor as forças a que são submetidos fossem desenvolvidos e/ou seus limites respeitados.

Discutindo sobre os principais aspectos da conexão de hexágono externo e a estabilidade do parafuso nesta união, Binon (2000a), descreveu os fatores que se destacam no envolvimento do mecanismo de uma junção parafusada e como eles atuam na sua performance. Segundo o autor, a função básica do parafuso é criar uma força de travamento entre as duas partes da conexão, que seja suficiente para prevenir a separação, deslizamento e afrouxamento da junção quando exposta à vibração, choques ou abalos e repetidas cargas cíclicas externas. Quando se inicia o processo de apertamento do parafuso, uma tensão é criada entre a cabeça do parafuso à medida que ela se ajusta à loja pertinente do pilar e também entre as roscas macho e fêmea dentro do corpo do implante. Essa força é denominada précarga e é diretamente proporcional ao torque aplicado. À medida que o parafuso é apertado, ele sofre um alongamento e pressiona as duas partes juntas, criando o que se chama de força de travamento. Muitos são os fatores que podem afetar a pré-carga e a estabilidade da junção, levando à sua instabilidade e conseqüente falha. São eles: a rugosidade superficial, relaxamento embutido, interação elástica, fricção, temperatura, fluídos corrosivos, flexão ou torção, desadaptação, falta de alinhamento entre os componentes, rigidez, tolerâncias de usinagem, vibrações, cargas externas, fadiga, desenho do parafuso, proteção do parafuso e incompatibilidade de material. Em relação ao torque, apenas cerca de $10 \%$ do torque aplicado é usado para manter a estabilidade da conexão, o restante é perdido por calor e pela resistência friccional entre as superfícies de contato e por qualquer componente que possa impedir adequado assentamento entre os componentes como desajustes e falta de alinhamento. Ao analisar a superfície dos componentes, 
o autor afirma que a condição das superfícies das partes que entram em contato tem influência direta e significante na obtenção de adequada força de travamento e manutenção da estabilidade. Quando o torque é aplicado, uma pré-carga é gerada no parafuso e a força de travamento une as partes, iniciando um processo de achatamento das micro-rugosidades existentes na superfície devido à compressão gerada pelo contato entre as superfícies metálicas; quando estas superfícies se achatam, acontece um acomodamento entre as superfícies de contato o que diminui a distância microscópica entre elas. Com isso, diminui-se a tensão no parafuso e, conseqüentemente, a pré-carga. Esse processo é chamado de relaxamento embutido ou acomodamento das superfícies (settling) e é dependente do tempo, do material e da rugosidade das superfícies. Para minimizar este efeito, o parafuso deve ser apertado no valor de torque requerido e após cinco minutos realizar um reaperto com o mesmo torque aplicado. Para o autor quando a interface não está corretamente alinhada devido à desadaptação dos componentes, a união é seriamente comprometida, já que a pré-carga aplicada é direcionada ao alinhamento das partes, e mais pré-carga é requerida para unir as partes, assim o torque aplicado se torna insuficiente para obter uma força de travamento adequada. O autor ainda dá sua opinião sobre o que se constitui um parafuso frouxo: "Qualquer parafuso que requer um quarto de volta ou mais pra atingir a sua pré-carga ideal, embora a prótese ou o intermediário possam não apresentar mobilidade detectável clinicamente" e, recomenda checar os parafusos a cada 12 ou 18 meses para se restabelecer a pré-carga ideal e, assim, evitar problemas mecânicos com os componentes. Ainda, segundo Binon, é prudente aplicar os valores de torque recomendados por cada fabricante e minimizar os contatos oclusais tanto em cêntrica como nos movimentos excêntricos.

Binon (2000b), a partir de uma revisão de prótese sobre implante, descreveu a evolução dos implantes e componentes, relatando a vasta aplicação de cada sistema, bem como a classificação das conexões protéticas em relação ao tipo de interface pilar / implante, a forma e superfície do implante. Em relação à forma de união pilar /implante, afirmou que existem mais de 20 tipos diferentes de configurações desta interface. Segundo o autor, a interface da conexão implante/pilar é geralmente descrita como uma conexão interna ou externa, cujo fator de distinção é a presença ou ausência de uma característica geométrica que se estende acima da superfície coronal do implante. Esta conexão pode também ser 
caracterizada como uma união que permite movimento de deslize para se conseguir o encaixe desejado, onde existe um pequeno espaço entre as partes e a conexão é passiva; ou como uma união onde o encaixe se dá por fricção, cujo espaço entre os componentes é inexistente e as partes são literalmente forçadas para adaptar. As superfícies de contato também podem ser caracterizadas como uma união de topo, que consiste em juntar duas superfícies planas em ângulos retos e também a união angulada, onde as superfícies são anguladas externa e/ou internamente. A superfície de união também pode incorporar um desenho que inclua uma configuração de resistência rotacional e/ou estabilização lateral. Dessa forma, a geometria pode ser octogonal, hexagonal, cone hexagonal, cilíndrica hexagonal, spline, entre outros, e sua importância reside no fato dela ser um dos determinantes primários da força e estabilidade de união, bem como da estabilidade rotacional e de localização. A conexão do tipo hexagonal externa tem sido a mais relatada na literatura, devido ao seu extenso uso clínico. Em aplicações parciais e unitárias, a interface e o parafuso ficam expostos a forças laterais, levando ao desaperto do parafuso, relatado na literatura entre $6 \%$ e $48 \%$ dos casos. Alterações no desenho do parafuso e aplicação de torque controlado melhoraram significativamente, mas não eliminaram o problema da junção. Para superar as limitações inerentes à conexão hexagonal externa, uma variedade de conexões têm sido desenvolvidas. Segundo o autor, as conexões internas demonstraram em testes mecânicos, melhores propriedades mecânicas, como boa resistência, mínima rotação, estabilidade do parafuso e excelente tolerância de usinagem, resultando em uma interface mais estável. Em relação aos componentes, uma ótima tolerância e adaptação, liberdade rotacional mínima, propriedades físicas melhoradas, interface previsível e uma aplicação de torque adequado, são determinantes na estabilidade da interface. Assim mesmo na parte clínica, uma adequada distribuição dos implantes, cargas dirigidas no longo eixo do implante, número, diâmetro e comprimento dos implantes, eliminação dos cantilevers, adaptação passiva da prótese e controle das cargas oclusais são igualmente importantes.

Considerando-se que os procedimentos laboratoriais podem alterar negativamente a superfície de contato do pilar UCLA com o implante e, portanto, a adaptação passiva, Vigolo, Majzoub e Cordioli (2000), avaliaram as mudanças nesta região em componentes com cinta metálica em ouro (3I) antes e após fundição com um metal nobre e depois da aplicação da porcelana. Nos pilares, foram realizados 
enceramentos com dimensões de um incisivo central e fundido com uma liga áurica de alta fusão. Nestes, foram realizadas aplicações de cerâmica, seguindo as instruções recomendadas pelos fabricantes. Foram utilizados 30 pilares e as medidas feitas para avaliar a profundidade e largura do hexágono interno do componente, o diâmetro da base do pilar UCLA e a liberdade rotacional entre a extensão hexagonal do implante e a contraparte do pilar. Os resultados evidenciaram médias de 0,620 $\mathrm{mm}, 0621 \mathrm{~mm}$, e 0,620 $\mathrm{mm}$ na profundidade do hexágono; 2,712mm, 2,710mm, e 2,711mm para a largura do hexágono interno; 4,408mm, 4,407mm, e 4,409mm para o diâmetro da base; 60,33min, 60,37min, 60,68min de liberdade rotacional (antes, após fundição e após aplicação da cerâmica respectivamente). Concluíram que a adaptação dos pilares UCLA de ouro (3i), não demonstraram alterações significantes em nenhum dos parâmetros estudados. Os autores sugeriram a seleção adequada de componentes com baixa tolerância de usinagem, seleção adequada da liga metálica e a utilização de procedimentos clínicos e laboratoriais meticulosos, para reduzir a desadaptação rotacional e aumentar a estabilidade do parafuso.

Tan e Nicholls (2001) mediram e compararam a pré-carga produzida na interface pilar/implante em sete sistemas diferentes de hexágono externo, por meio da utilização de dois extensômetros ("strain gauges") instalados nos pilares e, também a influência da velocidade de aplicação do torque. Segundo os autores, cada sistema de pilar protético tem um parafuso específico que apresenta variações na constituição dos materiais (titânio comercialmente puro, titânio e ouro), nas configurações mecânicas (passo de roscas, desenho da cabeça, diâmetro da haste, configuração, comprimento da haste e área de contato entre a cabeça do parafuso do pilar e o rebordo interno do pilar), assim como na qualidade de fabricação (nível de tolerância de usinagem). Para este estudo, foram utilizados os seguintes pilares da Nobel Biocare: Standard regular (parafuso de titânio comercialmente puro), EsthetiCone regular (parafuso de titânio comercialmente puro), MirusCone regular (parafuso de titânio comercialmente puro), CeraOne regular (parafuso de ouro), cilindro de ouro direto no implante (parafuso de ouro) e TiAdapt regular (parafuso de ouro). Além destes foi também analisado o pilar de titânio da Implant Innovations (3i) (parafuso de titânio). Um controlador eletrônico de torque (Nobel Biocare) aplicou 20 ou $32 \mathrm{~N} . \mathrm{cm}$ de torque, seguindo as recomendações dos fabricantes, em alta ou baixa velocidade, registrando a pré-carga em um computador, utilizando-se os 
extensômetros. Os resultados encontrados nos diferentes pilares mostraram médias de pré-carga de $181,6 \mathrm{~N} \pm 60,0 \mathrm{~N}$ para Standard $5.5 \mathrm{~mm}, 291,3 \mathrm{~N} \pm 41,2 \mathrm{~N}$ EsthetiCone, 456,5N \pm 44,0N MirusCone, 369,7 \pm 32,9N Pilar Titânio, 643,4N \pm 143,1N CeraOne, 536,3N \pm 68,6N Cilindro de ouro, e 556,9N \pm 145,6N TiAdapt. Diferenças estatisticamente significantes foram encontradas entre os diferentes sistemas e na velocidade de aplicação de torque, sendo que pilares com parafusos de ouro registraram os maiores valores de pré-carga, e as maiores médias de précarga foram alcançadas por meio de baixas velocidades do torque de fixação.

Nos implantes unitários, a pré-carga na junção parafusada do pilar é crítica para manter a integridade e resistência anti-rotacional. Quanto maior a pré-carga, mais estável é a junção parafusada e maior a resistência ao desaperto de parafuso. Dessa forma os autores concluíram que a pré-carga na união implante / pilar do sistema hexágono externo, depende do desenho do pilar, diâmetro e material do parafuso, assim como do torque de aperto e da velocidade de aplicação.

Um dos maiores problemas encontrados em restaurações unitárias implantosuportadas é a instabilidade da junção, especificamente o afrouxamento e/ou fratura do parafuso do pilar. Vários esforços têm sido feitos para tentar solucionar esta dificuldade e com objetivo de verificar os fatores causadores envolvidos na falha da junção pilar/implante foi que Khraisat et al. (2004b) realizaram esta extensa revisão clínica e mecânica. Trata-se de um estudo a respeito da estabilidade da junção implante/abutment em sistema de implante hexágono externo para próteses unitárias, onde foi verificado que a sobrecarga por flexão e a presença de desadaptações na interface dessa união são condições mecânicas críticas que podem levar à instabilidade da junção. Segundo os autores, do ponto de vista mecânico, são dois os fatores principais relacionados à estabilidade nesta junção: a pré-carga na junção parafusada e o elemento anti-rotacional. Os autores definiram conceitos importantes como pré-carga e sua relação o torque aplicado e os fatores que afetam a redução da pré-carga no parafuso do pilar, dentre eles: a- sobrecarga por flexão, b- fadiga, c- relaxamento embutido e d- vibração e/ou amortecimento. Sobre o elemento anti-rotacional, descreveram que, segundo pesquisas, a desadaptação rotacional na interface hexagonal implante/ abutment tem sido considerada um grande problema para a estabilidade da junção parafusada e que sua eliminação faria desta união mais resistente ao afrouxamento dos parafusos. 
A restauração de implantes unitários demanda o maior grau possível de integridade mecânica na interface implante/ pilar. Por isso, é necessário que se tenha adaptação passiva entre os componentes da prótese e o implante bem como torque no valor recomendado pelo fabricante, para gerar uma pré-carga que seja suficiente para assegurar a união entre os componentes da junção parafusada e assim, suportar a ação de forças externas. Em 2008, Quek et al. publicaram um estudo no qual foram comparados diferentes sistemas de implantes unitários com 4 tipos de interface de implante/pilar sob fadiga mecânica e alterando-se a quantidade de torque aplicada. Os sistemas estudados, ambos de diâmetro regular, foram Branemark-CeraOne (hexágono externo), 3i Osseotite - STA abutment (hexágono externo), Replace Select - Easy abutment (cilindro tubular) e Lifecore Stage 1 COC abutment system (parafuso cônico). Três diferentes aplicações de torque foram utilizadas: $+20 \%$ do torque recomendado pelo fabricante, valor do torque recomendado e $-20 \%$ do torque recomendado. As amostras foram divididas em 12 grupos com 5 espécimes cada $(n=5)$ e sujeitas à aplicação de uma carga rotacional pela máquina de fadiga. A força aplicada era sinusoidal no valor de $35 \mathrm{~N} . \mathrm{cm}$ de momento de flexão/ torção a uma freqüência de $14 \mathrm{~Hz}$. Um contador de ciclos automático contava a quantidade de ciclos até a falha de cada amostra, sendo que o limite máximo utilizado foi $5,0 \times 10^{6}$ ciclos. No grupo do sistema Brånemark ocorreu falha de dois implantes e um parafuso de pilar, para o sistema $3 \mathrm{i}$ foram quatro implantes que falharam e cinco parafusos de pilar (todos do grupo de $-20 \%$ do torque recomendado). Para o sistema Replace Select somente um implante falhou e cinco parafusos cônicos falharam no sistema Lifecore, provavelmente, devido a um alto estresse sob aplicação de carga oblíqua. Segundo os autores, não houve diferença estatisticamente significante entre a quantidade de ciclos aplicados até a falha entre os 4 sistemas de implante/pilar, quando o torque nos valores recomendados pelos fabricantes foi aplicado. Entretanto, houve diferença estatisticamente significante para o sistema $3 \mathrm{i}$, entre os torques de $-20 \%$ e $+20 \%$. Ainda, é de opinião dos autores que a performance de fadiga por carga e a localização da falha é específica ao sistema e relacionada às características dos desenhos das combinações implante/pilar. Eles acreditam que se a interface implante/pilar fosse mantida, a falha através da fadiga por carga ocorreria no ponto mais fraco do implante. Além disso, é de extrema importância que sejam seguidas as recomendações dos valores de torque dos fabricantes. 
A falta de adaptação passiva é considerada um dos maiores problemas em prótese sobre implante, especialmente, quando se trata de restaurações unitárias em regiões que recebem altas cargas funcionais como os pré-molares e molares. As forças externas sempre amplificam as mudanças dinâmicas nas junções parafusadas, por isso a presença de desadaptações e deformações pré-existentes nos componentes irão aumentar ainda mais as chances de ocorrer afrouxamento do parafuso do pilar, podendo levar à falha nesta união. Desadaptações horizontais e angulares permitem movimentos de flexão ou torção e estresse nos parafusos e componentes dos implantes. Assunção et al. (2009) avaliaram o efeito de diferentes níveis de desadaptações unilaterais angulares na manutenção da pré-carga de parafusos de retenção de titânio em restaurações implanto-suportadas unitárias. Para este estudos foram utilizados 48 pilares UCLA plásticos calcináveis com antirotacional que foram fundidos em liga de Cobalto-Cromo (Co-Cr), obtendo-se coroas metálicas e, 48 implantes de hexágono externo de $3,75 \mathrm{~mm}$ de diâmetro com 15,0mm de comprimento, que foram embutidos em resina acrílica autopolimerizável, ambos da empresa SIN- Sistema de Implantes. Foram formados 4 grupos, cada um com 12 conjuntos de implante/pilar: Grupo A - coroas metálicas com adaptação

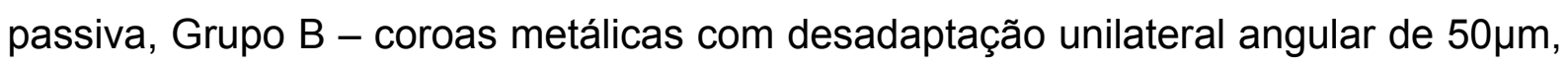
Grupo C - coroas metálicas com desadaptação unilateral angular de 100 $\mu \mathrm{m}$ e Grupo D - coroas com desadaptação de $200 \mu \mathrm{m}$. Cada conjunto de implante e coroa foi apertado com um parafuso de titânio com torque de 30,0 $\pm 0,5 \mathrm{~N} . \mathrm{cm}$, valor recomendado pelo fabricante, com auxílio de um torquímetro calibrado (BTG36CN$\mathrm{S}$, Tohnichi). Após o tempo de 2 minutos, o parafuso foi afrouxado e o torque requerido para afrouxá-lo (destorque) foi anotado. Três parafusos de titânio foram submetidos à avaliação de destorque em cada conjunto de implante/coroa, sendo que o procedimento de medida foi repetido duas vezes para cada parafuso, totalizando seis medidas de destorque para cada amostra. Todos os grupos analisados foram estatisticamente diferentes um do outro e apresentaram significante decréscimo nos valores de destorque $(p<0,05)$. O Grupo A foi o que apresentou o menor valor de decréscimo e foi estatisticamente diferente dos Grupos $B, C$ e $D(p<0,05)$. Já entre os Grupos B e D não houve diferença estatística significante $(p>0,05)$. De acordo com os autores, desadaptações unilaterais angulares influenciaram na manutenção da pré-carga e maiores desadaptações geraram maiores decréscimos de pré-carga, ou seja, coroas com desadaptação 
unilateral apresentaram grande decréscimo nos valores de pré-carga quando comparadas com coroas bem adaptadas aos implantes osseointegrados.

\section{2 - O pilar UCLA}

Embora alguns artigos relatados na revisão de literatura tenham citado esse tipo de pilar, é interessante destacar algumas considerações sobre seu surgimento e evoluções referentes ao seu desenvolvimento.

A proposta inicial dos implantes osseointegrados era de reabilitar somente pacientes desdentados totais. Por isso, o sistema Brånemark de componentes foi projetado para alcançar tais objetivos. Ao se estender a aplicabilidade dos implantes osseointegrados a pacientes com edentulismos parciais, utilizando-se o sistema então existente, diversos problemas começaram acontecer. Para tentar solucionar estes "impasses", Lewis et al. (1988a) descreveram uma técnica desenvolvida para a confecção de restaurações implanto-suportadas diretamente sobre o implante, sem utilizar o pilar intermediário. Segundo o autor, seriam estas as duas maiores vantagens de eliminação desse componente: estética, pois permite que a porcelana possa emergir através dos tecidos moles, e a criação de um maior espaço de trabalho para fabricação da restauração. O baixo custo, a capacidade em superar problemas como a distância interoclusal limitada, bem como a possibilidade de compensação de erros de angulação dos mesmos, são também apontados como vantagens desse tipo de pilar. O pilar denominado UCLA em plástico calcinável foi desenvolvido para ser utilizado como matriz de fundição, sendo eliminado juntamente com a cera do enceramento, resultando em pilar fundido a ser fixado de forma precisa diretamente sobre o implante. O pilar plástico foi idealizado pela Universidade da Califórnia - Los Angeles e, posteriormente, patenteado pela empresa norte-americana (Attachments International, San Mateo, Califórnia, USA) e apresentava um orifício central para alojar o parafuso em titânio com 45 graus de inclinação em sua cabeça, permitindo que o mesmo fosse aparafusado no interior do implante da mesma forma que os parafusos dos pilares convencionais. Este componente possui um desenho que permite formar um colar metálico na base que, ao estar acima da crista óssea e com a restauração em posição, forneça integridade estrutural tanto para a infra-estrutura quanto para a porcelana, sem comprometer a 
estética. Embora apresente inúmeras vantagens, uma desvantagem de seu uso refere-se a sua adaptação com o implante, uma vez que as etapas laboratoriais podem induzir a um possível desajuste. Uma inadequada adaptação pode resultar em perda e/ou fratura dos parafusos e a possibilidade de perda e/ou fratura dos implantes. Por essas razões, uma adequada adaptação passiva se faz necessária, motivo pelo qual, os autores recomendam o uso de um dispositivo de fresagem para o acabamento da porção cervical que se adapta ao implante, assegurando uma melhor adaptação da peça fundida. O pilar UCLA original apresentava-se sem um sistema de indexação, sendo a sua superfície interna lisa sem um hexágono para se encaixar no hexágono do implante, visando facilitar a fundição e os procedimentos clínicos, de forma que seu uso era e obviamente ainda é contra-indicado para restaurações unitárias, até que alterações sejam feitas para o pilar não rotacionar sobre o implante. Mudança esta que, segundo o autor, já estava sendo à época planejada para permitir o uso com implantes unitários.

O pilar UCLA tem esse nome por ter sido idealizado e desenvolvido pela Universidade da Califórnia - Los Angeles, na década de 80 e, trouxe como principal vantagem a eliminação do pilar intermediário. Em 1992 Lewis, Llamas e Avera demonstraram uma variedade de opções para o uso clínico do abutment UCLA e relataram os resultados de um estudo após 4 anos de sua utilização. Visando solucionar o problema de espaço interoclusal limitado, o conceito de fabricação da restauração empregada diretamente sobre o implante, sem a necessidade de um pilar intermediário, foi aplicado e esse abutment ficou reconhecido por sua versatilidade. Também é possível conseguir adequado perfil de emergência subgengival, devido à cinta metálica adequada para aplicação da porcelana, o que possibilita uma melhora da estética. Além disso, a porção subgengival da restauração pode ser feita mais estreita para permitir seu assentamento e acesso a higiene oral, desta forma, possibilitando a alteração do contorno da restauração para compensar a proximidade entre os implantes.

O abutment UCLA é um padrão plástico, que é encerado e depois fundido, resultando na peça fundida que se adapta diretamente à cabeça do implante de acordo com a condição clínica existente. Fato este, importante, principalmente onde a angulação dos implantes é desfavorável ou estes se encontram muito próximos, o que exige adaptações. Os autores também comentaram que os processos de fundição são mais sensíveis tecnicamente, enquanto que os componentes pré- 
fabricados são mais precisos. Dessa forma, uma fundição com uma pobre adaptação, resulta em afrouxamento ou fratura do parafuso, e possibilidade de fratura ou perda do implante, portanto uma adaptação precisa é muito importante para este tipo de componente.

Este pilar não só pode ser empregado para próteses unitárias, como beneficia diretamente os pacientes com edentulismos parciais. Quando ele apresenta um hexágono em sua porção interna, que atua como elemento anti-rotacional, é indicado para próteses unitárias ou para próteses múltiplas quando a porção interna é lisa sem a presença do hexágono. Quando utilizado para esse tipo de prótese, os autores sugerem que as porções sejam fundidas independentes e unidas na boca para posterior soldagem a fim de se evitar um assentamento não passivo com conseqüente sobrecarga. Os resultados clínicos do estudo apresentado pelos autores foram obtidos através do tratamento de 46 pacientes que receberam 59 restaurações utilizando 118 abutment tipo UCLA, sendo 65 na maxila e 53 na mandíbula. Das próteses, 12 eram tipo overdenture, 2 eram próteses totais fixas e 46 eram próteses parciais fixas. Dos 65 pilares maxilares, 5 falharam representando uma taxa de sucesso de $92,3 \%$. Três dessas falhas ocorreram em um único paciente e duas falhas em outro, sendo que ambos haviam recebido próteses parciais fixas metalocerâmicas na região posterior da maxila, ocorrendo as falhas num período de 6 semanas de função das próteses, sendo portanto creditadas à falta de osseointegração e não ao tipo de pilar utilizado. Nenhuma fratura de parafuso foi observada, também não houve insucesso na mandíbula sendo a taxa de sucesso considerada de $100 \%$, e a taxa média de sucesso dos tratamentos de $95,8 \%$.

\section{3 - Perda de torque de aperto e desajuste rotacional em próteses unitárias implanto suportadas}

Becker e Becker, em 1995, realizaram um estudo retrospectivo a respeito da substituição de molares na maxila e mandíbula por implantes unitários. Os resultados são baseados na colocação de 24 implantes em 22 pacientes, sendo todos restaurados por 7 dentistas treinados no sistema de implantes utilizado. Vinte e um implantes tinham diâmetro de $3,75 \mathrm{~mm}, 1$ de $4 \mathrm{~mm}$ e 2 de $5 \mathrm{~mm}$, sendo 18 implantes mandibulares e seis maxilares. Restaurações foram realizadas e fixadas utilizando-se parafusos de ouro e após duas semanas da inserção das coroas, os 
parafusos foram reapertados. A taxa de sucesso após 1 ano de função foi $95,7 \%$, com perda de um implante de diâmetro largo que, posteriormente foi substituído. Afrouxamento dos parafusos de retenção ocorreu em oito implantes (38\%), sendo que $14,2 \%$ afrouxaram uma vez, $9,5 \%$ duas vezes e $14,3 \%$ três vezes. A fratura do parafuso do pilar ocorreu em um paciente, porém logo foi substituída, nenhuma fratura da coroa ou implante ocorreu. Segundo os autores, vários fatores contribuíram para a elevada taxa de sucesso, tais como: qualidade e quantidade óssea, comprimento dos implantes, contatos oclusais e interferências laterais minimizados e exclusão de pacientes com bruxismo. Hábitos parafuncionais podem ser fatores de risco relacionados à fratura de implantes e desaperto de parafusos e podem originar carregamento de forças oclusais descontroladas e excessivas. Os autores acreditam que a alta incidência de afrouxamento do parafuso de ouro (38\%), pode ser diminuída com a utilização do pilar CeraOne, desde que um valor de torque apropriado seja aplicado.

Dixon et al. (1995), compararam os movimentos de rotação e de deflexão do complexo pilar/implante durante a aplicação de forças e também a quantidade de força necessária para afrouxar o parafuso do pilar, para três sistemas de implantes de diferentes fabricantes. Foram utilizados implantes de hexágono externo, hexágono interno e octógono interno, que foram divididos em 03 grupos de 10 implantes de cada sistema, nos quais foram fixados, para cada grupo, 05 pilares retos e 05 pilares angulados. Sobre os pilares foram confeccionadas e cimentadas coroas de $10 \mathrm{~mm}$ de altura simulando a porção disto-vestibular do primeiro pré-molar superior com uma inclinação cúspidea de $25^{\circ}$. Cargas cíclicas foram aplicadas a uma força de $2,73 \mathrm{Kg}$ (6lb ou 26,69N) por 4,63 horas (16.667 ciclos) a uma frequência de $60 \mathrm{rpm}$ e distância de $2,5 \mathrm{~mm}$ do centro do implante utilizando-se uma máquina de ensaio de fadiga desenvolvida para o experimento. A máquina foi ainda, ajustada para percorrer uma distância de $4 \mathrm{~mm}$ ao longo da superfície oclusal do dente, sendo os primeiros $3 \mathrm{~mm}$ do percurso no movimento acima da inclinação bucal e o restante de $1 \mathrm{~mm}$ consiste no movimento ao longo da superfície plana oclusal em direção à superfície lingual. Os parafusos foram apertados com um de dois dispositivos de torque disponíveis, Torquedyne (para a maioria das amostras) e Tonichi 6BTG-A (para o grupo dos pilares retos de Calcitek Omniloc), com um torque de 29 N.cm. Os resultados não mostraram diferenças estatisticamente significantes entre pilares retos e angulados nos testes realizados para os diferentes sistemas. $\mathrm{Na}$ 
quantidade de torque necessária para afrouxar os parafusos depois da carga, obteve-se uma perda média de 2,97 N.cm no sistema de hexágono externo (Minimatic), de 1,62 N.cm no sistema de octógono interno (Calcitek) e 5,58 N.cm no sistema de hexágono interno (Spectra-System).

Uma variação considerável tem sido relatada a respeito da precisão, uniformidade, e fidelidade de alguns componentes e implantes. Pensando nisso, Binon em 1995, desenvolveu um estudo em que foram avaliadas treze marcas comercias de implantes de hexágono externo em relação as suas características de precisão de usinagem e de fidelidade, além de determinar a liberdade rotacional entre o hexágono externo do implante e o hexágono interno do pilar. Para realizar o estudo, cinco implantes selecionados aleatoriamente foram medidos com um micrômetro digital (Mitutoyo, 293) e um microscópio com precisão de 1 micrometro. As medidas foram feitas em locais selecionados e são eles: diâmetro da cabeça do implante, diâmetro do corpo do implante (largura), altura e largura do hexágono externo de superfície plana a superfície plana (lados opostos entre si), tanto para os implantes como para seus análogos. Todos os três pares de superfícies planas (lados) foram medidos e a média obtida. O maior e menor valor de medida entre os lados do hexágono de todos os implantes avaliados foi 2,790 mm para SwedeVent e 2,657 mm para IMTEC, respectivamente. A liberdade rotacional entre o hexágono do implante e o hexágono do pilar foi medida em graus, por um dispositivo desenvolvido para este objetivo. Isso foi feito para cinco sistemas com seus respectivos pilares e em combinações de empresas, mudando-se os pilares. Quando foram considerados os componentes do mesmo fabricante, os menores valores encontrados foram para Xmark e $3 \mathrm{i}$ com $4^{\circ}$ e $4,6^{\circ}$ de rotação, e os maiores valores foram para ISS e NP com $6,7^{\circ}$ de rotação. Nas combinações de empresas, o menor valor de liberdade rotacional foi para o implante Nobelpharma com o pilar IMP com $3,5^{\circ}$ de rotação. As próximas três combinações foram o implante ISS / pilar IMP com $4,2^{\circ}$, implante $3 \mathrm{i} /$

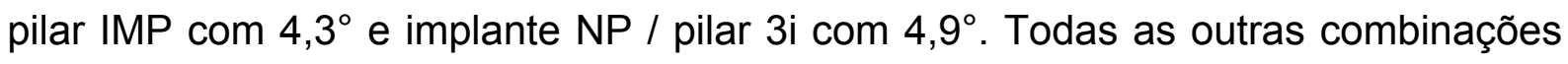
excederam $5^{\circ}$, com a maior liberdade rotacional registrada para o implante STR e pilar OTC com $10,1^{\circ}$ de rotação. Dois outros tipos de junções foram analisados quanto à liberdade rotacional de seus componentes. O implante hexágono interno ScrewVent apresentou $1,4^{\circ}$ de rotação e o implante octógono interno Omniloc apresentou $7,5^{\circ}$ de rotação. O autor considera que a redução ou eliminação das discrepâncias entre hexágonos de pilar e implante e seu potencial para movimento 
rotacional resulta em uma junção parafusada mais estável e previsível. Considera ainda, que a rotação menor que $5^{\circ}$ é desejável para ótima estabilidade da junção. Isto é especialmente importante em restaurações unitárias onde o exato assentamento é crítico para atingir contatos interproximais reproduzíveis e ótimas características anti-rotacionais.

A partir de todas as medidas, com a diferença entre os maiores e menores valores, obteve-se um índice composto para cada um dos três parâmetros avaliados com o objetivo de verificar a variabilidade e precisão de fabricação das empresas. Quanto menor for o valor do índice composto, maior será a precisão e a consistência (uniformidade) dos componentes e, menores serão as tolerâncias de usinagem. Neste trabalho, os índices compostos resultantes variaram de 0,014 e 0,015 (3i) a 0,151 (SwedeVent).

As menores tolerâncias observadas entre a largura das superfícies planas (lados opostos entre si) foram para Implant Innovations Inc. (3i) de $1 \mu \mathrm{m}$, Nobelpharma $(4 \mu \mathrm{m})$ e, Impla-Med $(5 \mu \mathrm{m})$. Já as maiores tolerâncias foram observadas para a empresa SwedeVent com $27 \mu \mathrm{m}$.

As menores tolerâncias em relação à altura do hexágono foram observadas para IMTEC $(18 \mu \mathrm{m})$ e Stryker $(28 \mu \mathrm{m})$ e a maior, para Steri-Oss $(147 \mu \mathrm{m})$.

Assim, pôde-se verificar que as especificações de usinagem podem variar enormemente entre as empresas, entretanto, existem sistemas disponíveis que exibem pequenas tolerâncias, excelente precisão e uniformidade (consistência) de usinagem.

Em um estudo realizado por Binon (1996), o efeito da desadaptação entre o hexágono externo do implante e o hexágono interno do pilar na estabilidade da junção parafusada foi avaliado durante a função mastigatória, simulada por meio de teste de carga cíclica. Para isso, foram utilizados 50 implantes hexágono externos de $3,75 \times 10 \mathrm{~mm}$ confeccionados pela empresa Implant Support Systems, que tiveram as distâncias entre os lados do hexágono medidas, com 2,68mm de média, com o maior e o menor valor 2,703mm e 2,663mm, respectivamente. O número correspondente de pilares UCLA foi utilizado. Estes pilares possuíam tamanhos crescentes de hexágonos de 2,705 a 2,820mm, com variação de 0,13mm entre eles, totalizando 10 grupos. Ainda, outro grupo adicional, com 8 implantes sem a presença do hexágono externo foi testado. Os espécimes construídos, fundidos em titânio aos UCLA, mediam $8 \mathrm{~mm}$ de altura com $8 \mathrm{~mm}$ de diâmetro na sua parte 
superior, com uma mesa de aplicação de cargas de $3 \mathrm{~mm}$. Antes da aplicação da carga cíclica, a liberdade rotacional de cada grupo foi medida. Os valores variaram de $1,94^{\circ}$ para o menor hexágono interno a $14,87^{\circ}$ para o maior hexágono do pilar. Cada pilar foi conectado ao implante com parafuso de titânio e aplicado torque de 30 $\mathrm{N} . \mathrm{cm}$. As amostras foram então posicionadas na máquina de ciclagem e giradas a 28 ciclos por minuto no sentido anti-horário. A carga vertical de $133,3 \mathrm{~N}$ foi aplicada fora de eixo, a uma velocidade de 1.150 ciclos por minuto até que ocorresse a falha da conexão, a qual foi determinada pelo afrouxamento do parafuso. Essas falhas na junção parafusada ocorreram de 134.895 ciclos a 9.337 .080 ciclos. A média de 6,7 milhões de ciclos foi encontrada para as junções que utilizavam os pilares com o menor tamanho de hexágono interno, ou seja, que continham a menor distância entre os hexágonos dos implantes e dos pilares. O grupo adicional de implantes, com ausência do hexágono externo, teve a falha da junção parafusada com a média de 630.000 ciclos. Os resultados mostraram que existe uma correlação direta entre a liberdade rotacional e o afrouxamento dos parafusos. Assim, o autor conclui que quanto melhor o ajuste entre pilar e implante e, menor a liberdade rotacional, mais estável e resistente é a junção parafusada, sendo menor a probabilidade de afrouxamento dos parafusos. Os grupos com desajuste rotacional inferior a dois graus apresentaram uma maior resistência ao afrouxamento (média de 6,7 milhões de ciclos), cerca de $26 \%$ maior que a resistência apresentada pelos grupos com desajuste rotacional superior a dois graus. Além disso, os sete grupos com liberdade rotacional maior que $5^{\circ}$ apresentaram um comportamento semelhante, com a rigidez da junção e a pré-carga comprometidas e a falha dos parafusos ocorrendo entre 2,5 e 1,1 milhões de ciclos, ou seja, uma redução de $63 \%$ quando comparado ao grupo com menor liberdade rotacional. O autor concluiu, também, que a presença do hexágono aumenta significativamente a resistência ao afrouxamento dos parafusos e que a eliminação do desajuste rotacional resultou em uma conexão mais rígida e mais resistente ao afrouxamento.

Binon e McHugh (1996) avaliaram o efeito da eliminação do desajuste rotacional entre a interface pilar / implante na estabilidade da junção parafusada. Para tanto, a técnica de remodelamento do hexágono interno do pilar foi utilizada. Neste estudo, dez implantes de 3,75 de diâmetro por diversos comprimentos e cinco diferentes tamanhos de hexágono $(2,680 \mathrm{~mm}, 2,692 \mathrm{~mm}, 2,705 \mathrm{~mm}, 2,718 \mathrm{~mm}$ e $2,731 \mathrm{~mm}$, sendo dois implantes para cada dimensão) de diferentes fabricantes 
foram utilizados e divididos em dois grupos de acordo com o tipo de pilar fundível utilizado: pilar UCLA com cinta pré-usinada em ouro (grupo controle) e pilar UCLA plástico, ambos com seus respectivos parafusos de titânio. Os cilindros foram fundidos em liga nobre de ouro-paládio-prata. Os cilindros fundidos a partir do padrão plástico foram submetidos a alterações por retificador alterando o hexágono de acordo com os tamanhos correspondentes aos 5 implantes utilizados na pesquisa. Já os cilindros com cinta pré-usinadas foram encaixados aos implantes sem modificações após as fundições. A liberdade rotacional de cada grupo foi medida antes e após o teste de carga cíclica. A média encontrada foi de $5^{\circ}$ e $0,1^{\circ}$ para o pilar com cinta de ouro e para o pilar remodelado, respectivamente.

Os pilares foram apertados com 20 e 30 N.cm em dois estágios e submetidos a cargas cíclicas. As amostras foram então posicionadas na máquina de ciclagem e giradas a 28 ciclos por minuto no sentido anti-horário. A carga vertical de $133,3 \mathrm{~N}$ foi aplicada a uma velocidade de 1.150 ciclos por minuto. Quando submetidos ao torque de $20 \mathrm{~N} . \mathrm{cm}$ os pilares remodelados apresentaram um desajuste rotacional entre 0,0 a 0,5 graus e apenas uma falha por fratura do implante, que foi prontamente substituído, e todos os cinco pilares permaneceram intactos por todo ciclo (1 milhão de ciclos) sem evidência de afrouxamento ou fratura do parafuso e nem fratura do implante; já os pilares pré-usinados, apresentaram uma desadaptação rotacional variando de 3 a 7 graus e perda de torque em todos os parafusos em uma média de 357.162 ciclos (desvio-padrão $=77,981$ ). No segundo estágio do teste, todos os parafusos de pilar foram apertados com torque de 30 N.cm e seguiu os mesmos parâmetros de carga do primeiro estágio. Com este valor de torque, os pilares remodelados sofreram duas falhas, sendo uma a $4,4 \times 10^{6}$ ciclos com fratura do implante (sem afrouxamento do parafuso) e a outra a $9,5 \times 10^{6}$ ciclos com perda do torque do parafuso do pilar, já os demais não sofreram nenhum tipo de falha mesmo com mais de $10 \times 10^{6}$ ciclos. Os pilares pré-usinados apresentaram a primeira falha com fratura em implante a 290 mil ciclos e com 2,4 x $10^{6}$ ciclos, a segunda, com perda de torque do parafuso do pilar. As falhas subseqüentes foram a $3,4 \times 10^{6}$ ciclos, apresentando fratura do implante e clara evidência de afrouxamento do parafuso do pilar e a $6,5 \times 10^{6}$ ciclos com afrouxamento e fratura do parafuso e do implante, sendo a última amostra com 7,9 x 
$10^{6}$ ciclos, demonstrando perda de torque do parafuso do pilar. É de opinião dos autores que o desajuste rotacional resulta em diminuição da rigidez na junção, mais rápida perda da pré-carga e aumento do índice de desaperto do parafuso do pilar. Também quanto maior a desadaptação rotacional, maior será o torque de apertamento e a pré-carga necessária para manter a conexão parafusada intacta e estável.

O sucesso da junção parafusada está diretamente relacionado ao alongamento do parafuso do pilar ou à pré-carga conseguida pelo torque de apertamento e pela manutenção dessa força durante todo o tempo. Por isso, em um estudo, Cibirka et al. (2001) examinaram potenciais diferenças nos valores de desaperto do parafuso do pilar após o teste de fadiga quando as dimensões entre o hexágono externo do implante e o hexágono interno do pilar foram alterados ou o hexágono externo do implante foi eliminado. Para o experimento, foram utilizados três grupos de desenhos experimentais com 10 amostras para cada, sendo todos os implantes da empresa Nobel Biocare*. (1) Implante de plataforma regular de 3,75mm com hexágono externo convencional, tendo uma superfície média de largura hexagonal de 2,700mm e uma altura de 0,633mm (Standard, chamado de grupo R). (2) Implante de plataforma regular de $3,75 \mathrm{~mm}$, com hexágono externo modificado, tendo uma média de largura hexagonal de 2,664mm e uma altura de 0,608mm (grupo M). (3) Implante de 3,75mm com hexágono removido por desgaste para criar uma forma circular com um diâmetro de 2,668mm e uma altura de 0,668mm (grupo C). Trinta pilares em Procera CAD / CAM (Nobel Biocare) foram fabricados com uma plataforma angulada em 25 graus e área de $2 \mathrm{~mm}^{2}$. Os pilares foram parafusados com parafusos de ouro (Unigrip, Nobel Biocare) a $32 \mathrm{~N} . \mathrm{cm}$, seguindo as recomendações do fabricante, utilizando um torquímetro eletrônico. Marcas verticais que cruzavam a interface implante / pilar permitiram a avaliação do deslocamento longitudinal. Para o teste de fadiga, foi utilizado um suporte para 10 amostras com controle de temperatura $\left(37^{\circ} \mathrm{C}\right)$. Uma carga dinâmica foi aplicada sobre a plataforma de cada pilar por um pistão em uma única direção. O suporte era posicionado em uma máquina de fadiga hidráulica (Instron) calibrada para cargas cíclicas entre 20 e $200 \mathrm{~N}$, com um sistema de ondas sinusoidal com 8 ciclos/segundo, num total de 5 milhões de ciclos, o equivalente a 5 anos de função mastigatória in vivo. Um exame macroscópico e radiográfico da interface pilar / implante de cada amostra foi 
realizado. Depois da carga, as amostras foram fixadas em um dispositivo, e com um medidor de torque Tohnichi BTG-6 foram removidos os parafusos e registrados os valores do destorque. Através do exame macroscópico e radiográfico não foi observado afrouxamento ou deslocamento rotacional na interface pilar / implante. A média dos valores de destorque para $R, M$ e $C$ foram 14,40 $\pm 1,84 \mathrm{Ncm}, 14,70 \pm$ $1,89 \mathrm{Ncm}$, e 16,40 $\pm 2,17 \mathrm{~N} . \mathrm{cm}$, respectivamente. A análise de variância demonstrou diferenças significativas somente entre os subgrupos $R$ e $C(p=0,031)$, com este último apresentando maiores valores de torque de desaperto e indicando menor perda da pré-carga. Os autores concluíram que aumentando a distância entre a largura do hexágono externo do implante e o hexágono interno do pilar não produziu um efeito estatisticamente significante nos valores de torque de desaperto do parafuso após a carga cíclica. Já quando foi eliminado o hexágono externo do implante e aumentado a altura da coluna circular houve um efeito significativo no parafuso do pilar de liga de ouro, quanto aos valores do torque de desaperto, após a carga cíclica, comparados com implantes de hexágono externo regular. Também, após o teste de fadiga com a aplicação dos $5,0 \times 10^{6}$ ciclos não foi observado nas amostras implante/pilar, com ou sem o hexágono externo, qualquer sinal clínico de instabilidade ou afrouxamento do parafuso.

( ${ }^{*}$ A empresa Nobelpharma passou a ser chamada de Nobel Biocare a partir de 1996).

Um dos maiores problemas relacionados a restaurações com implantes unitários e próteses parafusadas é o afrouxamento do parafuso do pilar. Muitas pesquisas são feitas para encontrar soluções viáveis para este problema. Entre as várias tentativas para reduzir o afrouxamento dos parafusos destacam-se os avanços na tecnologia de fabricação dos parafusos de retenção, cujo objetivo principal é produzir parafusos com tratamento especial de superfície para diminuir o coeficiente de fricção, aumentar a pré-carga e reduzir o afrouxamento dos mesmos. Em um estudo conduzido por Martin et al. (2001), foram avaliados os materiais e superfícies de quatro marcas comerciais de parafusos de pilar, e realizados testes para medir o ângulo de rotação e o torque de remoção, analisando o potencial de geração da pré-carga. Para isso foram utilizados 80 implantes de hexágono externo de $3,75 \mathrm{~mm} \times 15 \mathrm{~mm}$ (3i) montados em um bloco de resina acrílica e parafusados a um pilar de titânio do tipo convencional. Foram avaliados parafusos com diferentes superfícies: 1) Gold-Tite (Gt - 3l), parafusos com superfície de ouro e paládio 
alterada pela adição de um lubrificante sólido; 2) TorqTite (Tt - Nobel Biocare) com superfície tratada para redução da fricção; 3) parafusos de ouro (Ga - 3l); 4) parafusos de titânio ( $\mathrm{Ta}$ - 3l). Vinte parafusos de cada tipo foram utilizados e, de forma randomizada, divididos em dois grupos com 10 de cada, sendo um grupo o dos parafusos que receberiam torque de aperto de $20 \mathrm{~N} . \mathrm{cm}$ e outro recebendo 32 N.cm. Com um dispositivo de plástico de $360^{\circ}$, e com cada conjunto já fixado em um bloco de resina, foi realizada a medição do ângulo de rotação de cada parafuso. Os valores de torque de remoção foram anotados e usados de forma indireta para gerar os valores de pré-carga. Para a análise de rotação do parafuso e a pré-carga, a amostra era posicionada no aparelho de medidas angulares e com um torquímetro eletrônico digital aplicava-se um pré-torque de $5 \mathrm{Ncm}$. Após a aplicação deste prétorque, a posição inicial do parafuso era registrada como zero. Aguardava-se um período de 5 minutos, então o torque desejado, de acordo com o grupo da amostra, era novamente aplicado; após 5 minutos, o grau de rotação do parafuso era novamente registrado. Após esses consecutivos apertos, o desaparafusamento era realizado por meio de um destorque, e o pico do valor obtido era então registrado. Essas mensurações eram, então, repetidas por mais 4 vezes, com intervalos de 5 minutos, a fim de que fossem registradas eventuais variações nos graus de rotação dos parafusos, depois de 5 repetidos ciclos de torque e destorque, e possibilitar também o cálculo da pré-carga. Os resultados mostraram que, para o torque de 20 N.cm, a maior rotação foi apresentada pelos parafusos Torq-tite $\left(19,3^{\circ} \pm 2,1\right.$ a $21,2^{\circ}$ $\pm 3,1)$, seguidos pelos Gold-tite $\left(14,9^{\circ} \pm 1,1\right.$ a $\left.14,4^{\circ} \pm 1,8\right)$, de ouro $\left(9,8^{\circ} \pm 2,2\right.$ a $\left.11,1^{\circ} \pm 1,7\right)$ e titânio $\left(9,6^{\circ} \pm 1,3\right.$ a $\left.10,2^{\circ} \pm 1,8\right)$, sendo que a diferença entre os parafusos de titânio (Ta) e ouro (Ga) e Gold-tite (Gt) foi estatisticamente significante. Também foi estatisticamente significante a diferença entre os parafusos Torq-tite e Gold-tite, que também foram diferentes estatisticamente de Ga e Ta. Para o torque de 32 N.cm, o grupo TorqTite apresentou novamente o maior grau de rotação $\left(31,3^{\circ}\right.$ $\pm 8,4$ a $\left.38,1^{\circ} \pm 8,7\right)$, seguido dos parafusos Gold-Tite $\left(20,4^{\circ} \pm 1,6\right.$ a $\left.29,0^{\circ} \pm 2,5\right)$, ouro $\left(16,5^{\circ} \pm 1,7\right.$ a $\left.18,0^{\circ} \pm 2,0\right)$ e titânio $\left(14,9^{\circ} \pm 1,5\right.$ a $\left.17,0^{\circ} \pm 3,1\right)$, sendo todos os grupos estatisticamente diferentes entre si. Além disso, é importante citar que, com exceção do grupo composto dos parafusos de titânio (Gt e Tt) apertados a 20 N.cm e a 32 N.cm, todos os grupos mostraram uma diminuição no coeficiente de fricção após repetidos ciclos de torque e destorque. Já os maiores valores de rotação atribuídos aos grupos Gt e Tt, nas primeiras medidas de torque a 20 e $32 \mathrm{~N} . \mathrm{cm}$, pode ser 
devido ao desgaste da superfície de tratamento após repetidos ciclos de torque e destorque e, por isso, o aumento nos valores de fricção. Quando o torque dado foi de $20 \mathrm{~N} . c m$, a maior pré-carga foi obtida para os parafusos Gold-Tite $(521,7 \mathrm{~N}$ a $596,8 \mathrm{~N})$, seguido dos parafusos TorqTite $(355,9 \mathrm{~N}$ a $470,2 \mathrm{~N})$, ouro $(430,8 \mathrm{~N}$ a $576,8 \mathrm{~N})$ e titânio $(347,8 \mathrm{~N}$ a $478,3 \mathrm{~N})$, não havendo diferença entre os parafusos de ouro e Gold-Tite. Porém houve diferença estatisticamente significante entre os grupos $\mathrm{Gt}, \mathrm{Tt}$ e Ta e também entre Ga e Ta. Para o torque de $32 \mathrm{Ncm}$, a maior pré-carga foi obtida para o grupo Gold-Tite $(928,4 \mathrm{~N}$ a $1015,3 \mathrm{~N})$, TorqTite $(723,0 \mathrm{~N}$ a $877,1 \mathrm{~N})$, ouro $(573,0 \mathrm{~N}$ a $833,8 \mathrm{~N})$ e titânio $(434,8 \mathrm{~N}$ a $636,1 \mathrm{~N})$, havendo diferença entre os parafusos Gold-Tite e os demais grupos e entre os parafusos TorqTite e ouro em relação aos parafusos de titânio. Não houve diferença significante no grau de rotação e pré-carga tanto para $20 \mathrm{~N} . c m$ como para $32 \mathrm{~N} . \mathrm{cm}$ entre as 5 medidas repetidas realizadas. A análise em microscopia eletrônica de varredura (MEV) das superfícies dos parafusos, em aumento de 17 e 80 vezes, não mostrou diferença visual entre os torques de 20 N.cm e 32 N.cm. Todas as amostras analisadas demonstraram um mesmo padrão de contato entre as roscas, predominando o contato entre a superfície superior das roscas do parafuso e as roscas do implante na porção média das roscas contactantes. Os autores concluíram que os tratamentos superficiais dos parafusos foram capazes de reduzir a fricção, levando a valores de pré-carga maiores, no entanto, ressaltaram que esses valores deveriam ser investigados sob carga cíclica.

Khraisat et al. (2004b) investigaram através de um estudo in vitro, o efeito da aplicação de cargas cíclicas laterais em diferentes posições, no afrouxamento de parafusos de pilares em implantes do sistema hexágono externo. Para isso foram usados 15 implantes Brånemark Mark IV (Nobel Biocare) de 4mm x 10mm, montados em um bloco semi-cilíndrico de latão,15 pilares CeraOne com cinta de $3 \mathrm{~mm}$ (Nobel Biocare) e 15 infra-estruturas experimentais $(7 \times 10 \times 7 \mathrm{~mm})$, representando as supra-estruturas das próteses, que foram enceradas, fundidas em liga de ouro-prata-paládio e cimentadas com fosfato de zinco em cima dos pilares CeraOne. Acessos aos parafusos dos pilares foram confeccionados previamente à cimentação. Um torquímetro BTG60CN (Tohnichi Mfg Co) foi usado para a realização dos torques de $32 \mathrm{~N} . \mathrm{cm}$ recomendados pelo fabricante para esses parafusos. Após 10 minutos, os parafusos foram reapertados com o mesmo valor de torque para minimizar o relaxamento embutido e, desta forma, ajudar na 
manutenção de uma pré-carga otimizada. Após cinco minutos novamente foram desapertados, os valores dos torques de remoção foram registrados e novamente, os parafusos foram apertados e reapertados após 10 minutos. O torque reverso do parafuso do pilar foi registrado antes e após a aplicação de carga cêntrica e excêntrica, e os resultados comparados. Além disso, o deslocamento rotacional do pilar e as mudanças microscópicas das superfícies encaixadas dos componentes da junção parafusada foram examinados. Os exemplares foram divididos em 3 grupos onde o grupo A representava as amostras que foram submetidas a ensaios de cargas cíclicas laterais cêntricas (perpendiculares aos longos eixos dos implantes), grupo B amostras que foram submetidas a cargas laterais excêntricas (aplicadas a $4 \mathrm{~mm}$ do longo eixo do implante) e grupo $\mathrm{C}$ sem cargas. As cargas foram simuladas em uma máquina de fadiga com cargas cíclicas variando de 0 a $50 \mathrm{~N}$, com $1,0 \times 10^{6}$ ciclos referentes a 40 meses de simulação. A velocidade do carregamento foi 75 ciclos/min $(1,25 \mathrm{~Hz})$, similar à freqüência mastigatória humana relatada. Imagens em microscópio eletrônico de varredura EPMA-8705 (Shimadzu) das roscas e das bordas dos pilares antes e após as cargas foram realizadas. Marcações horizontais e verticais na base do pilar e na face externa da plataforma dos implantes (2 de cada grupo) serviram de referência para o registro de rotações dos componentes após submetidos às cargas.

O grupo A apresentou a maior média dos valores da diferença entre torques de remoção enquanto o grupo $C$ apresentou os menores, com diferença estatisticamente significante entre os grupos $(p<0,001)$. Após o teste Tukey foi verificada diferença significante entre o grupo A comparado ao B e C $(p<0,001)$, e não houve diferença entre $B$ e $C(p=0,528)$. Somente os exemplares do grupo $B$ apresentaram rotação do pilar com média de $58 \pm 2 \mu \mathrm{m}$ e $53 \pm 1 \mu \mathrm{m}$. Alterações foram percebidas nas superfícies das roscas como ranhuras e bruniduras em todos os grupos e nos hexágonos dos pilares como bruniduras das superfícies mais evidentemente no grupo $B$. Os autores concluíram que a queda do torque reverso após o carregamento está de acordo com o mecanismo de falha da junção. As forças externas progressivamente desgastam a pré-carga por causa da vibração do parafuso, do desgaste das superfícies de encaixe e do assentamento (relaxamento embutido). Também, de acordo com os autores, valores do torque reverso do parafuso da junta foram preservados sob carga lateral excêntrica, quando comparados com carga cêntrica. 
Em um estudo piloto, Carrilho et al. (2005) fizeram uma comparação entre implantes de hexágonos externo e interno, a respeito do comportamento de liberdade rotacional entre os implantes e os pilares de prótese. Cinco implantes de cada tipo foram utilizados com seus respectivos pilares protéticos e, as medidas dos hexágonos de ambos foram realizadas em sistema de medidas óticas, com precisão de $0,0001 \mathrm{~mm}$. Foram feitas três medidas por hexágono que correspondem à distância entre as linhas limites opostas entre si. O torque manual de $20 \mathrm{~N} . \mathrm{cm}$ foi dado aos parafusos dos pilares protéticos e com o uso de um dinamômetro, o torque de $40 \mathrm{~N} . c m$ foi aplicado aos pilares, e a diferença entre o movimento no sentido horário e o sentido anti-horário, foi anotada como o valor, em graus, da liberdade rotacional do conjunto com precisão de $0,5^{\circ}$. A média de liberdade rotacional encontrada para os implantes hexágono interno foi de $5,5 \pm 1,9^{\circ}$ e para os implantes hexágono externo foi de $2,9 \pm 0,3^{\circ}$, sendo que todas as amostras hexagonal externa apresentaram liberdade rotacional menor que $5^{\circ}$.

Junções parafusadas estão sujeitas à perda do torque inicial aplicado por causa da fricção e da desadaptação dos componentes protéticos. Alguns autores têm sugerido que essa perda é menor em pilares metálicos usinados em detrimento aos calcináveis (totalmente plásticos). Buscando esclarecer o efeito do procedimento de fundição no afrouxamento dos parafusos de pilares tipo UCLA, Kano et al. (2006), realizaram uma pesquisa na qual foram avaliados 48 pilares de cada tipo, divididos em quatro grupos, cada um com 12 espécimes $(n=12)$. Os grupos foram divididos da seguinte forma: (1) pilares usinados em Titânio; (2) pilares calcináveis com a base pronta, usinada em paládio e sobrefundida em paládio; (3) pilares plásticos totalmente calcináveis em liga de Níquel-Cromo (Ni-Cr) e (4) pilares plásticos totalmente calcináveis em liga de Cobalto-Cromo (Co-Cr). Cada pilar recebeu o torque de $30 \mathrm{~N} . c m$ de acordo com as instruções do fabricante. Após 3 minutos, o parafuso foi afrouxado e o destorque foi anotado. Este procedimento foi repetido 3 vezes para cada amostra e o valor de destorque ou torque de afrouxamento foi anotado como uma porcentagem do torque aplicado. Os resultados encontrados foram: grupo $1-92,3 \pm 2,9 \%$, grupo $2-81,6 \pm 5,0 \%$, grupo $3-86,4 \pm 4,6 \%$ e grupo $4-84,0 \pm 7,0 \%$, valores estes referentes à porcentagem de retenção dos 30 N.cm de torque aplicado. Os pilares usinados de Titânio retiveram a maior porcentagem, significativa, do torque aplicado quando comparados aos que passaram pelo processo de fundição $(p<0,05)$. Os valores de destorque para os pilares calcináveis 
com a base usinada em paládio tiveram valores estatisticamente significantes antes e após fundição $(86,4 \pm 4,87 \%$ e $81,6 \pm 5,07 \%$, respectivamente) e nenhuma diferença significativa foi encontrada quando foram comparados os grupos 3 e 4 . Os autores sugerem que o procedimento de fundição pode influenciar na perda de retenção do torque aplicado, provavelmente devido à produção de irregularidades e rugosidades nas superfícies de contato que podem resultar num grande acomodamento das roscas (relaxamento embutido) e numa grande perda da précarga, fatos estes que podem influenciar a estabilidade final da junção parafusada.

Khraisat et al. (2006) investigaram o efeito do carregamento cíclico lateral, com diferentes posições de aplicação de carga e de períodos, no deslocamento rotacional (DR) dos pilares em sistema de implantes de hexágono externo. Para isso foram utilizados amostras constituídas de 20 implantes de tamanhos de 4x10mm (sistema Brånemark Mk IV - Nobel Biocare), 20 pilares (CeraOne de 3mm - Nobel Biocare) e também 20 espécimes, de tamanho $7 \times 10 \times 7 \mathrm{~mm}$, fundidos e cimentados. 0 torque foi dado com torquímetro digital no valor de $32 \mathrm{~N} . \mathrm{cm}$, de acordo com as recomendações do fabricante. Estes conjuntos foram divididos em 04 grupos, sendo que para os grupos A e B, uma força de $50 \mathrm{~N}$ foi aplicada central e perpendicularmente ao longo eixo dos implantes, por um período de 0,25 × $10^{6} \mathrm{e}$ $0,50 \times 10^{6}$ ciclos, respectivamente e, os grupos C e D receberam a mesma carga, porém aplicada a $4 \mathrm{~mm}$ de distância do centro, ou seja, de forma excêntrica, também por $0,25 \times 10^{6}$ e $0,50 \times 10^{6}$ ciclos, respectivamente. $O$ teste de fadiga foi realizado com uma freqüência de 75 ciclos por minuto, valor similar à freqüência de mastigação humana. O deslocamento rotacional foi calculado da seguinte forma: marcação em linha longitudinal foi feita através da interface implante /pilar e duas linhas laterais uma na parte superior da linha longitudinal, situada na parte inferior do colar do pilar e a outra na parte inferior, situada na plataforma do implante, desta forma, formando um ponto de referência. Após a ciclagem, a distância lateral entre os dois pontos (referência) foi medida para cada conjunto, em um microscópio com alta resolução $(200 x)$ e precisão de $1 \mu \mathrm{m}$. A diferença foi calculada para cada conjunto e o resultado obtido em micrometros. O grupo $D$ teve a maior média de DR $(55,00 \pm 1,871 \mu \mathrm{m})$, enquanto o grupo $A$ teve o menor valor $(2,800 \pm 0,837 \mu \mathrm{m})$. Os grupos A e B tiveram diferença estatística $(2,800 \pm 0,837 \mu \mathrm{m}$ e 3,400 $\pm 1,140 \mu \mathrm{m}$, respectivamente) quando comparados aos grupos $C$ e $D(51,400 \pm 2,074 \mu \mathrm{m}$ e 55,00 $\pm 1,871 \mu \mathrm{m}$, respectivamente), com $\mathrm{p}<0,001$. O grupo $\mathrm{C}$ foi estatisticamente 
diferente do grupo $D(p=0,011)$ e não houve diferença estatisticamente significante entre os grupos A e B. Os autores concluíram que o deslocamento rotacional (DR) entre os componentes ocorreu de forma significativa sob carga lateral excêntrica quando comparada `a carga central e, que aumentou significativamente com longo período de carregamento excêntrico lateral.

A perda de torque é uma situação observada em próteses implantossuportadas parafusadas e considerada um grande problema clínico, uma vez que, a união pilar protético/ implante está sempre sob condições de estresse na cavidade oral. Em 2006, Nakamura et al. realizaram um estudo comparando diferentes parafusos de fixação de abutment em implantes de hexágono e interno, em relação ao afrouxamento, ou seja, o quanto eles perderam de torque aplicado após o ensaio de ciclagem mecânica. Para o estudo foram formados 06 grupos: 1Grupo HE-TiS (implante hexágono externo (HE) sobre o qual foi colocado um pilar para cimentação fixado com parafuso de titânio (Ti) quadrado, coroa cimentada e (S) submetido à ciclagem mecânica; 2- Grupo HE-TiNS (implante HE +pilar fixado com parafuso de titânio + não submetido à ciclagem mecânica); 3- Grupo HE-AuS; 4Grupo HE-AuNS: implante HE sobre o qual foi conectado um pilar (abutment) para cimentação para $\mathrm{HE}$, fixado por parafuso de ouro (Au) quadrado, coroa cimentada e S - submetido à ciclagem mecânica e NS - não submetido; Grupo 5 - HI-TiS e Grupo 6 - HI-TiNS - sendo os implantes de hexágono interno $(\mathrm{HI})$, sobre os quais foram conectados pilares para cimentação para HI, fixados por parafusos de titânio (Ti) quadrados, com coroa cimentada e S - submetido e NS - não submetidos à ciclagem mecânica. Os implantes e componentes protéticos foram fornecidos pela empresa SIN (Sistema de Implante Nacional). Os pilares foram fixados aos implantes por meio dos parafusos de fixação citados com torque manual com uso de chaves digitais apropriadas. O conjunto pilar / parafuso de fixação / implante foi denominado corpo-de-prova 1 e foi utilizado nos grupos não-submetidos ao ensaio de ciclagem mecânica. Sobre cada pilar foi feito enceramento de uma coroa total, com altura e diâmetro total de $8 \mathrm{~mm}$ que, posteriormente foram fundidos em liga de níquel-cromo, de acordo com as especificações do fabricante. O conjunto obtido após a cimentação da coroa foi denominado corpo-de-prova 2, utilizado nos grupos submetidos ao ensaio de fadiga. Um torquímetro analógico Tohnichi (modelo BTG60CN-S, Japão) foi utilizado para aplicar uma força reprodutível em cada parafuso de pilar. Seguindo recomendações do fabricante, o torque de 32 N.cm foi 
aplicado aos parafusos dos pilares, decorridos 10 minutos, o torque no mesmo valor foi repetido visando a diminuição do efeito da sedimentação (ou relaxamento embutido) para se conseguir uma ótima pré-carga.

Quanto à ciclagem mecânica, uma força de $120 \mathrm{~N}$ foi aplicada em sentido axial, de forma excêntrica a $3 \mathrm{~mm}$ do centro, com deslizamento de $0,3 \mathrm{~mm}$ sobre a superfície da coroa e força de atrito de $28 \mathrm{~N}$ a uma freqüência de 60 ciclos por minuto, durante 500.000 ciclos. Durante o ensaio os corpos-de-prova foram mantidos lubrificados por saliva artificial. O torque de afrouxamento foi mensurado a cada 100.000 ciclos nos grupos submetidos ao ensaio e a cada 24 horas após o torque de apertamento nos grupos não-submetidos ao ensaio. A média de torque necessária para afrouxar os parafusos de fixação dos pilares dos grupos submetidos ao ensaio de fadiga foi HE-TiS = 15,56 \pm 1,39 N.cm; HE-AuS=18,15 \pm 1,86 N.cm; HI-TiS= $18,56 \pm 1,15 \mathrm{~N} . \mathrm{cm})$ foi estatisticamente menor do que os parafusos dos grupos que não foram ciclados (HE-TiNS= 23,76 \pm 1,60 N.cm; HE-AuNS= 27,06 \pm 1,24 N.cm; HI-TiNS= 24,01 \pm 1,91 N.cm). Quando a comparação ocorreu entre grupos, verificou-se que ao se comparar os grupos de implantes hexágono externo: HE-TiS $(15,56 \pm$ 1,39 N.cm), HE-AuS (18,15 \pm 1,86 N.cm) com HE-TiNS $(23,76 \pm$ 1,60 N.cm) e HE-AuNS $(27,06 \pm 1,24$ N.cm), houve diferença estatisticamente significante, com os menos valores de destoque (torque de afrouxamento) para os grupos de parafuso de titânio. A média de destorque do grupo HE-TiS (15,56 \pm 1,39 N.cm) é estatisticamente menor do que o grupo HI-TiS $(18,56 \pm 1,15 \mathrm{~N} . \mathrm{cm})$ e não houve diferença estatisticamente significante para o destorque entre os grupos $\mathrm{HE}$ TiNS e HI-TiNS (23,76 \pm 1,60 N.cm; 24,01 \pm 1,91 N.cm, respectivamente), quando não-submetidos ao ensaio de ciclagem mecânica. Os autores acreditam que em relação à comparação entre parafusos de titânio e de ouro, os de ouro apresentam maiores valores de destorque, por permitirem maiores valores de pré-carga em função de um menor coeficiente de fricção, haja vista a maior maleabilidade das ligas áuricas em relação às de titânio. Já em relação à comparação entre as conexões $\mathrm{HE}$ e $\mathrm{HI}$ quando submetidas à ciclagem, segundo os autores, a maior média de destorque e provavelmente menor afrouxamento dos parafusos dos pilares do grupo HI-TiS, pode ter acontecido em função das características inerentes ao tipo de conexão pilar/implante HI, que sugere maior proteção dos parafusos de fixação.

A desadaptação rotacional tem sido uma das maiores causas encontradas para a falha da junção parafusada, particularmente relacionada ao afrouxamento 
e/ou fratura dos parafusos dos pilares. A passividade entre os componentes protéticos é de extrema importância para se evitar tais complicações mecânicas. Distorções e irregularidades são inerentes aos procedimentos de fundição de trabalhos laboratoriais e, podem afetar a adaptação e função de restaurações implanto-suportadas. Baseados neste contexto foi que Kano et al. (2007) avaliaram o efeito do procedimento de fundição na desadaptação rotacional (DR) em pilares calcináveis em comparação com pilares usinados de titânio. Foram utilizados 48 implantes de hexágono externo e a mesma quantidade de pilares com hexágono interno, ambos da empresa Conexão Sistema de Prótese, que foram divididos em 4 grupos com 12 amostras cada um. Grupo 1 - pilares usinados em titânio no formato cônico do corpo-de-prova ( $8 \mathrm{~mm}$ de altura x $8 \mathrm{~mm}$ no maior diâmetro), usado como grupo controle; grupo 2 - pilares calcináveis com a base usinada em paládio; grupo 3 - pilares plásticos totalmente calcináveis em liga de Níquel-Cromo ( $\mathrm{Ni}-\mathrm{Cr}$ ) e grupo 4 - pilares plásticos totalmente calcináveis em liga de Cobalto-Cromo (Co-Cr). Os grupos 2, 3 e 4 foram encerados e fundidos nas mesmas dimensões do corpo-deprova do grupo 1, cada um em sua respectiva liga. A desadaptação rotacional entre o hexágono externo do implante e o hexágono interno do pilar foi medida utilizandose uma mesa transferidora calibrada, previamente descrita por Binon, e registrada em graus. Os pilares foram posicionados e segurados com o parafuso de pilar apertado com suave pressão digital, sem aplicação de torque, para prevenir o levantamento e instabilidade do pilar durante a fase de medição. As médias de DR foram de $1,21 \pm 0,57^{\circ}$ para os pilares do grupo $1 ; 1,77 \pm 1,30^{\circ}$ para o grupo $2 ; 1,98 \pm$ $0,72^{\circ}$ para o grupo 3 e para o grupo 4 uma média de $2,79 \pm 1,13^{\circ}$. Os resultados mostram que diferença estatisticamente significante foi encontrada para os pilares plásticos fundidos em CoCr quando comparados aos pilares usinados em titânio $(p<$ 0.05). A presença de imperfeições não afetou a desadaptação rotacional dos pilares calcináveis com a base usinada em paládio e dos pilares plásticos (totalmente calcináveis) fundidos em NiCr quando comparados aos pilares usinados em titânio. De acordo com os autores, a desadaptação rotacional foi menor do que $2^{\circ}$ para todos os grupos, exceto para o grupo 4 (pilares plásticos fundidos em $\mathrm{CoCr}$ ), rejeitando, desta forma, a hipótese de que o processo de fundição não influenciaria a desadaptação rotacional.

Estudando desadaptação rotacional de sistemas de implantes unitários, Garine et al. (2007) mediram as dimensões dos hexágonos externos dos implantes e 
interno dos pilares para mensurar a liberdade rotacional entre o implante e o pilar e assim, correlacionar os dados do tamanho do espaço presente entre os hexágonos com a desadaptação rotacional de 5 combinações de implante/ pilar de dois fabricantes diferentes. Para esta pesquisa foram utilizados 20 implantes de hexágono externo ( $n=10$ Nobel Biocare; $n=10$ Biomet/3i) e 50 novos pilares, sendo 10 para cada grupo $($ Procera Zirconia $=$ ProZir, Procera Alumina $=$ ProAl, Esthetic Ceramic Abutment $=$ EstAb, ZiReal $=$ ZiReal e GingiHue post ZR Zero Rotation abutments $=$ ZeroRot - este último utilizado como grupo controle, porque, segundo seu fabricante, possui liberdade rotacional de menos de $1^{\circ}$ ). As superfícies contactantes de todos os implantes e pilares foram fotografadas antes e após as medições de liberdade rotacional, através de microscopia eletrônica de varredura $(\mathrm{MEV}=\mathrm{SEM})$. A distância do centro aos cantos dos hexágonos dos implantes e pilares foi calculada inserindo-se as coordenadas $x$ e y dos cantos dos hexágonos no programa de um microscópio de medidas (Mitutoyo), com um instrumento de erro de menos de $1 \mu \mathrm{m}$ e, posteriormente, incluídas no teorema de Pitágoras. Uma estrutura de metal personalizada foi construída para segurar as amostras de implante e pilar e o aparelho de mensuração de ângulos. A desadaptação rotacional foi medida com um codificador óptico de precisão com 0,088 graus de precisão de medida. A diferença dimensional entre os hexágonos do implante e o do pilar foi calculada e correlacionada com a desadaptação rotacional. Após a fixação do implante na base de metal do aparelho, o pilar (abutment) foi ajustado e parafusado sobre o implante com torque de $1 \mathrm{~N} . \mathrm{cm}$, valor suficiente para segurar os componentes juntos enquanto oferece mínima resistência à rotação. Cada pilar foi rotacionado $(3 x /$ sessão) no sentido horário e anti-horário até que houvesse a resistência da união, ou seja, até que o vértice do implante tocasse o lado do pilar. $O$ ângulo entre a posição no sentido horário e o valor na posição do sentido antihorário era anotado como desadaptação ou liberdade rotacional. Após análise estatística verificou-se que em relação à desadaptação rotacional houve diferença estatisticamente significante entre os grupos de pilares $(p=0,001)$, à exceção dos grupos Procera Zirconia e Esthetic Ceramic $(p=0,4)$. A média de liberdade rotacional em graus foi de $4,13 \pm 0,68^{\circ}$ para o grupo ProZir, 3,92 $\pm 0,62^{\circ}$ para ProAl, $4,10 \pm 0,67^{\circ}$ para o grupo EstAb, $3,48 \pm 0,40^{\circ}$ para os pilares do grupo ZiReal e para os pilares de metal do grupo controle ZeroRot 1,61 $\pm 0,24^{\circ}$. Este estudo demonstrou não haver correlação entre a média do tamanho de espaço (gap) entre o conjunto 
implante/ pilar (desadaptação linear) e a desadaptação rotacional. Isto foi explicado pelos autores como uma situação em que quando os implantes e pilares são reunidos, 6 diferentes espaços são criados, 1 para cada um dos 6 vértices ou cantos do hexágono, dada a relativa inconsistência de usinagem dos implantes, estes espaços provavelmente teriam dimensões ligeiramente diferentes, não sendo suficiente para resultar em valores estatisticamente significantes. De acordo com os autores, inconsistências de usinagem foram encontradas tanto para os implantes quanto para os pilares e, os pilares do grupo ZeroRot mostraram menores resultados significantes $(p=0,0001)$ em relação aos outros pilares testados, muito embora, tenha sido confirmado que sua desadaptação rotacional foi maior do que a propaganda de seu fabricante que diz ser menor do que $1^{\circ}$. Ainda, de acordo com os resultados encontrados neste estudo, a presença do colar metálico nos pilares do grupo ZiReal e os pilares totalmente metálicos do grupo ZeroRot melhoraram os valores de liberdade rotacional quando comparados aos outros pilares cerâmicos de Procera (Alumina ou Zircônia) e os pilares estéticos (Esthetic Ceramic abutments).

Implantes dentais são colocados por meio de conexões externas e internas e por meio da aplicação de certa quantidade de torque. A fragilidade de alguns sistemas de hexágono externo pode comprometer a futura prótese dental se deformações ocorrerem nos vértices do hexágono devido ao torque aplicado ao implante no momento da inserção cirúrgica. Nestas situações, os ângulos de liberdade rotacional entre o pilar e o implante são aumentados, fator crítico quando implantes são utilizados para restaurações unitárias. Uma grande liberdade rotacional na interface implante/ pilar transfere estresse aos componentes do implante e ao osso, situação que pode levar ao afrouxamento e/ ou fratura de parafusos dos pilares, micro-fraturas no osso e conseqüente perda da osseointegração. Davi et al. (2008) realizaram um estudo em que diferentes torques de inserção foram aplicados em sistemas de implantes de hexágono externo e interno, com objetivo de avaliar a integridade deste hexágonos após ação dos diferentes torques. Para isso, a liberdade rotacional (LR) entre os hexágonos externos dos implantes e os internos dos pilares foi medida antes e após aplicação dos diferentes valores de torque e, as medidas das distâncias entre os vértices do hexágono externos também foram obtidas antes e após aplicação de cada torque. Para esta pesquisa foram utilizados 10 implantes de hexágono externo (HE- Titamax Poros com montador) e 10 implantes com hexágono externo e interno, mas com a 
conexão protética em hexágono externo (TI - Titamax Cortical), ambos fabricados pela empresa Neodent Implante Osteointegrável e com plataforma de largura $4.1 \mathrm{~mm}$. Os implantes foram submetidos a três níveis de torque de inserção cirúrgica: 45, 60 e 80 N.cm, sendo o torque de 45 N.cm aplicado com o auxílio controlador de torque eletrônico e os de 60 e 80 N.cm com torquímetro cirúrgico. Foi desenvolvido um aparelho experimental para inserção cirúrgica do implante e mensuração do ângulo de liberdade rotacional entre os implantes e os pilares. Este aparelho utiliza um dispositivo que trava o implante em posição com o auxílio de dois parafusos e suas respectivas porcas de fixação, uma escala graduada com precisão de $0,025^{\circ}$, uma haste para medir o ângulo de liberdade rotacional e um dispositivo de aço onde o pilar é adaptado sob pressão. O pilar já fixado no dispositivo de aço foi adaptado ao implante sem utilizar o parafuso do pilar. As primeiras medidas de LR foram feitas com os implantes intactos, posicionados no aparelho e em seguida, após cada aplicação de torque. Não houve significância estatística entre os implantes HE e TI com os implantes intactos ( $\mathrm{HE}-3,31 \pm 0,41^{\circ}$ e $\mathrm{TI}-3,30 \pm 0,17^{\circ}$ ) e após a aplicação do torque de $45 \mathrm{~N} . \mathrm{cm}$ ( $\mathrm{HE}-3,27 \pm 0,38^{\circ}$ e $\mathrm{TI}-3,31 \pm 0,22^{\circ}$ ). Entretanto, após aplicação do torque cirúrgico de $60 \mathrm{~N} . \mathrm{cm}$, houve diferença estatisticamente significante entre os implantes ( $\mathrm{HE}-4,03 \pm 0,54^{\circ}$ e $\mathrm{TI}-3,40 \pm 0,20^{\circ}$ ) e, depois da aplicação do torque de $80 \mathrm{~N} . \mathrm{cm}$, os implantes de torque interno (TI) apresentaram valores de $3,39 \pm 0,21^{\circ}$, enquanto que os implantes $\mathrm{HE}$ não suportaram esta quantidade de torque e tiveram seus hexágonos deformados a tal ponto de anular 0 efeito anti-rotacional. O torque de $60 \mathrm{~N} . c m$ causou um aumento significante de LR nos implantes $\mathrm{HE}$, embora o valor tenha sido menor do que $5^{\circ}$ o que sugere que há uma boa estabilidade na junção; já com o torque de $80 \mathrm{~N} . c m$ o hexágono foi completamente danificado, situação esta, que não ocorreu com os implantes $\mathrm{TI}$ porque eles utilizam o hexágono interno para transmitir o torque para a inserção do implante. Em relação às dimensões dos hexágonos (distância entre os vértices), não houve diferença estatística entre os implantes HE e TI nas situações de implante intacto, após 45 e 60 N.cm. Após o torque de 80 N.cm, os vértices de HE deformaram e houve diferença estatisticamente significante entre os implantes HE e TI. Os autores sugerem a preferência de uso de implantes TI (Torque Interno) em situações onde o posicionamento do implante dentro de uma certa densidade óssea pode gerar torques maiores do que 60 N.cm. 
Os pilares protéticos têm melhorado consideravelmente com a introdução da tecnologia CAD/CAM e a personalização destes componentes, porém os pilares tradicionais como os usinados em titânio, pilares resinosos totalmente calcináveis e os parcialmente calcináveis com a conexão com o implante já usinada (tipo UCLA) ainda são as soluções mais difundidas e utilizadas. A duração da restauração implanto-suportada pode ser afetada por complicações biológicas e técnicas. Para as restaurações unitárias, especialmente em regiões de pré-molares e molares, as complicações técnicas mais relatadas são afrouxamento e/ ou fratura dos parafusos dos pilares bem como a desadaptação rotacional, fatores estes que estão relacionados à falha da junção parafusada. Em 2009, Malaguti et al. realizaram um estudo no qual os objetivos eram desenvolver um protocolo original, analítico, de avaliação dimensional, sem contato, das conexões entre implante e pilar. Uma avaliação da precisão do encaixe das partes, porém sem realizar sua montagem, através de uma análise das partes macho e fêmea. Particularmente, a desadaptação rotacional (DR) pode ser, segundo os autores, analiticamente derivada pelos apótemas dos dois hexágonos (externo do implante e interno do pilar). Além disso, outro objetivo deste estudo foi aplicar as medidas das dimensões para calcular a grade de tolerância internacional (IT) dos componentes.

Este estudo utilizou o sistema de hexágono externo, o que significa que como parte macho do encaixe, considerou-se o hexágono externo do implante e fêmea, o hexágono interno do pilar. Considerou-se o sistema de encaixe de hexágono externo, por ser a configuração mais utilizada e estudada, com resultados facilmente comparáveis a pesquisas anteriores.

Um grupo de cinco implantes de tamanho regular $(3,75 \mathrm{~mm}$ de diâmetro) foi utilizado com todas as possíveis combinações de encaixe com este implante escolhido, sendo elas: grupo 1 - cinco pilares UCLA calcináveis com a base pronta usinada em uma liga de ouro platina e paládio antes do procedimento de fundição; grupo 2 - os mesmos cinco pilares pré-usinados após o procedimento de fundição com liga de prata-cobre e ouro e, o grupo 3 - pilares de titânio totalmente usinados. O procedimento de medida é baseado na largura do hexágono ou o dobro do apótema, no caso chamado de $\mathrm{D}$, que foi medido para cada hexágono através de um microscópio óptico de medidas. Os dados foram processados para obter os valores da grade de tolerância internacional (IT). Os resultados das medições dimensionais foram processados para avaliar a desadaptação rotacional entre o 
hexágono externo do implante e o interno do pilar. A DR foi calculada acoplando-se cada implante com todos os pilares e aplicando-se fórmulas geométricas para medir os apótemas dos hexágonos externos e internos. Todos os pilares foram classificados como IT8, enquanto os implantes apresentaram uma grande tolerância e foram classificados como IT9. A desadaptação rotacional (DR) de todas as combinações de implante e pilar foi menor do que o valor relatado de limite clínico aceitável de $5^{\circ}$, com valores máximos absolutos um pouco acima de $4^{\circ}$ e uma média por volta de $3,5^{\circ}$. O objetivo proposto pelos autores foi alcançado e um protocolo de medidas inovador, objetivo e analítico foi desenvolvido para calcular a grade internacional de tolerância (IT) de implantes dentários e seus componentes, baseado em padrões internacionais, uma vez que o IT é aceito no mundo todo como um indicador de precisão e fundamental para garantir a normalização e aceitação dos produtos testados. Este protocolo desenvolvido é independente da montagem das partes constituintes de uma junção e baseada em ITs. Conseguiu-se a caracterização dimensional dos componentes protéticos e seus conjuntos, fato este, que é a base para a confiança em aplicações clínicas.

O processamento laboratorial de próteses implanto-suportadas pode causar alterações na superfície dos componentes protéticos e provocar algum nível de desadaptação entre as interfaces. Em 2010, Aramouni et al. realizaram um estudo no qual a liberdade rotacional $(R)$ foi mensurada entre implantes de hexágono externo e pilares cerâmicos SynOcta, antes e após preparação e infiltração pela cerâmica de vidro Vita In-Ceram Zirconia. A liberdade rotacional $(R)$ entre o implante (ITI Straumann de $4 \times 10 \mathrm{~mm}$ ) e o pilar, foi avaliada em 20 pilares de matrizes cerâmicas In-Ceram da SynOcta (ITI Straumann) sem alterações, ou seja, antes do preparo e infiltração da matriz e também após estes procedimentos. As mensurações foram feitas em um aparelho previamente descrito por Binon et al. (1995) e Vigolo et al. (2000) e foi anotada em minutos. Os pilares foram fixados aos implantes por parafusos do pilar de forma que permitisse a rotação do mesmo e a diferença entre o movimento no sentido horário pela ponta da agulha e o sentido anti-horário, era anotado como valor de R. Comparado aos pilares sem alterações, ou seja, antes de receber qualquer tipo de tratamento, houve aumento estatisticamente significante $(p=0,009)$ de 0,8 minutos na liberdade rotacional após os procedimentos de preparo e infiltração de vidro. Portanto, de acordo com o estudo realizado, pilares cerâmicos sujeitos à preparação e infiltração por vidro 
demonstraram uma significante alteração nos valores originais de liberdade rotacional $(R)$ entre a interface do pilar e o implante, com possibilidade de implicações biológicas e mecânicas. Os autores confirmam a importância da escolha apropriada de combinações entre implantes e pilares com baixa tolerância de usinagem, além de procedimentos clínicos e laboratoriais meticulosos para que se consiga diminuir a desadaptação rotacional entre os componentes e melhorar a estabilidade da junção parafusada. 
3 - Proposíção 
Considerando que a estabilidade da interface implante / pilar e o torque remanescente após função simulada são fatores que influenciam o sucesso longitudinal das restaurações unitárias implanto-suportadas, o presente trabalho propôs avaliar e comparar os tipos de pilares protéticos (sobrefundidos e fundidos) submetidos à ciclagem mecânica em relação à:

1. Liberdade rotacional entre implantes de hexágono externo com diferentes pilares UCLA (calcinável com a base usinada em Tilite e sobrefundido em liga Tilite e plástico totalmente calcinável, fundido em Níquel-Cromo) antes e após ciclagem mecânica;

2. Avaliação do efeito da fundição na liberdade rotacional;

3. Avaliação do efeito da ciclagem mecânica nas dimensões hexagonais dos implantes;

4. Influência da ciclagem mecânica com aplicação de 500.000 ciclos no afrouxamento (destorque) do parafuso de fixação do pilar. 
4 -Material e Método 
Os materiais e equipamentos utilizados encontram-se descritos nos Quadros 1 e 2.

Quadro 1 - Relação dos materiais utilizados.

\begin{tabular}{|c|c|c|}
\hline Material & Descrição & Marca \\
\hline Castorit super C & Revestimento fosfatado & $\begin{array}{c}\text { Dentaurum, Ispringen, } \\
\text { Alemanha }\end{array}$ \\
\hline $\begin{array}{c}\text { Catraca Torquímetro Protética } \\
\text { (ref. 104.026) }\end{array}$ & & Neodent, Curitiba, PR, Brasil \\
\hline Cera Schuller & Cera em esfera para escultura & $\begin{array}{l}\text { Schuler Dental, Ulm, } \\
\text { Alemanha }\end{array}$ \\
\hline $\begin{array}{c}\text { Conexão sextavada para catraca } \\
\text { (ref. 105.018) }\end{array}$ & $\begin{array}{l}\text { Conexão sextavada longa } \\
\text { para catraca }\end{array}$ & Neodent, Curitiba, PR, Brasil \\
\hline Fita Kera-Vlies & $\begin{array}{l}\text { Fita para permitir a expansão } \\
\text { do revestimento em anel } \\
\text { metálico }\end{array}$ & $\begin{array}{c}\text { Dentaurum, Pforzheim, } \\
\text { Alemanha }\end{array}$ \\
\hline Gesso tipo IV & & Fuji Rock, Leuven, Bélgica \\
\hline $\begin{array}{c}\text { Implante Titamax Ti Cortical } \\
\text { (ref. 109.286) }\end{array}$ & $\begin{array}{l}\text { Implante de hexágono externo } \\
\qquad(3,75 \times 13 \mathrm{~mm})\end{array}$ & Neodent, Curitiba, PR, Brasil \\
\hline Liga Tilite Ômega & $\begin{array}{c}\text { Liga de Níquel - Cromo - } \\
\text { Titânio }\end{array}$ & Talladium, Valencia, CA, EUA \\
\hline Liga Verabond II & Liga de Níquel - Cromo & $\begin{array}{l}\text { Aalba Dent Inc., } \\
\text { Cordélia, CA, EUA }\end{array}$ \\
\hline Óxido de alumínio & $\begin{array}{l}\text { Óxido de alumínio de } \\
\text { granulação de } 100 \mu \mathrm{m}\end{array}$ & $\begin{array}{l}\text { Polidental Indústria e Comércio } \\
\text { Ltda., São Paulo, SP, Brasil }\end{array}$ \\
\hline $\begin{array}{l}\text { Parafuso de titânio } \\
\text { (ref. 116.002) }\end{array}$ & $\begin{array}{l}\text { Parafuso sextavado de } 4,1 \\
\text { mm em titânio para implante } \\
\text { hexágono externo de } 3,75 \\
\text { mm de diâmetro }\end{array}$ & Neodent, Curitiba, PR, Brasil \\
\hline Redutor de Tensão de Superfície & Anti-bolhas & $\begin{array}{l}\text { Lubrofilm, Dentaurum, } \\
\text { Ispringen, Alemanha }\end{array}$ \\
\hline $\begin{array}{l}\text { Resina acrílica auto- } \\
\text { polimerizável }\end{array}$ & & $\begin{array}{l}\text { Jet Acrílico Auto Polimerizante } \\
\text { Clássico, São Paulo, SP, Brasil }\end{array}$ \\
\hline Super Bonder & Adesivo & $\begin{array}{l}\text { Henkel Ltda., Düsseldorf, } \\
\text { Alemanha }\end{array}$ \\
\hline $\begin{array}{l}\text { UCLA Calcinável com AR } \\
\text { (ref. 118.004) }\end{array}$ & $\begin{array}{l}\text { Pilar UCLA totalmente } \\
\text { calcinável, para implante } \\
\text { unitário de plataforma regular }\end{array}$ & Neodent, Curitiba, PR, Brasil \\
\hline $\begin{array}{l}\text { UCLA Tilite com AR } \\
\text { (ref. 118.121) }\end{array}$ & $\begin{array}{l}\text { Pilar UCLA calcinável com a } \\
\text { base usinada em Tilite, para } \\
\text { implante unitário de } \\
\text { plataforma regular }\end{array}$ & Neodent, Curitiba, PR, Brasil \\
\hline
\end{tabular}


Quadro 2 - Relação dos equipamentos utilizados.

\begin{tabular}{|c|c|c|}
\hline Material & Descrição & Marca \\
\hline $\begin{array}{c}\text { Dispositivo para mensuração de } \\
\text { Liberdade Rotacional }\end{array}$ & $\begin{array}{l}\text { Dispositivo para mensuração, } \\
\text { em graus, da liberdade } \\
\text { rotacional }\end{array}$ & Neodent, Curitiba, PR, Brasil \\
\hline Espatulador Elétrico & Nome: Turbo-Mix & $\begin{array}{c}\text { EDG Equipamentos e } \\
\text { Controles Ltda., São Carlos, } \\
\text { SP, Brasil }\end{array}$ \\
\hline Forno Elétrico & $\begin{array}{l}\text { Modelo EDG10P-S, para } \\
\text { expansão do revestimento e } \\
\text { eliminação da cera }\end{array}$ & $\begin{array}{c}\text { EDG Equipamentos e } \\
\text { Controles Ltda. São Carlos, } \\
\text { SP, Brasil }\end{array}$ \\
\hline Máquina de Fundição & Modelo Discovery Plasma & $\begin{array}{c}\text { EDG Equipamentos e } \\
\text { Controles Ltda., São Carlos, } \\
\text { SP, Brasil }\end{array}$ \\
\hline $\begin{array}{l}\text { Máquina para Simulação de } \\
\text { Fadiga com Termociclagem }\end{array}$ & Modelo MSFT & Elquip, São Carlos, SP, Brasil \\
\hline Microscópio Óptico & $\begin{array}{l}\text { Estereomicroscópio óptico } \\
\text { comparador, modelo DFC } 295\end{array}$ & Leica, Heerbrugg, Suíça \\
\hline Plastificador de cera & $\begin{array}{l}\text { Plastificador de cera com } \\
\text { controle digital de temperatura }\end{array}$ & $\begin{array}{l}\text { Hotty Led, Renfert GmbH, } \\
\text { Hilzingen, Alemanha }\end{array}$ \\
\hline Torquímetro Digital & Modelo TQ 680 & $\begin{array}{c}\text { Instrutherme, São Paulo, SP, } \\
\text { Brasil }\end{array}$ \\
\hline
\end{tabular}

\section{1 - Seleção e composição dos grupos}

Para realização desta pesquisa foram utilizados 10 implantes Titamax Ti Cortical 3,75x13mm ref. 109.286 (Neodent) de hexágono externo e 20 pilares protéticos para prótese unitária, (1-UCLA calcinável ref. 118.004, 2- UCLA Tilite ref. 118.121 - Neodent).

A divisão do material foi feita da seguinte maneira: 05 implantes para cada tipo de pilar protético e 10 pilares para cada tipo de cinta ou base (plástica e Tilite). Todos os pilares apresentavam sistema anti-rotacional (AR), sendo utilizados para confecção de prótese unitária. Todos os parafusos usados foram de titânio. 


\section{2 - Dimensões dos hexágonos dos implantes e pilares protéticos}

Uma vez adquiridos os materiais para a pesquisa, como implantes e componentes protéticos, o primeiro passo foi fotografar a plataforma dos implantes e o hexágono dos pilares (UCLA), para serem feitas as medidas de suas dimensões. Isso foi feito em duas etapas. Na primeira, os implantes e os pilares UCLA foram posicionados sobre a plataforma do estereomicroscópio óptico (Leica) com programa e câmera próprios para captura e medição da imagem com aumento de 25x e um ajuste de calibração de 1mm, (Figuras 1 e 1A). O programa utilizado para medidas foi o Leica Application Suite V3. As leituras foram feitas em relação às distâncias entre as faces opostas dos hexágonos (flat-to-flat), ou seja, entre os lados dos hexágonos e entre os seus vértices (diâmetros). Esta primeira etapa de leitura foi feita com todos os implantes e os 20 pilares UCLA antes e após o processo de fundição e também após o ensaio de fadiga mecânica. Na segunda etapa, foram lidos pelo programa os novos pilares UCLA antes e após processo de fundição, embora estes não tenham sido ciclados. Ao total foram feitas 12 medidas das dimensões dos hexágonos dos implantes e pilares UCLA. As primeiras medidas foram dos implantes antes de qualquer solicitação mecânica. Em seguida, foram feitas as medidas dos pilares UCLA plástico com a base usinada em Tilite e dos totalmente calcináveis, antes do processo de fundição e de qualquer solicitação mecânica. A quarta e quinta medidas foram feitas com os mesmos pilares UCLA, após fundição em suas respectivas ligas, Tilite e NiCr, respectivamente, ambos sem solicitação mecânica. As sextas e sétimas medidas, foram dos pilares UCLA fundidos e ciclados, tanto para o grupo Tilite quanto para o NiCr. A oitava medida foi dos implantes após ciclagem. A nona e a décima medidas foram dos novos pilares UCLA, tanto para o grupo Tilite como para o $\mathrm{NiCr}$, antes do processo de fundição. Já as décima primeira e décimas segundas medidas, foram feitas com os mesmos pilares, após o processo de fundição, para ambos os grupos, respectivamente. 


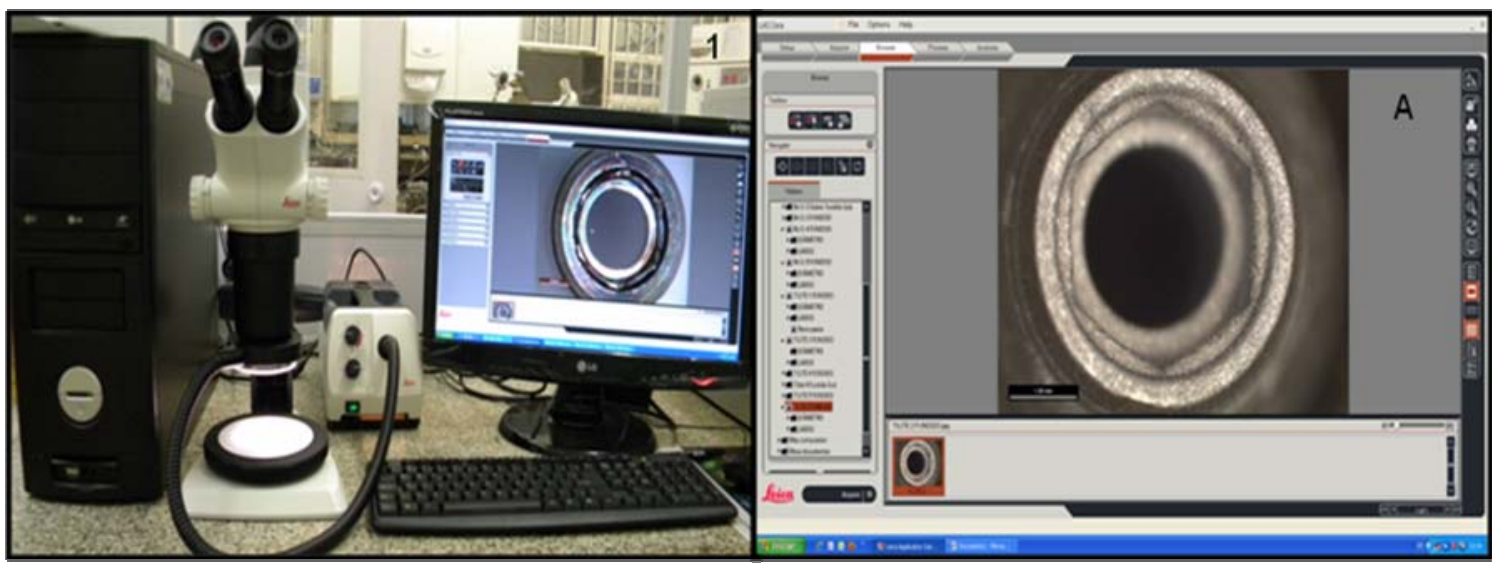

Figura 1 - Sistema Leica de microscopia óptica; A - Foto do pilar UCLA Tilite 2 após fundição, no programa Leica.

As primeiras medidas realizadas foram das distâncias entre os vértices, ou seja, dos diâmetros do hexágono interno dos pilares e do hexágono externo dos implantes (Figura 2). As leituras das três distâncias de cada hexágono foram repetidas 3 vezes e a média foi determinada.

As distâncias entre os lados do hexágono externo dos implantes e entre os lados do hexágono interno dos pilares protéticos também foram utilizadas para avaliar a integridade destes hexágonos antes e após simulação mecânica (Figura 2). Estas distâncias foram obtidas para todos os implantes intactos, antes de qualquer solicitação mecânica, e após a simulação de fadiga. Os pilares UCLA tiveram o hexágono interno medido antes e após o processo de fundição e também após ciclagem mecânica.

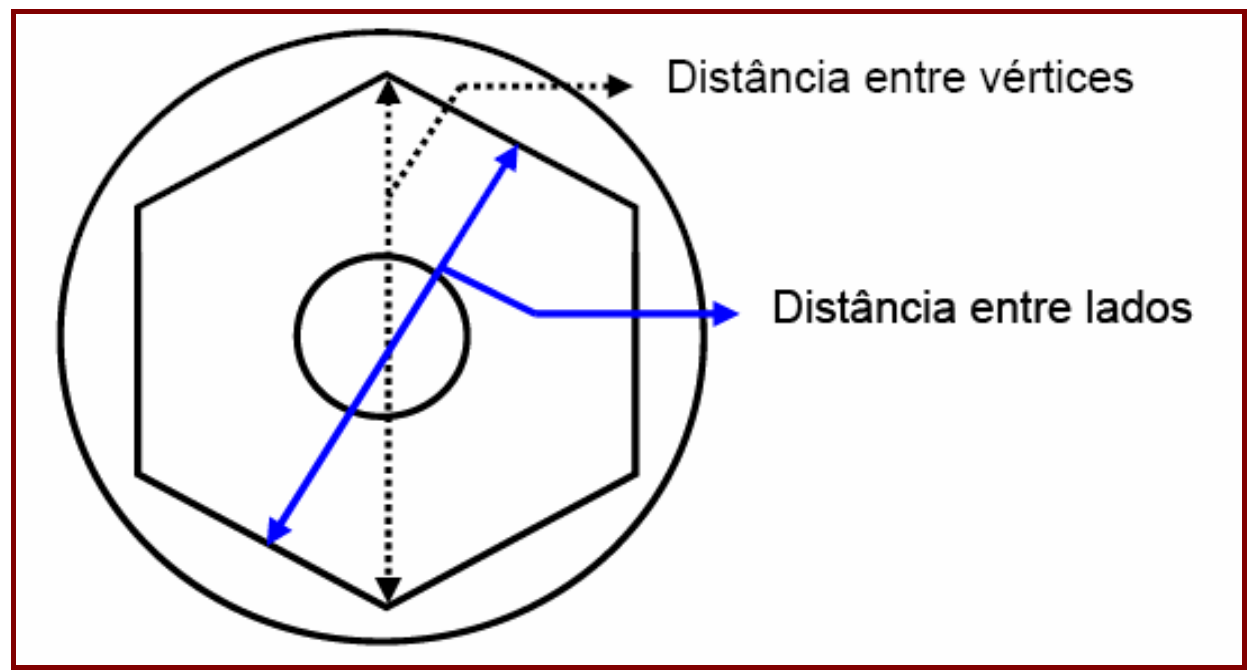

Figura 2 - Desenho esquemático das distâncias entre os vértices e entre os lados do hexágono. 


\section{3 - Medidas de liberdade rotacional}

Em seguida, prosseguiu-se com a primeira medição da liberdade rotacional, antes do enceramento dos corpos-de-prova para obter padrões de comparação em relação ao processo de fundição. Para isso foi usado um dispositivo que permite a leitura da liberdade rotacional. O dispositivo experimental foi projetado e fabricado pela empresa Neodent Implante Osteointegrável e possui as dimensões apresentadas no desenho esquemático da Figura 3. O dispositivo experimental foi utilizado para medir os ângulos de liberdade rotacional experimental entre o pilar e o implante. Inicialmente, o dispositivo possuía escala graduada com precisão de $0,5^{\circ}$ (Figura 4) e por isso foi confeccionado o nônio para aumentar a precisão da leitura dos ângulos rotacionais.

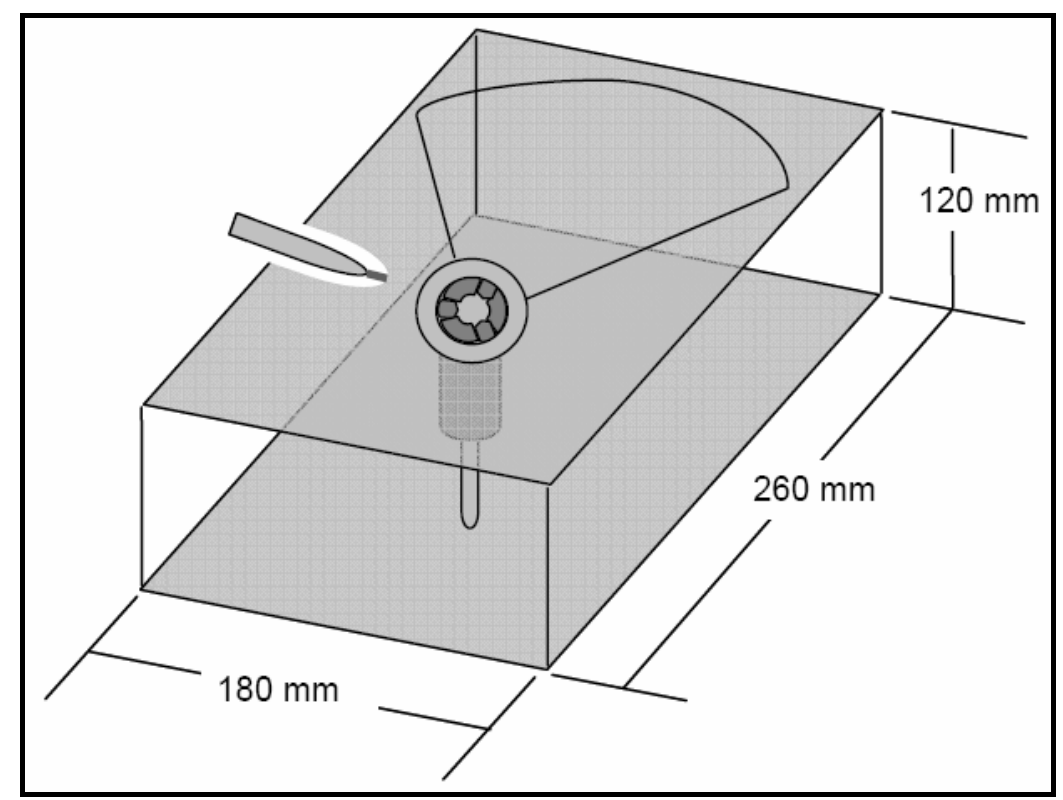

Figura 3 - Desenho esquemático do dispositivo experimental de mensuração do grau de liberdade rotacional. 


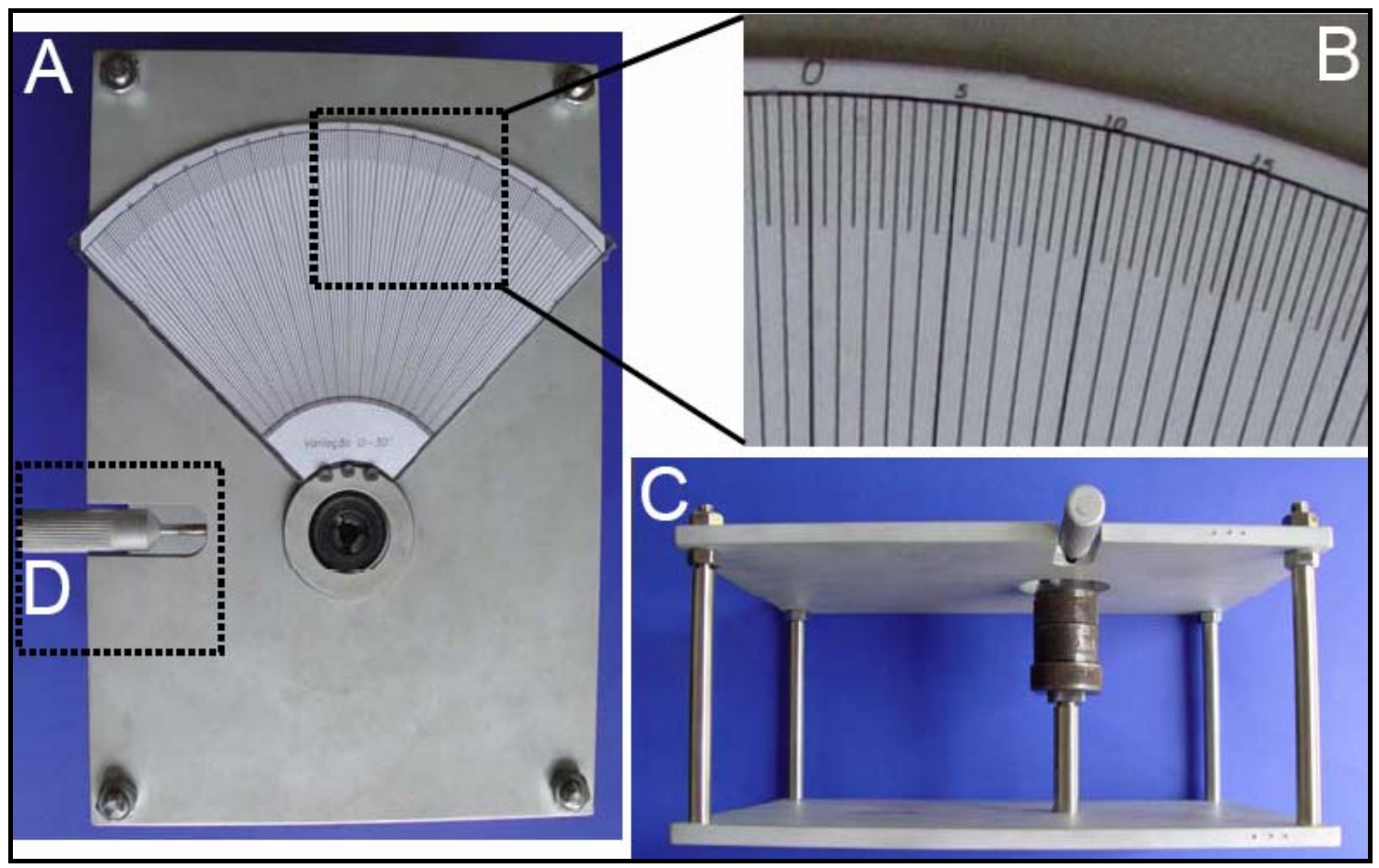

Figura 4 - Dispositivo Experimental; A - Dispositivo inicial; B - Escala graduada com precisão de $0,5^{\circ} ; \mathrm{C}$ - Vista lateral com mandril de aperto rápido para fixar o dispositivo que mantém fixo o implante durante a leitura; D Parafuso lateral.

O nônio foi desenvolvido na Faculdade de Odontologia de Uberlândia (UFU) e, sua confecção deu-se da seguinte maneira: dividiu-se a menor resolução $\left(0,5^{\circ}\right)$ em 20 partes iguais, aumentando, desta forma, a precisão da leitura para $0,025^{\circ}$, como pode ser observado na Figura 5 . A impressão do nônio foi feita em papel branco que, posteriormente foi plastificado e colado em placa de alumínio com adesivo instantâneo universal (Super Bonder, Henkel Itda.). Esta placa de alumínio foi colocada na haste e parafusada para facilitar o posicionamento correto do nônio por cima da escala graduada. 


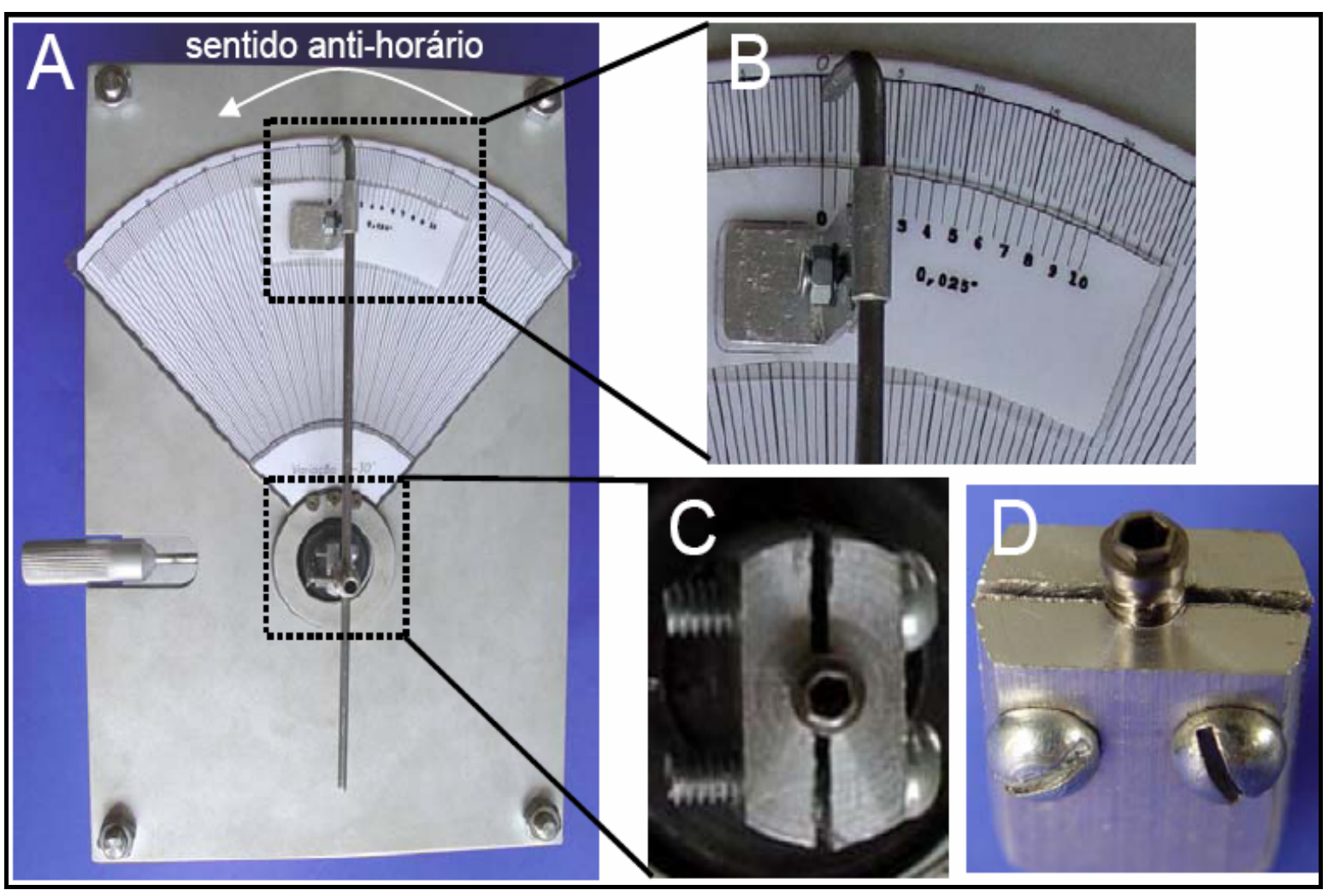

Figura 5 - Dispositivo Experimental; A - Dispositivo com a haste para medir os ângulos de liberdade rotacional; B - Escala graduada com precisão de $0,025^{\circ}$; C - Dispositivo que mantém o implante fixo para a leitura; D Implante posicionado no dispositivo.

A escala graduada é móvel para permitir seu deslocamento na mesa e assim posicionar o início da leitura do ângulo na marca de referência a $0 \mathrm{grau}$, sendo fixada por um parafuso lateral. Na parte superior da mesa há uma abertura circular para o posicionamento do mandril de aperto rápido (Rohm, Alemanha) que deverá segurar o dispositivo de aço cuja ação é a fixação dos implantes. A haste utilizada para a medida da liberdade rotacional foi confeccionada em aço e possui um comprimento adequado para posicionar o nônio próximo à escala graduada. Ao mesmo tempo, possui um braço de alavanca e rigidez que permitem melhorar a sensibilidade do movimento de medida do ângulo de liberdade rotacional, sem sofrer deflexões. O dispositivo para fixação do implante também foi confeccionado em aço e possui uma fenda cuja abertura é de $3,75 \mathrm{~mm}$ para o posicionamento do implante. Todos os implantes foram posicionados com duas roscas acima do nível do dispositivo (Figura 5 D) e apertados com o auxílio de dois parafusos, assim padronizando os ensaios. 


\subsection{1 - Medida dos ângulos de liberdade rotacional experimental}

Antes das etapas de mensurações, foram feitos dois sorteios, um para os implantes e outro para os pilares, para aleatorização das amostras.

Previamente ao início da medida dos ângulos de liberdade rotacional experimental, dois dispositivos foram confeccionados em latão, de forma que um acoplasse o pilar UCLA antes do processo de fundição mantendo-o estável em posição por meio de dois parafusos de aperto, e o outro para o UCLA fundido no tamanho do corpo-de-prova final. Estes também possuíam as perfurações para o encaixe da haste que era utilizada como ponteiro para indicar o grau de rotação, fixada por parafuso (Figura 6).

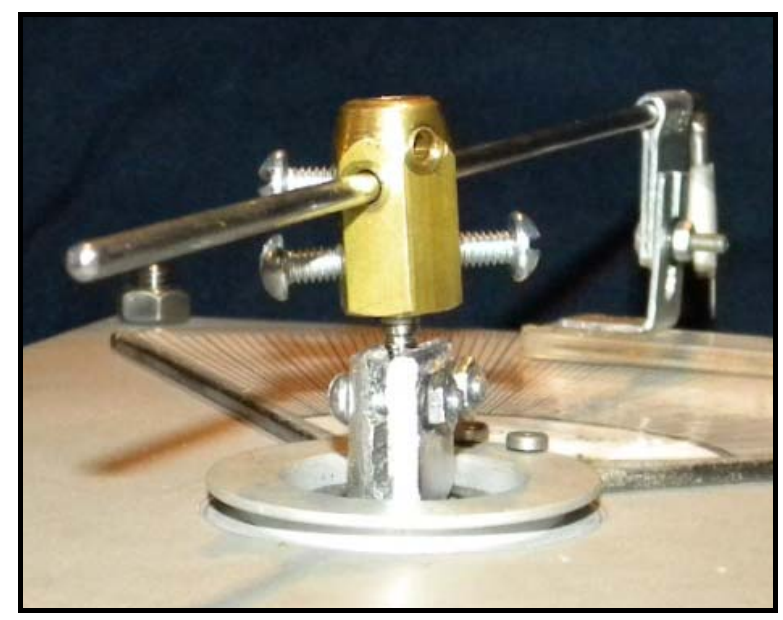

Figura 6 - Dispositivo de latão adaptado à coroa protética e posicionado sobre o implante no aparelho de leitura da liberdade rotacional.

Para a primeira medida de liberdade rotacional, cada implante foi colocado no dispositivo e adaptado ao pilar e à haste, por meio do dispositivo em latão. $\mathrm{O}$ parafuso de fixação do pilar era utilizado para que o mesmo não se deslocasse verticalmente durante as análises, ou seja, apenas para manter a estabilidade do conjunto implante-pilar protético. Assim sendo, o aperto do parafuso era feito até a primeira resistência, seguido de um desaparafusamento de $1 / 4$ de volta, seguindo a metodologia de KANO et al., 2007. Com uma visão superior do conjunto era anotado o ângulo de rotação entre o pilar UCLA e o implante. Repetiu-se o procedimento para todos os implantes. 
Foram feitas dez leituras de liberdade rotacional, sendo cinco para cada grupo de pilar (Tilite e Calcinável, fundido em NiCr). A primeira leitura foi feita com o pilar antes do processo de fundição associado ao implante, sem qualquer solicitação mecânica de ambos, medindo sempre nas 03 posições. Em seguida foi realizada uma segunda mensuração, após o enceramento e fundição dos corpos-de-prova (coroa protética sobre os UCLA), cada um em sua respectiva liga. Possibilitou-se, desta forma, comparar os hexágonos antes e após o processo de fundição sem que houvesse alguma solicitação mecânica nestes implantes e pilares. A terceira mensuração de LR foi feita já com os pilares fundidos e ciclados na máquina de fadiga mecânica, com os implantes também ciclados, após 500.000 ciclos, que correspondem, segundo Craig et al. (1993), a aproximadamente 1 ano e meio de mastigação, com carga axial média $=120 \mathrm{~N}$. A quarta e a quinta leituras foram feitas com novos pilares UCLA, antes e após fundição, respectivamente, associados aos implantes já ciclados, para verificar a ocorrência ou não de algum dano aos hexágonos dos implantes/pilares e, caso tenha ocorrido, em qual parte do sistema de encaixe dos hexágonos externos dos implantes com os internos dos pilares ocorreu este possível amassamento, o que poderia alterar a liberdade rotacional entre os componentes. A Figura 7 mostra um esquema resumido da sequência de leitura da liberdade rotacional do grupo Tilite. O mesmo acontece para o grupo de pilares UCLA calcináveis, posteriormente fundido em liga de $\mathrm{NiCr}$. 
Liberdade Rotacional (LR):

Grupo Tilite

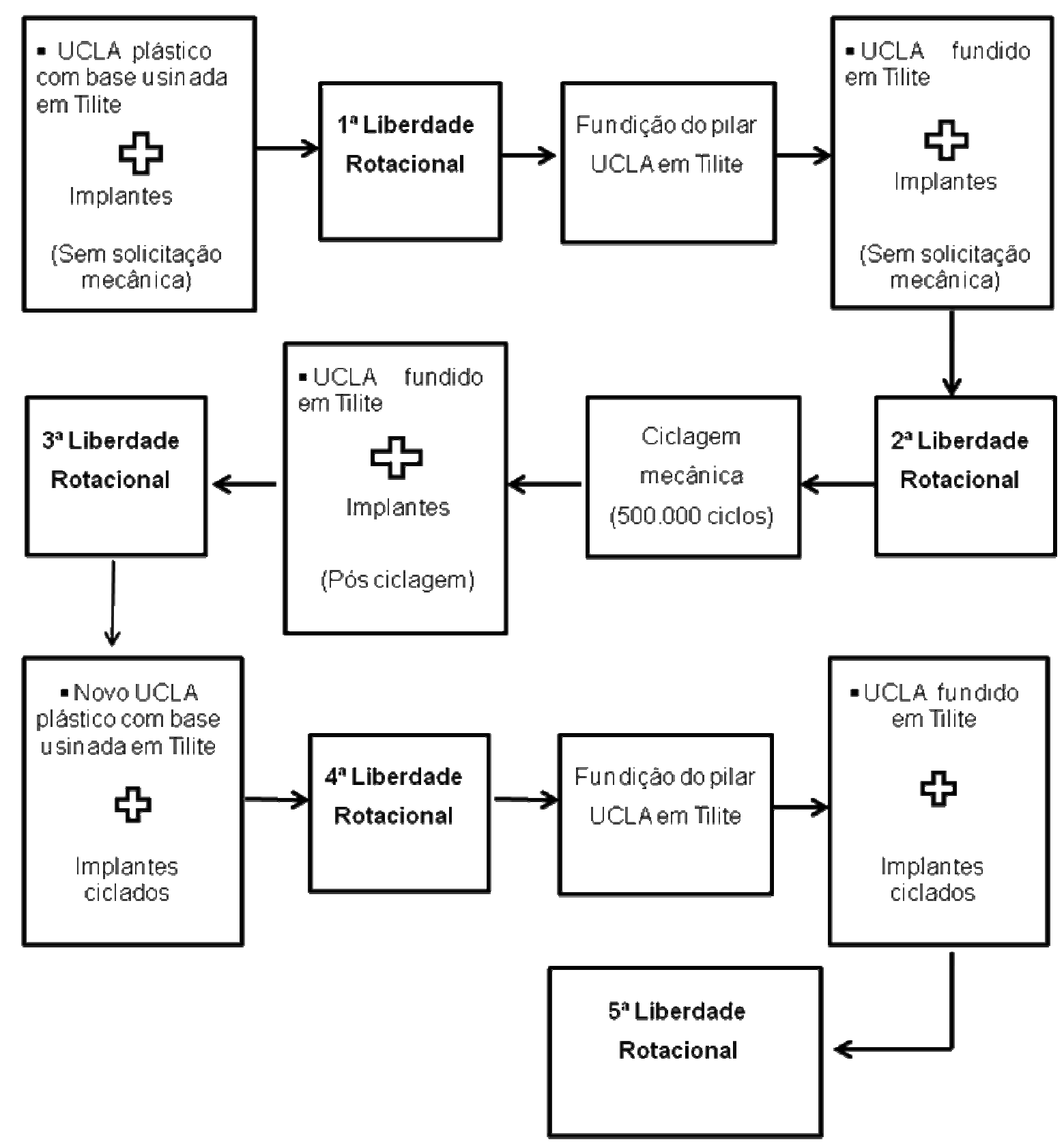

Figura 7 - Esquema de leitura da LR do grupo Tilite.

Como descrito no item 4.3.1, a escala graduada apresenta sistema que permite sua movimentação na mesa do dispositivo para que o zero da escala coincida com o ponto inicial de medida do ângulo rotacional. Este ponto inicial é marcado quando um dos vértices do hexágono externo do implante toca um dos lados do hexágono interno do pilar, como apresentado na Figura 8. 


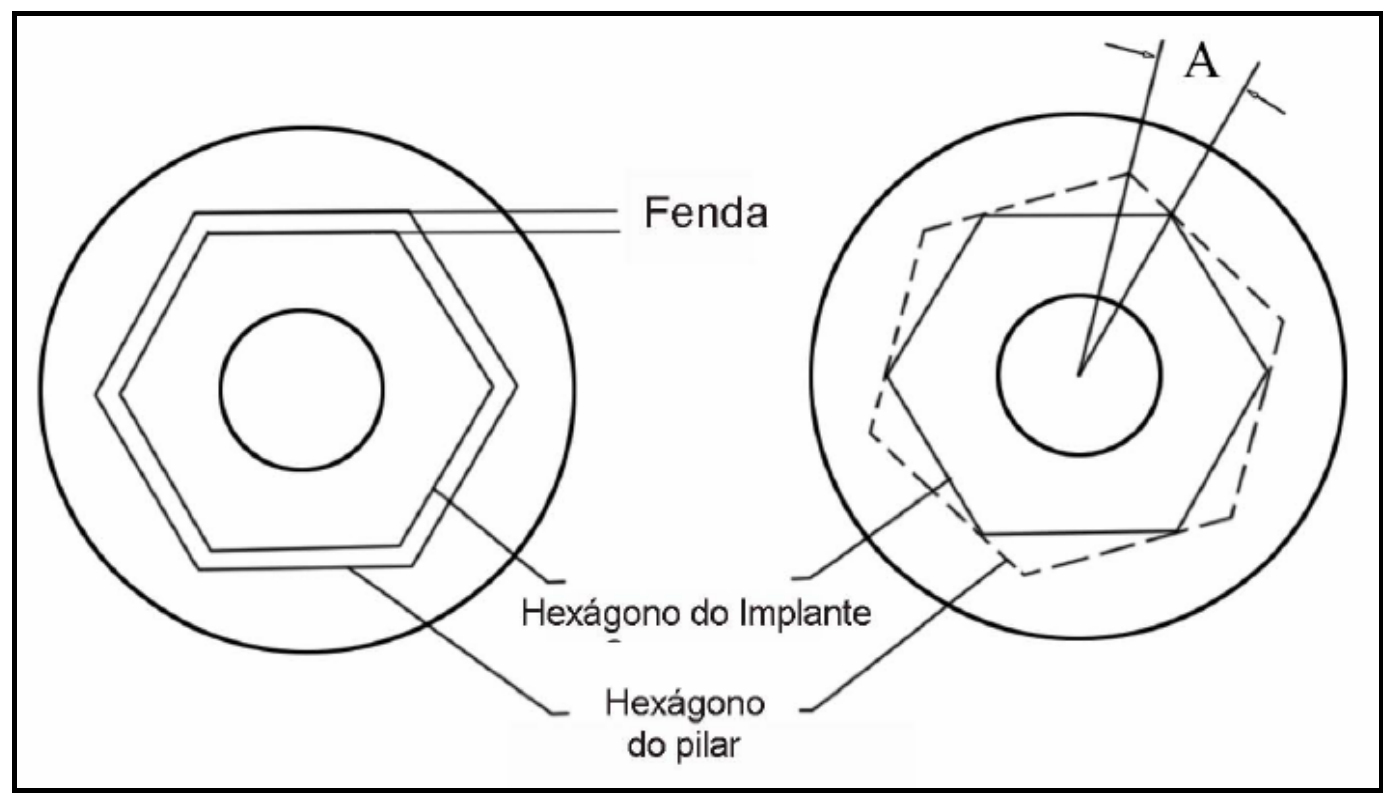

Figura 8 - Representação esquemática do desajuste rotacional $(A)$ em relação à diferença dimensional entre os hexágonos do implante e do pilar.

O ponto inicial foi obtido girando-se a haste manualmente no sentido antihorário até que houvesse resistência da junção, ou seja, até que o vértice do implante tocasse o lado do pilar. Nesta posição a escala graduada era ajustada na marca de referência a 0 grau e estabilizada pelo parafuso lateral do dispositivo experimental. Na seqüência, a haste foi movimentada no sentido horário até que, novamente, ocorresse resistência da junção, ou seja, até que o vértice do implante tocasse o lado do pilar, Figura 9. Neste momento era feita a leitura do ângulo de liberdade rotacional experimental.

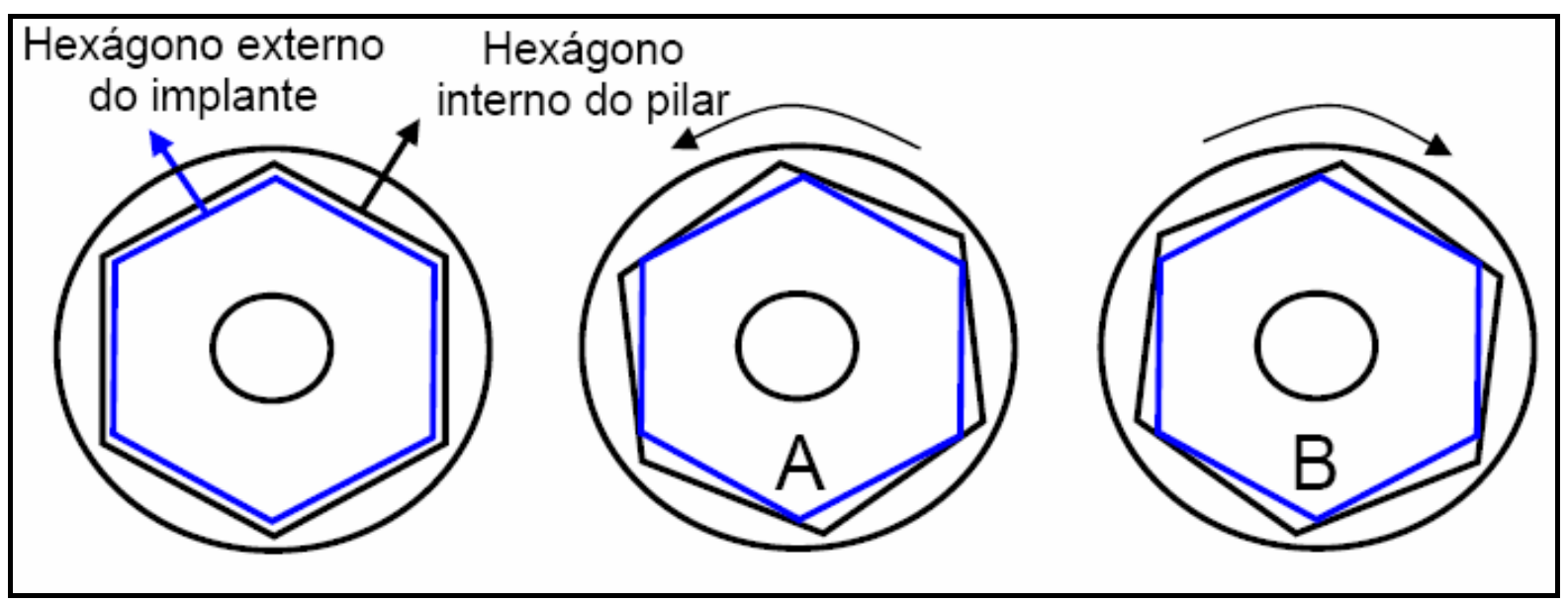

Figura 9 - Desenho esquemático do acoplamento do pilar ao implante; A Movimentação do pilar para o sentido anti-horário; B - Movimentação do pilar para o sentido horário. 
Para minimizar o efeito da interferência da sensibilidade da resistência nas leituras dos ângulos de liberdade rotacional, cada implante foi medido por dois observadores diferentes.

A liberdade encontrada entre os pilares e os implantes foi mensurada em graus, e os dados foram submetidos à análise estatística calculando-se a média e o desvio padrão dentro do grupo e aplicando-se testes estatísticos específicos com nível de significância de $5 \%(p<0,05)$.

\section{4 - Confecção dos dispositivos protéticos}

Para que fosse possível reproduzir uma condição semelhante àquela que ocorre clinicamente, foram confeccionados dispositivos que simulam as coroas protéticas sobre os pilares protéticos.

O enceramento do dispositivo que substitui uma coroa de prótese parcial fixa sobre os pilares UCLA foi feito simulando-se uma reabilitação na região posterior da mandíbula com a forma de um pré-molar inferior sem cúspides. Foi confeccionada uma matriz de acrílico retangular de medidas $(6,5 \times 1,7 \times 2,5 \mathrm{~cm})$, que foi preenchida com gesso tipo IV (Fuji Rock), deixando-se um espaço no centro para o posicionamento do implante. Feito isso, foi feita uma abertura circular no gesso ao redor e acima da plataforma do implante, de forma a mimetizar o perfil de emergência encontrado nos dentes. No gesso tipo IV foram confeccionados três entalhes, sendo dois paralelos entre si em forma de meia-lua e o outro perpendicular em forma de uma barra, para formar uma chave de posição com a matriz que se encaixa neste modelo. O silicone foi recortado no formato do modelo de gesso, com a chave de posição adaptada a ele, e no mesmo foram confeccionados três orifícios, o primeiro centralizado que serve para o posicionamento do parafuso do transferente da região que dá a forma de um pré-molar inferior ao enceramento, o segundo para injetar a cera líquida e posteriormente, formar o canal para posicionar o sprue e o terceiro, paralelo ao segundo, para saída e escoamento da cera (Figura $10 \mathrm{~A}$ ). Os UCLAs foram parafusados ao implante com o parafuso do transferente, a matriz de silicone foi adaptada ao modelo, e a câmara do molde de silicone foi preenchida com cera azul para escultura (Schuler Dental) liquefeita em plastificador com controle digital de temperatura (Hotty Led), mantida a $90^{\circ} \mathrm{C}$. Após o completo resfriamento da cera, a matriz foi removida e os excessos de cera foram recortados (Figura $10 \mathrm{~B}$ ). 
O mesmo processo foi realizado para obtenção de todas as coroas protéticas unitárias ( $n=20$ coroas). Os enceramentos foram feitos sobre o implante Titamax Ti Cortical de hexágono externo e de medidas $3,75 \mathrm{~mm} \times 13 \mathrm{~mm}$, e foram utilizados vinte cilindros protéticos, sendo 10 Cilindros Calcináveis e 10 cilindros Calcináveis com a base usinada em Tilite.
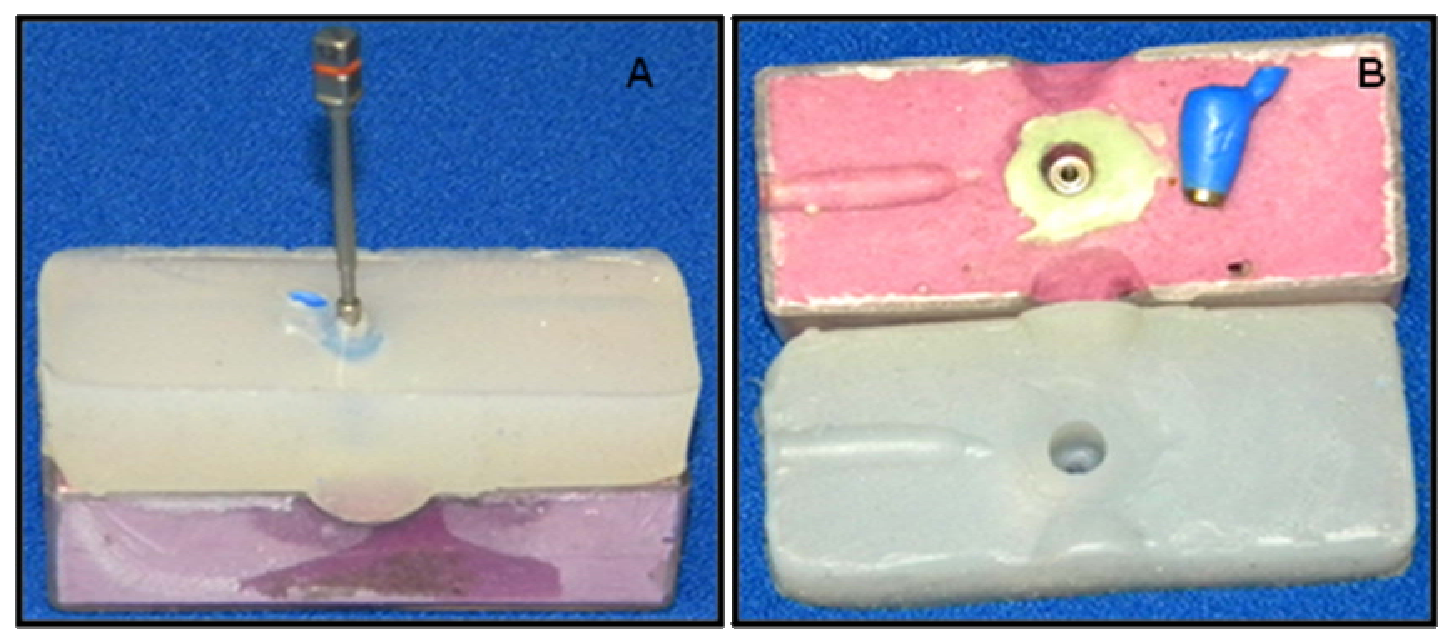

Figura 10 - Matrizes para o enceramento da coroa protética; A - matrizes encaixadas para prosseguir com o enceramento e chave para remoção do componente de moldagem, após resfriamento da cera; $\mathbf{B}$ - Visualização das partes constituintes das matrizes com 0 enceramento finalizado.

\section{5 - Inclusão e fundição das coroas}

Todas as coroas enceradas foram individualmente conectadas a canais de alimentação em cera (sprues), numa angulação que permitisse a visualização do preenchimento do interior dos pilares UCLA pelo revestimento, durante 0 procedimento de inclusão (Figura $11 \mathrm{~A}$ ). As coroas com os sprues foram conectadas aos anéis de borracha para a inclusão nos anéis de fundição (Figura 11 B). Os padrões de cera assim preparados foram fixados com cera 7 às bases conformadoras de cadinho, pulverizados com spray redutor de tensão de superfície (Lubrofilm) e deixados secar à temperatura ambiente. Os anéis metálicos de fundição receberam alívio interno com uma cinta de fibra de vidro de $1 \mathrm{~mm}$ de espessura (Kera-Vlies), que permite a expansão do revestimento, e foram então adaptados e fixados às bases conformadoras de cadinho. 

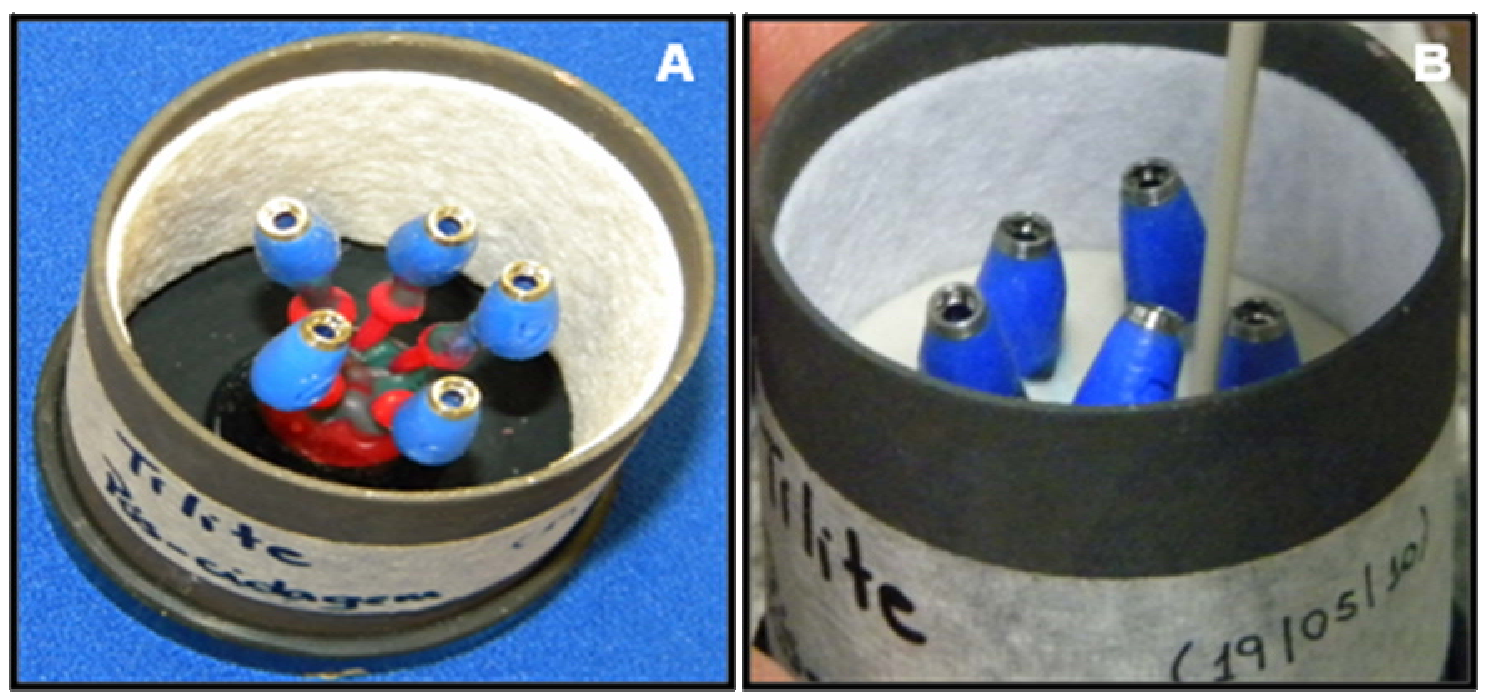

Figura 11 - Enceramentos concluídos com os canais de alimentação posicionados; A - enceramentos fixados ao anel de borracha e posicionados dentro do anel de fundição; B - revestimento sendo cuidadosamente despejado no anel de fundição

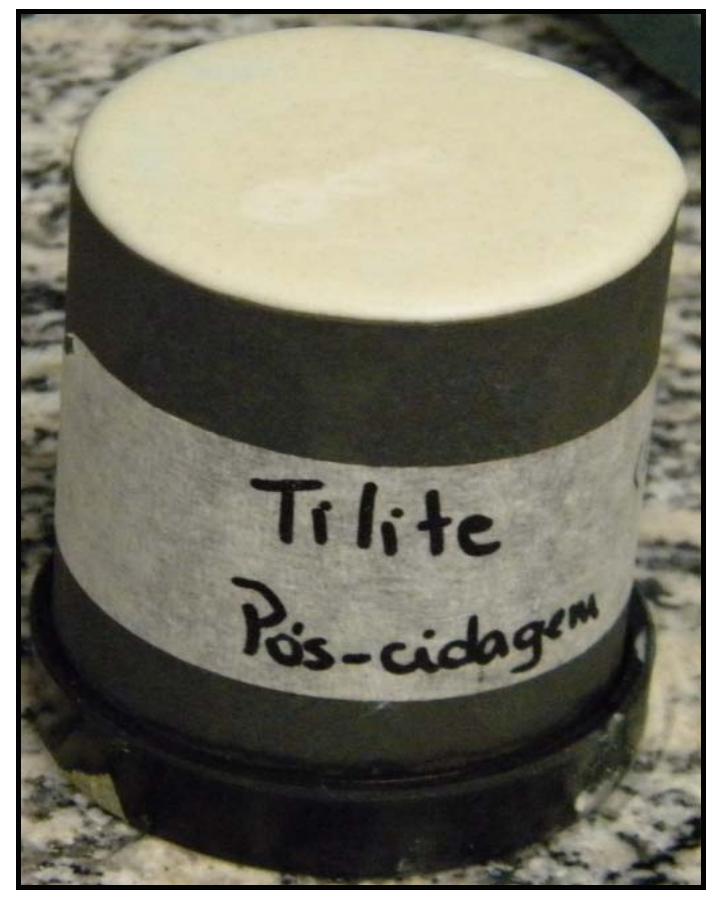

Figura 12 - Enceramentos incluídos no revestimento Castorit super $\mathrm{C}$, esperando o tempo de cristalização do revestimento.

Para a inclusão das coroas, foi utilizado um revestimento de precisão e de ciclo rápido, fosfatado e livre de grafite, Castorit Super C (Dentaurum, Lote 090734), proporcionado de acordo com as recomendações do fabricante. Este foi espatulado manualmente por 60 segundos e após isso, a espatulação foi completada 
mecanicamente a vácuo por 60 segundos em espatulador elétrico (Turbo-Mix, EDG Equipamentos e Controles Ltda). O revestimento foi cuidadosamente despejado no anel, de forma que o preenchimento da superfície interna dos UCLAs fosse visto de baixo para cima, completando-se posteriormente o preenchimento total do anel sob vibração, para evitar a formação de bolhas (Figura $11 \mathrm{~B}$ ). Os anéis assim preparados ficaram sobre bancada, em temperatura ambiente, até a cristalização do revestimento (Figura 12). Decorridos 40 minutos, qualquer excesso de revestimento foi removido e os anéis foram levados ao forno elétrico (EDG10P-S, EDG Equipamentos e Controles Ltda.), para permitir a expansão do revestimento e eliminação da cera, onde foram aquecidos até uma temperatura de $950^{\circ} \mathrm{C}$ (Figura 13), empregando o ciclo térmico representado na Figura 14. A expansão térmica que este revestimento permite é de 1,33\%, segundo informações do fabricante. As infraestruturas foram fundidas em liga de níquel-cromo (Vera Bond II - lote 990824) e níquel-cromo-titânio (Tilite Omega - lote 061207), cujo intervalo de fusão, temperatura de fundição e composição são apresentadas no Quadro 3.

Quadro 3 - Característica das ligas utilizadas (informações do fabricante)

\begin{tabular}{|c|c|c|}
\hline Ligas & TILITE OMEGA & VERA BOND II \\
\hline Intervalo de Fusão & $1204-1302^{\circ} \mathrm{C}$ & $1260-1315^{\circ} \mathrm{C}$ \\
\hline $\begin{array}{c}\text { Temperatura de } \\
\text { Fundição }\end{array}$ & $1329^{\circ} \mathrm{C}$ & \\
\hline $\begin{array}{c}\text { Composição Química } \\
\text { Ni }(60-76 \%) ; \mathrm{Cr}(12-21 \%) ;\end{array}$ & $\begin{array}{c}\mathrm{Ni}(75,55 \%) ; \mathrm{Cr}(11,5 \%) ; \\
\mathrm{Mi}(3,5 \%) ; \mathrm{Nb}(4,25 \%) ; \\
\mathrm{Al}(2,25 \%)\end{array}$ \\
\hline
\end{tabular}




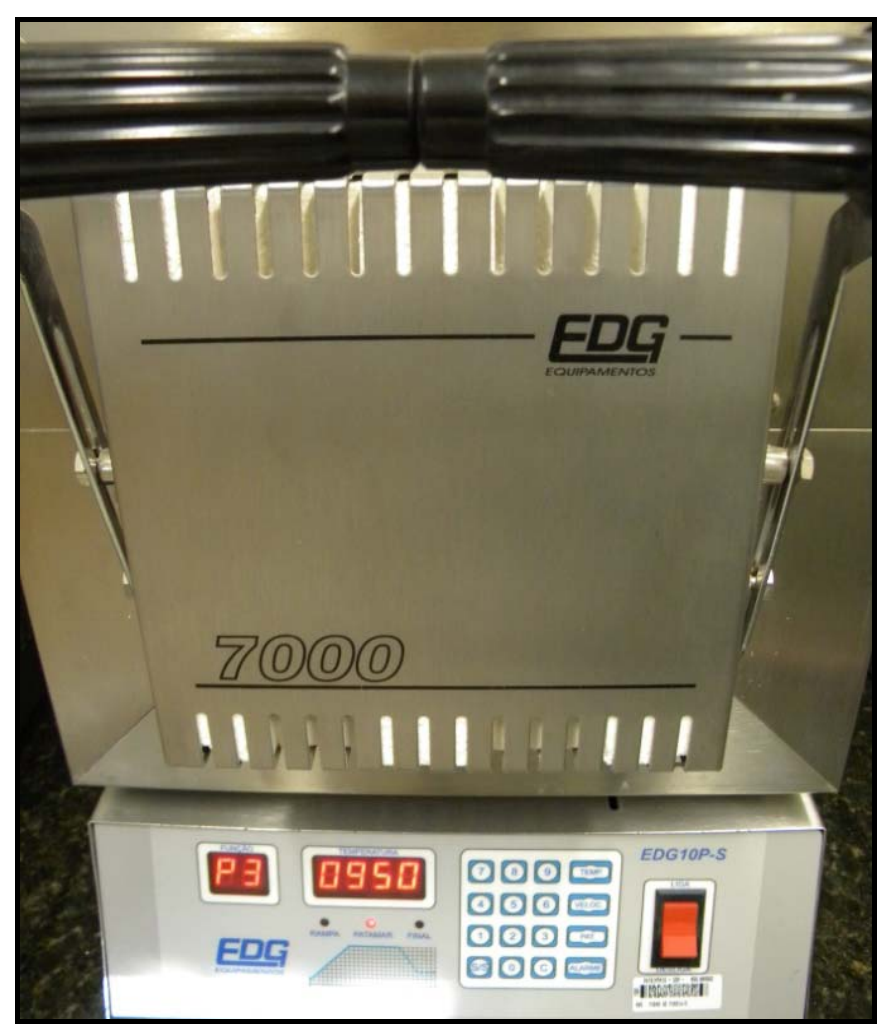

Figura 13 - Forno elétrico contendo o anel de fundição, para a expansão do revestimento e eliminação da cera.

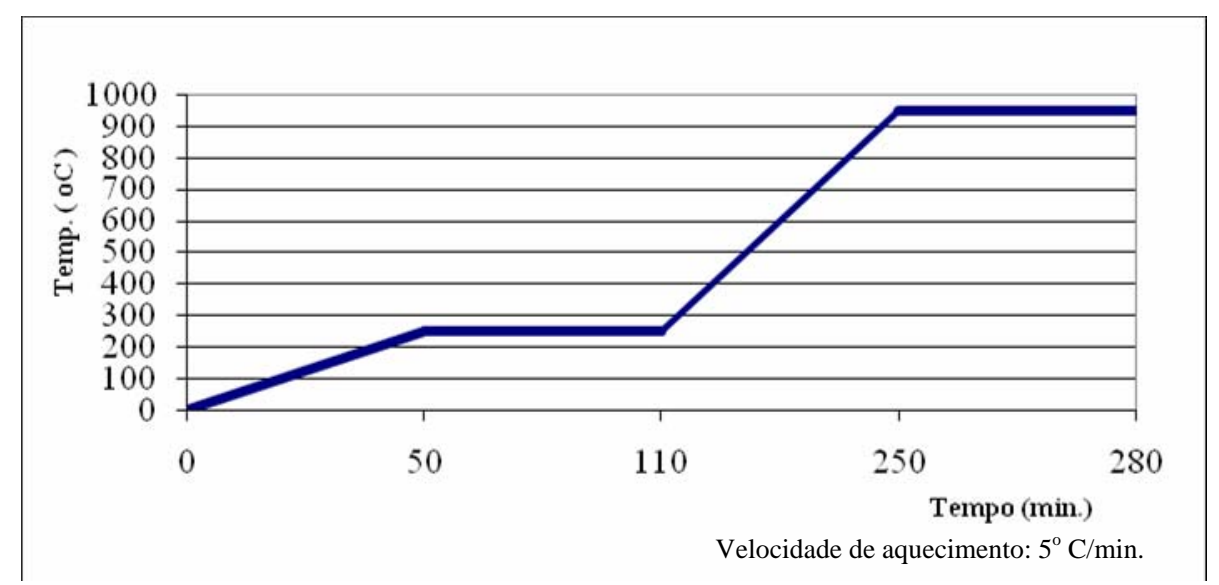

Figura 14 - Ciclo térmico de expansão do revestimento e eliminação da cera para fundição dos corpos-de-prova.

As fundições foram realizadas na máquina Discovery Plasma (EDG Equipamentos e Controles Ltda.), que promove fusão por arco voltaico de corrente contínua através de eletrodo de tungstênio, sobre crisol (cadinho) especial de cobre, sob vácuo e atmosfera inerte de argônio (Figura 15). 


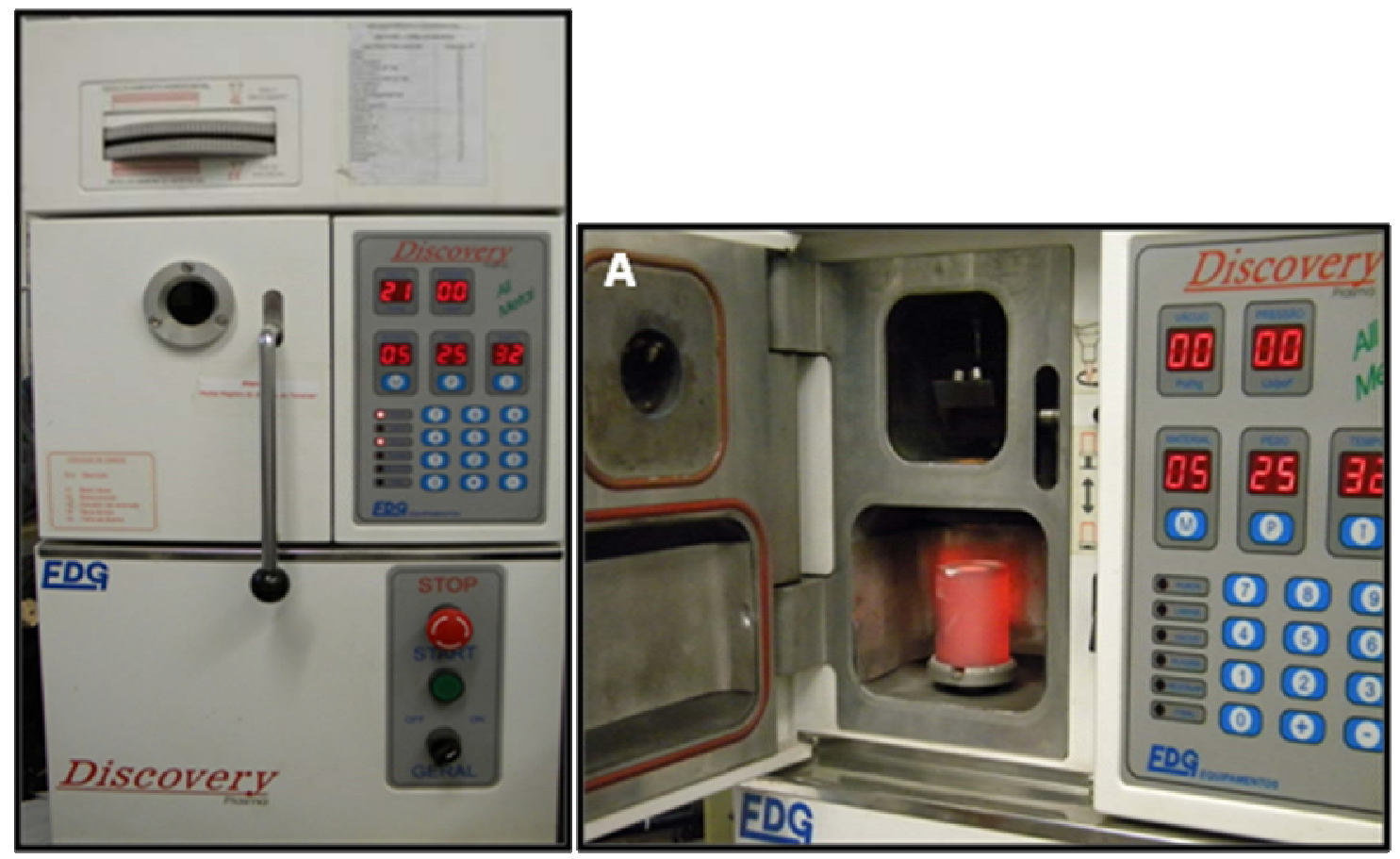

Figura 15 - Máquina de Fundição; A - anel de fundição sendo posicionado na câmara inferior da máquina de fundição

A unidade de fundição da máquina Discovery Plasma é formada por duas câmaras interligadas entre si (Figura 15 A). O metal a ser utilizado deve apresentarse sob a forma de pastilhas, as quais são posicionadas sobre o cadinho de cobre na câmara superior (Figura 16 A) e fundidas pela corrente elétrica gerada por arco voltaico. Depois de fundidas, a liga é injetada no anel de fundição, posicionado na câmara inferior, por ação do vácuo gerado nas duas câmaras e da pressão de argônio aplicada à câmara superior. Todo o processo de fundição ocorre de forma automática e programada (Figura 16 B).
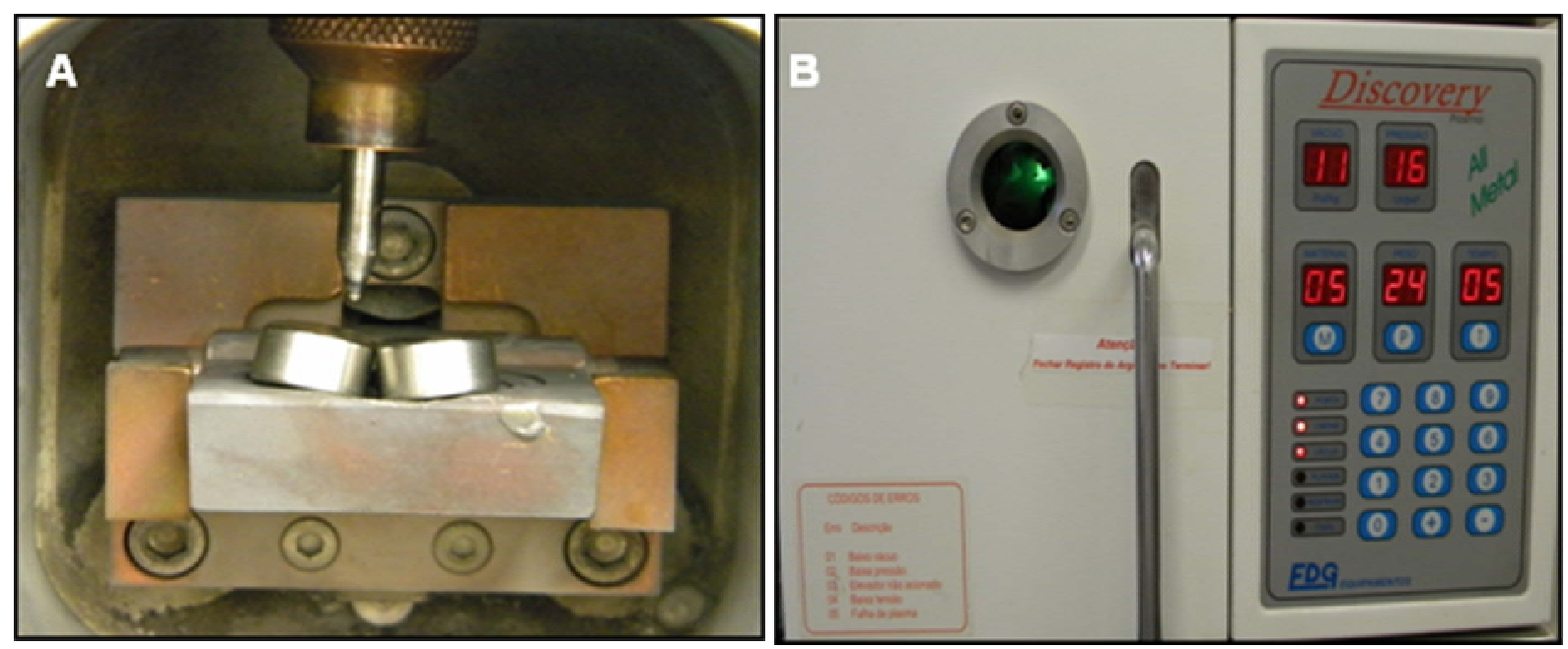

Figura 16 - Detalhes da máquina de fundição Discovery Plasma; A - liga em pastilhas posicionadas no cadinho de cobre; B - pastilhas sendo fundidas pela corrente elétrica gerada pelo arco voltaico. 


\section{6 - Desinclusão e acabamentos das coroas protéticas}

Após o processo de fundição e adequado resfriamento do revestimento em temperatura ambiente, as estruturas foram desincluídas por meio de uma prensa hidráulica (EDG) e em seguida o revestimento foi removido com um martelo pneumático. Os condutos de alimentação foram seccionados com discos de carborundum. Foram removidos pequenos nódulos e irregularidades com brocas de tungstênio em alta rotação sob refrigeração constante. Em seguida, as coroas foram jateadas com óxido de alumínio (Polidental Indústria e Comércio Ltda.) de granulação de $100 \mu \mathrm{m}$, com auxílio da máquina Mult Jet III (EDG) sob pressão de 80 lib/pol2 ou 90 Psi $(5,62 \mathrm{kgf} / \mathrm{cm} 2)$, até a total remoção do revestimento, externa e internamente, à exceção da plataforma que contém o hexágono, que não foi jateada diretamente e, em seguida, posicionadas sobre os respectivos implantes.

\section{7 - Preparo dos corpos-de-prova para simulação de fadiga mecânica}

\subsection{1 - Embutimento dos implantes}

Para que o conjunto implante-coroa protética pudesse ser ciclado na máquina para simulação de fadiga mecânica (MSFM), foi necessário fazer a inclusão dos mesmos em resina acrílica auto-polimerizável (Jet Acrílico Auto Polimerizante Clássico). Para possibilitar a inclusão na inclinação desejada, foi projetada uma matriz de alumínio bi-partida, que possui uma haste superior que permite a inclinação de $30^{\circ}$, angulação esta que segue o protocolo ISO 14801 (Figura 17 A). O implante foi posicionado no furo central da haste superior com o auxílio de um parafuso do transferente, e a altura do implante em relação à matriz foi marcada com uma caneta para retroprojetor preta, tanto no parafuso quanto na haste, de forma que todos implantes fossem posicionados na mesma altura (Figura 17 B). Para facilitar a limpeza da matriz dos excessos de resina, vaselina sólida foi aplicada por toda a superfície da matriz. O mesmo foi feito na plataforma e nas roscas dos implantes, visando-se facilitar o desembutimento dos corpos-de-prova, posteriormente, para dar continuidade ao experimento. A resina acrílica auto polimerizável foi manipulada de acordo com as instruções do fabricante, e vertida no interior da matriz, ao redor do implante já posicionado e fixado pelo parafuso lateral 
da haste. Esperou-se o tempo de polimerização da resina acrílica para retirar o conjunto da matriz. Prosseguiu-se com o acabamento da resina com fresas de tungstênio em baixa rotação para eliminar pequenas rebarbas que restavam por excesso de material.

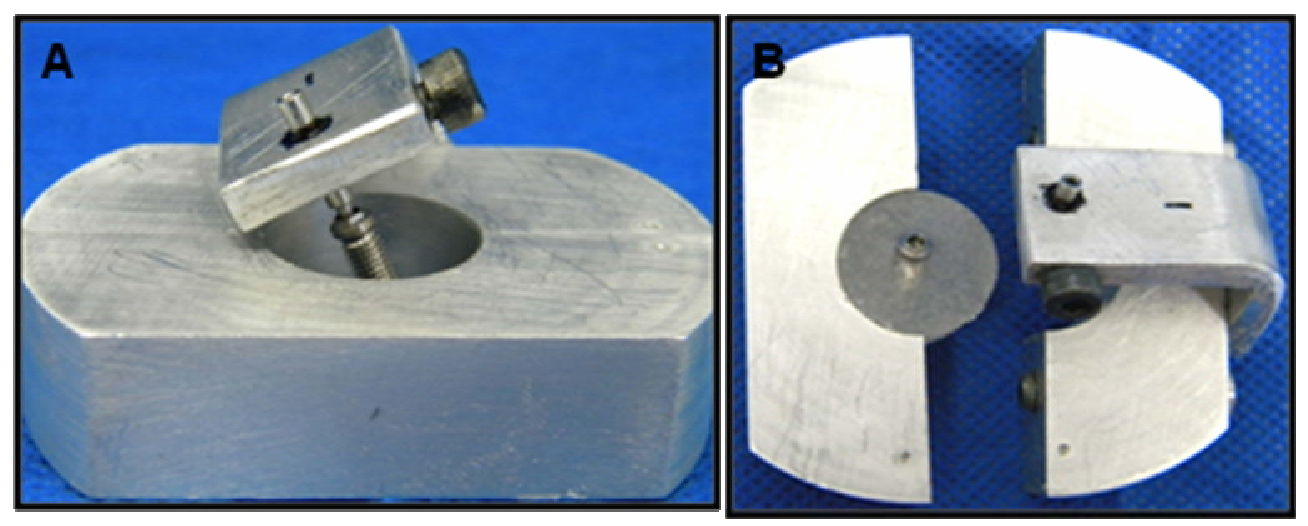

Figura 17 - Matriz de alumínio para o embutimento dos corpos-de-prova; A - matriz bi-partida com a resina já polimerizada; B - matriz com o implante posicionado a uma angulação de $30^{\circ}$ e marcação da altura da posição do implante.

\subsection{2 - Aplicação do torque}

Primeiramente, a coroa protética foi adaptada ao hexágono e parafusada com torque manual. Chamou-se o conjunto implante embutido + coroa protética de corpode-prova e este foi enumerado segundo a sequência de fundição da coroa. Em seguida, colocou-se o corpo-de-prova numa morsa e estabilizou-se o conjunto em uma posição, de forma que o orifício da coroa ficasse perpendicular à chave hexagonal de 1.2 para catraca. Então, a chave foi acoplada à catraca e à cabeça do parafuso do pilar, aplicando-se o torque recomendado pelo fabricante de 32 N.cm para o parafuso de titânio (Figura 18). Aguardou-se o tempo de três minutos, e os parafusos foram novamente reapertados com o mesmo valor de torque para minimizar o efeito da sedimentação (relaxamento embutido), auxiliando o alcance de uma ótima pré-carga. 


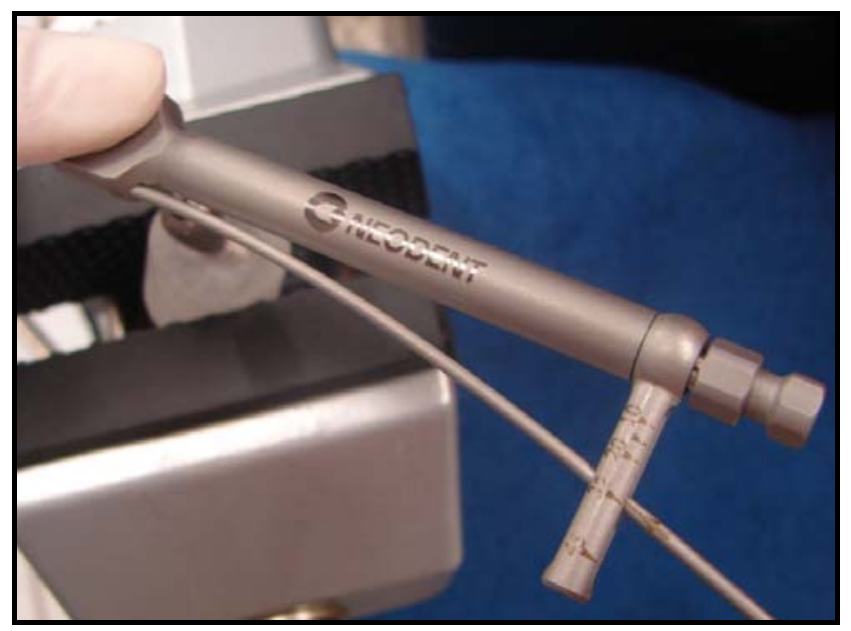

Figura 18 - Aplicação do torque de 32 N.cm, conforme recomendação do fabricante, no corpo-de-prova estabilizado na morsa.

\subsection{3 - Posicionamento dos corpos-de-prova na máquina de simulação de fadiga mecânica (MSFM)}

Os corpos-de-prova foram submetidos a ensaio de fadiga mecânica em uma máquina para simulação de fadiga com termociclagem (modelo MSFT, Elquip). Foram posicionados nos nichos da base da máquina e fixados com cola quente para prevenir qualquer tipo de micromovimento que pudesse interferir nos resultados do teste, de forma que a ponta aplicadora de carga com o formato de um platô circular, tocasse a borda da superfície do corpo-de-prova (Figura 19). A carga aplicada foi do tipo axial, com componente oblíquo fornecido pela angulação de $30^{\circ}$ dada ao implante, através da matriz construída para este estudo. O intuito desta situação a que foram submetidos os conjuntos implante/ coroa protética foi de criar forças de ação lateral no sistema durante o teste de ciclagem de carga, simulando desta forma as condições de forças excêntricas as quais os dentes são submetidos durante a mastigação (KHRAISAT et al., 2006). Essa angulação de $30^{\circ}$ segue o padrão internacional pré-estabelecido - Norma ISO 14801. 


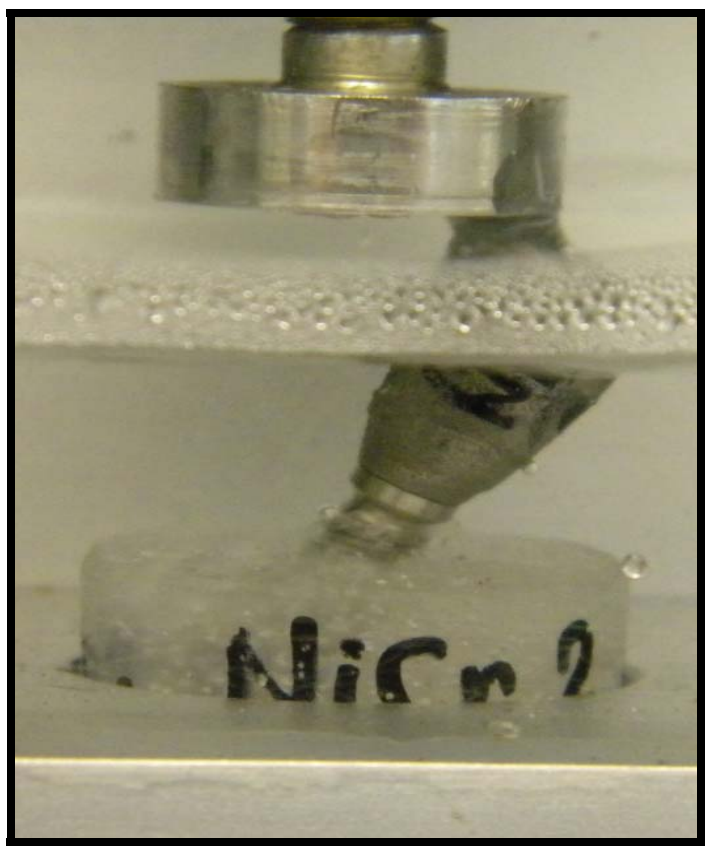

Figura 19 - Corpo-de-prova posicionado no nicho da máquina de fadiga mecânica.

\section{8 - Ensaio de Fadiga Mecânica}

Para o ensaio de aplicação de carga cíclica sobre os conjuntos implantescoroas protéticas, simulando o efeito da mastigação humana, foi utilizada uma máquina de simulação de fadiga (modelo MSFT, Elquip) do Laboratório de Solda a Laser e Corrosão da Faculdade de Odontologia de Ribeirão Preto - USP. Esta máquina possibilita a condução de ensaios dinâmicos de fadiga sobre 6 corpos de prova simultaneamente (Figura 20). Os seis pistões utilizados para a aplicação de carga atuam de forma independente sobre cada corpo de prova. A força gerada sobre o corpo de prova em cada ciclo de carga é dada por um sistema de molas, controlado através de uma célula de carga (Figura $21 \mathrm{~A}$ ). A máquina pode ser calibrada para a aplicação de uma carga de $20 \mathrm{~N}$ até o limite máximo de $300 \mathrm{~N}$, com uma freqüência de $1,8 \mathrm{~Hz}$, em sentido axial. Ela possui ainda, um sistema de termociclagem integrado à base de fixação dos corpos de prova que permite a manutenção da temperatura programada durante todo o teste, com uma variação de $\pm 1^{\circ} \mathrm{C}$. O processo de aplicação da carga é totalmente automatizado. 


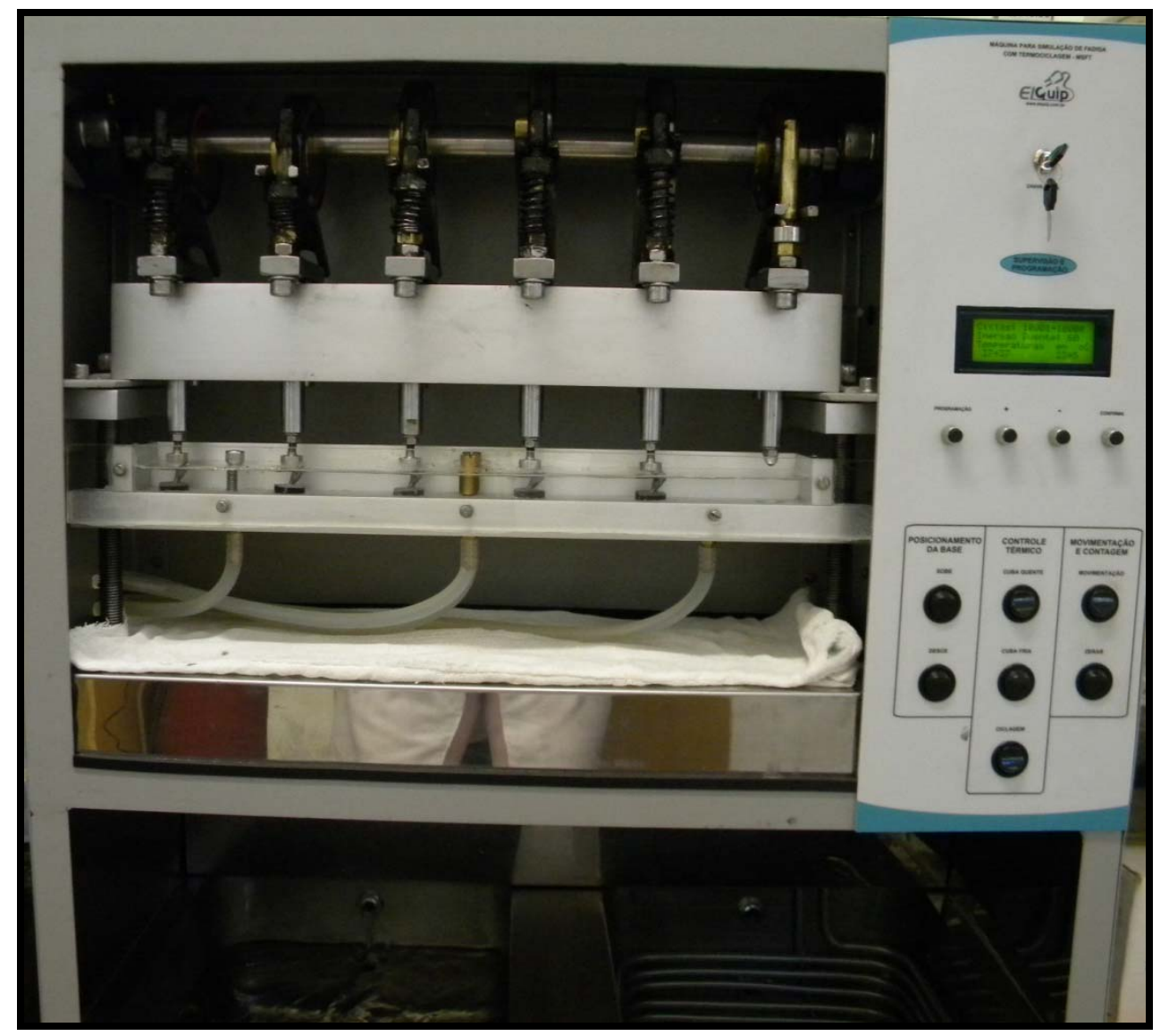

Figura 20 - Máquina para simulação de fadiga com termociclagem - MSFT.

Os pistões, juntamente com as pontas aplicadoras de carga, foram ajustados para incidirem simultaneamente sobre todas as coroas montadas, simulando desta forma uma condição de força excêntrica (Figura $21 \mathrm{~B}$ ). O sistema de termociclagem foi ajustado para uma temperatura de $37^{\circ} \mathrm{C}$, simulando a temperatura da cavidade oral. A máquina foi programada para a aplicação de uma carga com força de aproximadamente $120 \mathrm{~N}$ em média, sobre cada corpo de prova, com uma freqüência de 101 ciclos por minuto $(1,8 \mathrm{~Hz})$, similar à freqüência de mastigação humana, de 75 ciclos por minuto (MOHL et al., 1988), durante 500.000 ciclos, com o intuito de simular aproximadamente 1 ano e meio de mastigação (CRAIG, 1993). 


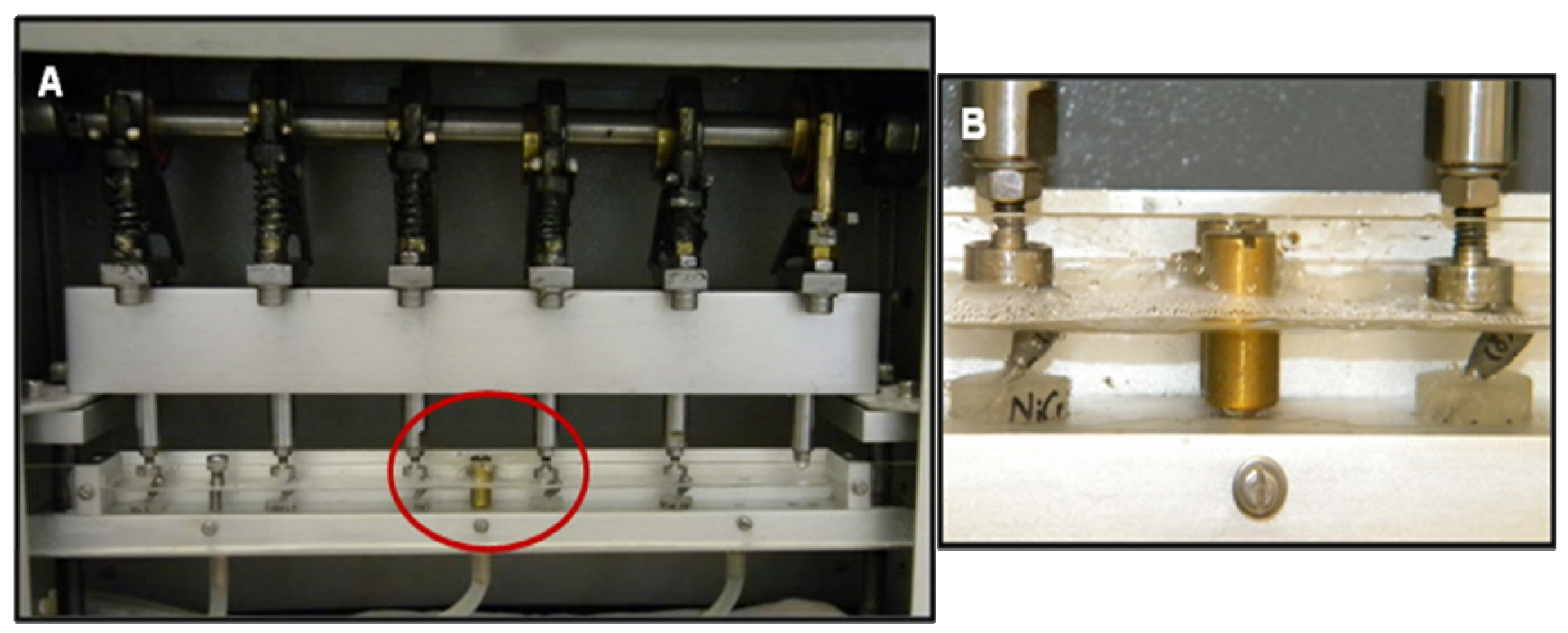

Figura 21 - A - Sistema de molas para aplicação de carga em 06 corpos-de-prova; B - pistões + pontas aplicadoras de carga incidindo sobre dois corposde-prova fixados nos nichos e imersos em água destilada a $37^{\circ} \mathrm{C}$.

\section{9 - Medida do torque de afrouxamento ou destorque}

O conjunto implante/ pilar protético foi fixado em uma matriz de aço com um parafuso lateral, para evitar a rotação do implante dentro da matriz. Em seguida, o cabo da chave hexagonal foi fixado em um mandril presente na extremidade de um torquímetro digital (TQ 680 - Instrutherme), que estava acoplado a uma haste vertical de um delineador (Figura $22 \mathrm{~A}$ ) e a chave foi adaptada à cabeça do parafuso do pilar. Quando a haste foi abaixada, o cabo entrou em contato com a chave já adaptada à cabeça do parafuso do pilar (Figura 22 B), e à medida que se rotacionou a base em que se encontrava a matriz posicionadora do conjunto, o registro do pico do torque de afrouxamento do parafuso foi obtido (Figuras 23 A e B). Esse valor foi anotado para cada conjunto de implante/pilar protético, após o teste de fadiga. 

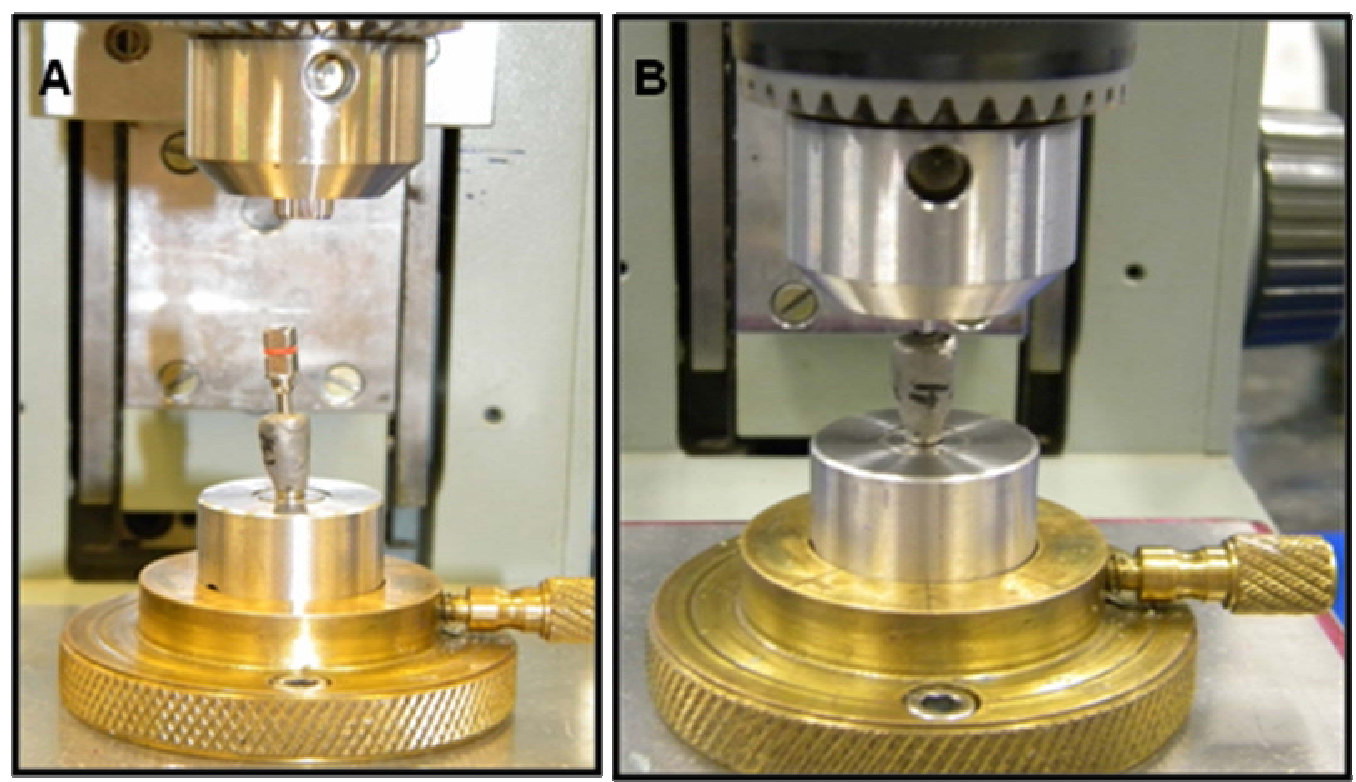

Figura 22 - Momento de verificação do torque de afrouxamento do parafuso ou destorque; A - Chave hexagonal adaptada à cabeça do parafuso do pilar prestes a encaixar no cabo da chave preso ao torquímetro; B conjunto adaptado, pronto para medir o destorque.

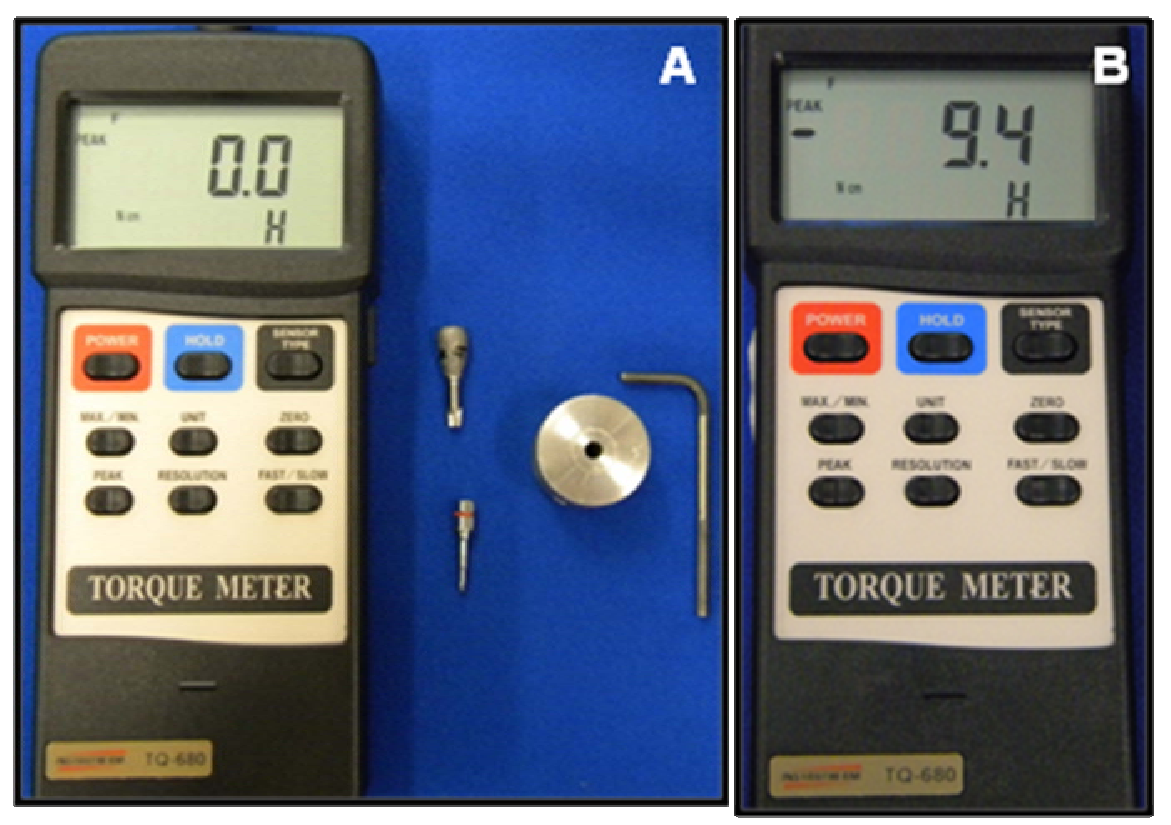

Figuras 23 - Aparelho identificador do valor de torque e destorque; $\mathbf{A}$ - marcação do valor imediatamente antes de iniciar o teste, com referência zero; B - marcação do pico de valor de destorque para o corpo-de-prova medido. 
Após as medidas do torque de afrouxamento, tanto os implantes quantos as coroas protéticas tiveram, novamente, suas dimensões medidas no estereomicroscópio Leica e, como descrito no item 4.2, também foram feitas as medidas de liberdade rotacional dos corpos-de-prova.

Após esta etapa, novos pilares UCLAs tiveram as dimensões dos hexágonos medidos antes e após processo de fundição. Eles foram associados aos implantes já ciclados para que, da mesma forma, tivessem as liberdades rotacionais mensuradas antes e após processo de fundição.

\subsection{0 - Análise estatística}

A análise estatística foi feita no programa SPSS (Statistic Package for the Social Science, versão 17 - SPSS Inc., Chicago, IL, EUA) e utilizou as médias dos grupos para aplicação dos testes. O primeiro teste feito foi o de aderência à curva de normalidade. Os resultados foram normais e assim permitiram a aplicação do teste paramétrico t (Student Newman Keuls), quando se tratava de apenas dois fatores de comparação, para localizar e quantificar as diferenças estatisticamente significantes. O intervalo de confiança adotado foi de $95 \%$ e nível de significância de $5 \%(p<0,05)$. 
5 - Resultados 


\section{1 - Dimensões dos hexágonos dos Implantes e pilares UCLA}

Para os implantes a avaliação foi feita em duas etapas: na primeira foi questionado o efeito da ciclagem mecânica nas dimensões dos hexágonos externos dos implantes e, na segunda, o efeito de cada liga (Tilite ou NiCr) sobre os mesmos hexágonos, após simulação de fadiga. Para análise desta primeira etapa foi aplicado o teste de aderência à curva normal, onde se verificou a normalidade dos resultados tanto para os diâmetros quanto para os lados dos hexágonos externos, permitindo, portanto, estatística paramétrica. Pelo fato de ser uma comparação de somente dois tempos, antes e após ciclagem mecânica, o teste estatístico aplicado foi o teste $\mathrm{t}$ (Student). É importante destacar que, durante a ciclagem mecânica houve a fratura da plataforma de um implante, de forma que este foi excluído da amostra que passou a ter $\mathrm{n}$ igual a 9 . As médias e desvios-padrão desta etapa se encontram descritas na Tabela 1. A Figura 24 demonstra os resultados.

Tabela 1 - Média e desvio padrão dos diâmetros $(\mathrm{mm})$ e lados $(\mathrm{mm})$ dos hexágonos externos dos implantes, antes (AF) e após simulação de fadiga mecânica (PF).

Antes da Fadiga (AF)

Pós Fadiga Mecânica (PF)

\begin{tabular}{lll}
\hline Diâmetros $(\mathrm{mm})$ & $3,199 \pm 0,030^{\mathrm{a}}$ & $3,093 \pm 0,064^{\mathrm{b}}$ \\
Lados $(\mathrm{mm})^{2,776 \pm 0,025^{\mathrm{c}}}$ & $2,691 \pm 0,055^{\mathrm{d}}$
\end{tabular}

* A análise foi feita entre linhas e letras diferentes indicam significância estatística.

Esses resultados mostram que houve uma mudança significativa no tamanho dos hexágonos dos implantes, antes e após ciclagem, tanto para o tamanho dos diâmetros quanto para os lados $(p<0,05)$. Inicialmente o diâmetro era de 3,199 \pm $0,030 \mathrm{~mm}$ e, após ciclagem $3,093 \pm 0,064 \mathrm{~mm}$ e, para os lados era de 2,776 \pm $0,025 \mathrm{~mm}$ e foi para $2,691 \pm 0,055 \mathrm{~mm}$. 


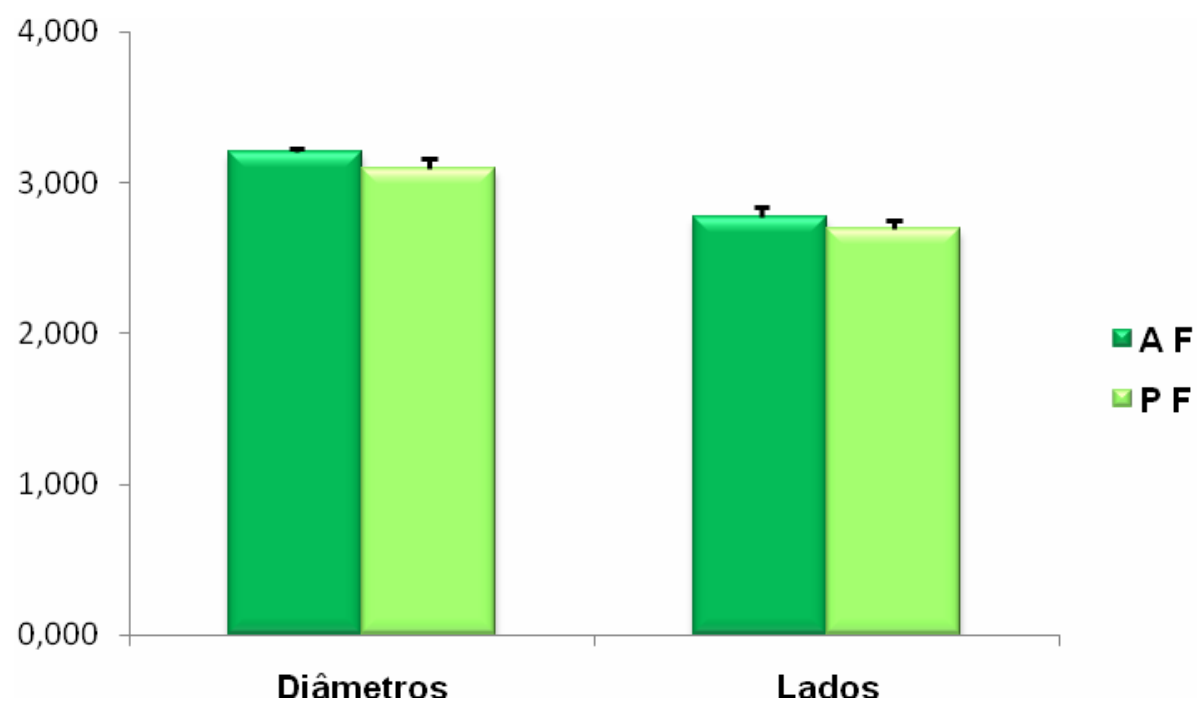

Figura 24 - Médias dos diâmetros e lados dos hexágonos externos dos implantes (mm) nas diferentes situações.

$\mathrm{Na}$ segunda parte deste trabalho, avaliou-se o efeito da liga em que foram fundidas as coroas protéticas na cabeça dos implantes, após simulação de fadiga mecânica. Para isso foi levado em conta o delta $(\Delta)$ dos valores, ou seja, os valores utilizados foram resultados da subtração do valor inicial, antes da ciclagem mecânica, em relação ao valor final, depois da fadiga. Após verificação dos dados apresentarem distribuição normal e as variâncias homogêneas, o teste t de amostras independentes foi aplicado. O implante fraturado durante a ciclagem mecânica pertencia ao grupo Tilite, por isso, a amostra passou a ter $n=4$. $\mathrm{Na}$ análise de comparação entre as ligas, verificou-se que para os diâmetros do hexágono externo dos implantes ( $\mathrm{NiCr}-0,141 \mathrm{~mm}$; Tilite - 0,063mm), embora não tenha dado diferença estatística significativa, houve um limite de significância $(p=0,057)$.

Já para as medidas das distâncias entre os lados do hexágono externo dos implantes, essa comparação entre as ligas demonstrou diferença estatística significativa ( $p=0,044)$, com maior valor, em média, para o grupo fundido na liga $\mathrm{NiCr}(0,114 \mathrm{~mm})$ em relação ao grupo sobrefundido na liga de Tilite $(0,049 \mathrm{~mm})$. Esses resultados podem ser visualizados na Tabela 2 e Figura 25.

Tabela 2 - Valores dos deltas $(\Delta)$, em milímetros, para os diâmetros e lados dos hexágonos externos dos implantes dos grupos $\mathrm{Ni}-\mathrm{Cr}$ e Tilite.

\begin{tabular}{lcc}
\hline \multicolumn{1}{c}{ Grupos (n) } & Diâmetros $(\Delta)$ & Lados $(\Delta)$ \\
\hline Ni-Cr $(n=5)$ & $0,141^{\mathrm{a}}$ & $0,114^{\mathrm{b}}$ \\
\hline Tilite $(\mathrm{n}=4)$ & $0,063^{\mathrm{a}}$ & $0,049^{\mathrm{c}}$ \\
\hline
\end{tabular}

*Letras diferentes, nas colunas, indicam diferença estatística. 


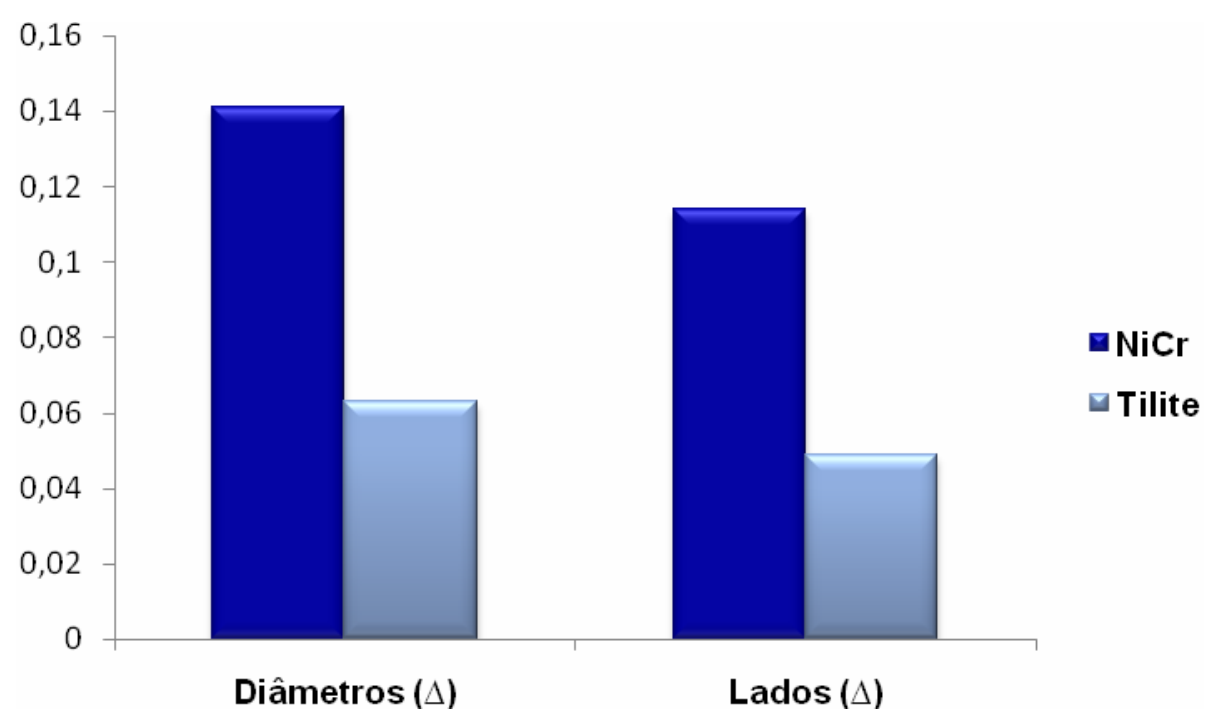

Figura 25 - Deltas $(\Delta)$, em milímetros, para os diâmetros e lados dos hexágonos externos dos implantes dos grupos $\mathrm{Ni}-\mathrm{Cr}$ e Tilite.

Para os pilares de ambos os grupos, foram feitas as mensurações de seus hexágonos internos, tanto para os diâmetros quanto para os lados, antes e após fundição e também após ciclagem mecânica. Porém nenhum teste estatístico foi aplicado. As médias e desvios-padrão para os diâmetros e lados estão descritos nas Tabelas 3 e 4.

Tabela 3 - Média e desvio padrão dos diâmetros dos hexágonos internos dos pilares UCLA (mm) nas diferentes situações

\begin{tabular}{lcc}
\hline \multicolumn{1}{c}{ Situações } & UCLA Ca/ NiCr $(\mathrm{mm})$ & UCLA Tilite $(\mathrm{mm})$ \\
\hline Antes da fundição $(\mathrm{n}=10)$ & $3,230 \pm 0,033$ & $3,217 \pm 0,037$ \\
Após fundição $(\mathrm{n}=10)$ & $3,162 \pm 0,034$ & $3,198 \pm 0,097$ \\
Após fundição e ciclagem $(\mathrm{n}=5)$ & $3,122 \pm 0,011$ & $3,257 \pm 0,029$ \\
\hline
\end{tabular}

Tabela 4 - Média e desvio padrão dos lados dos hexágonos internos dos pilares UCLA (mm) nas diferentes situações

\begin{tabular}{lcc}
\hline \multicolumn{1}{c}{ Situações } & UCLA Ca/ NiCr $(\mathrm{mm})$ & UCLA Tilite $(\mathrm{mm})$ \\
\hline Antes da fundição $(\mathrm{n}=10)$ & $2,804 \pm 0,032$ & $2,784 \pm 0,032$ \\
Após fundição $(\mathrm{n}=10)$ & $2,755 \pm 0,039$ & $2,786 \pm 0,082$ \\
Após fundição e ciclagem $(\mathrm{n}=5)$ & $2,713 \pm 0,005$ & $2,839 \pm 0,027$ \\
\hline
\end{tabular}




\section{2 - Liberdade Rotacional}

Para análise dos dados de liberdade rotacional o primeiro teste aplicado foi o de aderência à curva normal, onde foi verificado que os dados são normais.

Em seguida, a análise foi dividida em duas etapas: na primeira, foram analisadas as diferentes situações de comparação de liberdade rotacional para cada tipo de liga, comparando-se duas a duas, com o teste t de Student. O mesmo teste foi utilizado na segunda etapa onde a comparação foi feita entre as ligas para a mesma condição de leitura da LR. A Tabela 5 demonstra as médias e desviospadrão nas diferentes leituras de liberdade rotacional (LR), juntamente com 0 tamanho da amostra (n) para as duas ligas utilizadas.

Tabela 5 - Médias, desvios-padrão e tamanho da amostra para as comparações entre as diferentes leituras de liberdade rotacional $\left(^{\circ}\right)$

\begin{tabular}{|c|c|c|c|}
\hline \multirow{7}{*}{ 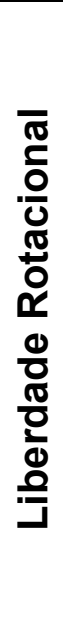 } & \multicolumn{3}{|c|}{ Ligas utilizadas e tamanho da amostra (n) } \\
\hline & & $\mathrm{NiCr}(\mathrm{n})$ & Tilite $(n)$ \\
\hline & $1^{a}$ & $4,684 \pm 0,788^{\circ A, a}(5)$ & $2,930 \pm 0,273^{\circ \mathrm{B}, \mathrm{b}}(5)$ \\
\hline & $2^{\mathrm{a}}$ & $3,21 \pm 1,370^{\circ \mathrm{A}, \mathrm{a}}(5)$ & $4,506 \pm 2,448^{\circ \mathrm{B}, \mathrm{a}}(5)$ \\
\hline & $3^{a}$ & $3,818 \pm 1,904^{\circ \mathrm{A}, \mathrm{a}}(5)$ & $5,126 \pm 2,885^{\circ \mathrm{B}, \mathrm{a}}(4)$ \\
\hline & $4^{a}$ & $6,029 \pm 0,503^{\circ A, a}(5)$ & $3,229 \pm 0,235^{\circ B, b}(4)$ \\
\hline & $5^{a}$ & $4,421 \pm 2,499^{\circ \mathrm{A}, \mathrm{a}}(5)$ & $2,813 \pm 0,406^{\circ \mathrm{B}, \mathrm{a}}(4)$ \\
\hline
\end{tabular}

* Letras maiúsculas referem-se à análise das colunas e, minúsculas à análise horizontal das linhas. Letras diferentes indicam significância estatística.

Para análise da tabela acima devem ser considerados os sentidos vertical (colunas) e horizontal (linhas). Primeiramente fez-se a análise das colunas e, as letras maiúsculas foram designadas para identificar significância ou não dos resultados. Em seguida as letras minúsculas foram utilizadas para verificar significância no sentido das linhas, ou seja, comparando-se as ligas para cada tipo de leitura de liberdade rotacional. 


\subsection{1 - Etapa 1}

As comparações da primeira etapa, entre as situações de liberdade rotacional para cada tipo de liga, encontram-se descritas na Tabela 6 e Figura 26.

Tabela 6 - Comparação entre as leituras de Liberdade Rotacional $\left({ }^{\circ}\right)$ para cada tipo de liga.

\begin{tabular}{cccccc}
\hline Ligas & $\mathbf{1}^{\mathbf{a}}$ & $\mathbf{2}^{\mathbf{a}}$ & $\mathbf{3}^{\mathbf{a}}$ & $\mathbf{4}^{\mathbf{a}}$ & $\mathbf{5}^{\mathbf{a}}$ \\
\hline $\mathrm{Ni}-\mathrm{Cr}$ & $1-2$ & $4-5$ & $2-3$ & $2-5$ & $3-5$ \\
\hline Tilite & $1-2$ & $4-5$ & $2-3$ & $2-5$ & $3-5$ \\
\hline
\end{tabular}

- Liberdade Rotacional (LR) 1 - pilares UCLA antes do processo de fundição, calcináveis totalmente plásticos e calcináveis com a base usinada em Tilite associados aos implantes, ambos na condição de recém adquiridos, ou seja, sem solicitação mecânica.

- $\quad$ Liberdade Rotacional (LR) 2 - pilares UCLA após processo de fundição, calcináveis totalmente plásticos fundidos em liga de níquel-cromo (Ni-Cr) e calcináveis com a base usinada em Tilite fundidos em liga de níquel-cromo-titânio (Tilite), associados aos implantes, ambos na condição de recém adquiridos, ou seja, sem solicitação mecânica.

- Liberdade Rotacional (LR) 3 - pilares UCLA fundidos em suas respectivas ligas e ciclados associados aos implantes ciclados, ou seja, após simulação de fadiga mecânica.

- $\quad$ Liberdade Rotacional (LR) 4 - novos pilares UCLA, de ambos tipos, na condição de recém adquiridos, ou seja, antes do processo de fundição, associados aos implantes já ciclados.

- Liberdade Rotacional (LR) 5 - os mesmos pilares da situação anterior, porém, após fundição em suas respectivas ligas, sem solicitação mecânica, associados aos implantes ciclados. 


\subsubsection{1 - $1^{\text {a }}$ Situação - comparação entre os pilares UCLA antes de fundir (1) e depois de fundidos (2) associados aos implantes, ambos sem solicitação mecânica}

- GGrupo NiCr: Os resultados do teste $t$ indicam um limite de significância $(p=0,053)$, ou seja, embora os valores de liberdade rotacional destes pilares antes de fundir tenham sido numericamente maiores $\left(4,684 \pm 0,788^{\circ}\right)$ do que os valores de LR após fundição $(3,210$ $\left.\pm 1,370^{\circ}\right)$, esta diferença não foi estatisticamente significante.

- Grupo Tilite: Os pilares UCLA do grupo Tilite também não apresentaram diferença estatisticamente significante antes e após o processo de fundição. Os valores de LR dos pilares UCLA calcináveis com a base usinada antes da fundição apresentaram média de 2,930 \pm $0,273^{\circ}$, após fundição em Tilite a média foi para $4,506 \pm 2,448^{\circ}$. Portanto, embora a média tenha aumentado após fundição, esta não foi suficiente para alterar, de forma significativa, a LR dos conjuntos $(p=0,214)$.

\subsubsection{2 - 2a Situação - comparação entre os novos pilares UCLA antes de fundir (4) e pós fundição (5), ambos associados aos implantes que foram ciclados}

- Grupo NiCr: Na análise destes pilares, verificou-se que embora tenha havido diminuição nos valores da LR após fundição $\left(4,421 \pm 2,499^{\circ}\right)$ em comparação aos padrões de plástico $\left(6,029 \pm 0,503^{\circ}\right)$ antes de serem fundidos, essa redução não foi suficiente para resultar em um valor de diferença estatística significativa $(p=0,176)$.

- Grupo Tilite: A LR dos pilares plásticos com base usinada em Tilite, antes de fundir, era em média de $3,229 \pm 0,235^{\circ}$ e após fundição em liga de Tilite foi para 2,813 $\pm 0,406^{\circ}$. Esta diferença, embora observada a redução nos valores, não foi estatisticamente significativa $(p=0,261)$. 


\subsubsection{3 - 3a Situação - comparação entre os pilares UCLA fundidos, associados aos implantes, ambos na condição de recém adquiridos com os mesmos pilares associados aos mesmos implantes, porém após ciclagem mecânica}

- Grupo NiCr: Após aplicação do teste t de amostras pareadas, verificouse que quando a liberdade rotacional dos pilares fundidos associados aos implantes, ambos na condição de novos (2), sem solicitação mecânica, foram comparados aos mesmos pilares e implantes, porém após fadiga (3), não houve diferença estatisticamente significante. Embora tenha havido aumento da média de liberdade rotacional verificado após a simulação de fadiga mecânica $\left(3,818 \pm 1,904^{\circ}\right)$ em relação à média antes da ciclagem $\left(3,210 \pm 1,370^{\circ}\right)$.

- Grupo Tilite: Durante a ciclagem mecânica do grupo Tilite, o implante (6) teve sua plataforma fraturada, o que fez com que fosse retirado da amostra $(n=4)$. Como o teste aplicado foi o teste $t$, automaticamente, ele retirou os valores desse implante da condição (2), pois as amostras são dependentes e o teste pareado. Os resultados encontrados foram numericamente maiores após a ciclagem $\left(5,126 \pm 2,885^{\circ}\right) \mathrm{em}$ comparação à média anterior à fadiga $\left(4,513 \pm 2,827^{\circ}\right)$, entretanto, esta diferença se confirmou não ser estatisticamente significante $(p=0,077)$.

Até esta parte, os testes $\mathrm{t}$ aplicados sempre foram em amostras com dados dependentes, ou seja, tratava-se de teste t pareado. A partir da $4^{a}$ situação, os dados passaram a ser independentes e o teste aplicado foi o t de amostras não-pareadas.

\subsubsection{4 - $4^{a}$ Situação - comparação entre os pilares UCLA fundidos, ambos sem solicitação mecânica, associados aos implantes antes e após ciclagem}

- Grupo NiCr: Na comparação entre LR dos UCLAs fundidos do grupo NiCr, ambos sem ciclagem mecânica, um com implante novo (2) e outro com implante ciclado (5), não houve diferença estatisticamente significante ( $p=$ 0,378). Isto significa que apesar do valor da LR com o implante ciclado ter sido numericamente maior $\left(4,421 \pm 2,499^{\circ}\right)$ do que com o pilar fundido e 
implantes novos, ou seja, sem ciclagem mecânica $\left(3,210 \pm 1,370^{\circ}\right)$, esta diferença, para a quantidade de ciclos a que os implantes foram submetidos (500.000 ciclos), não foi suficiente para alterar, de forma significativa, o grau de liberdade rotacional entre os conjuntos.

- Grupo Tilite: Neste caso, tem-se uma comparação de amostras independentes, de variâncias homogêneas, dos pilares do grupo Tilite. A comparação foi feita entre os pilares UCLA fundidos em Tilite, na primeira leitura com implantes e pilares novos $\left(4,506 \pm 2,448^{\circ}\right)$, sem simulação de fadiga e, na segunda com os pilares novos, sem ciclagem mecânica associados aos implantes ciclados (2,813 \pm $\left.0,406^{\circ}\right)$. A estatística aplicada demonstrou não haver diferença significativa entre os valores $(p=0,219)$.

\subsubsection{5 - 5a Situação - comparação entre os pilares UCLA fundidos, associados aos implantes, ambos após terem sido ciclados (3), com novos pilares UCLA} fundidos, sem ciclagem, associados aos implantes que foram ciclados (5)

- Grupo NiCr: Neste caso, tem-se uma comparação de amostras independentes, de variâncias homogêneas, dos pilares do grupo $\mathrm{NiCr}$. Comparou-se a LR dos UCLAs fundidos e ciclados com os implantes também ciclados $\left(3-3,818 \pm 1,904^{\circ}\right)$ com os novos pilares fundidos, sem ciclagem mecânica, mas com os mesmos implantes ciclados (5 $\left.4,421 \pm 2,499^{\circ}\right)$. O teste demonstrou que não houve diferença estatisticamente significante na LR destes conjuntos $(p=0,679)$.

- Grupo Tilite: Neste caso, tem-se uma comparação de amostras independentes, de variâncias homogêneas, dos pilares do grupo Tilite. Comparou-se a LR dos UCLAs fundidos e ciclados com os implantes também ciclados $\left(3-5,126 \pm 2,885^{\circ}\right)$ com os novos pilares fundidos, sem ciclagem, associados aos mesmos implantes ciclados $(2,813 \pm$ $0,406^{\circ}$ ). O teste demonstrou que não houve diferença estatisticamente significante na LR destes conjuntos $(p=0,163)$. 


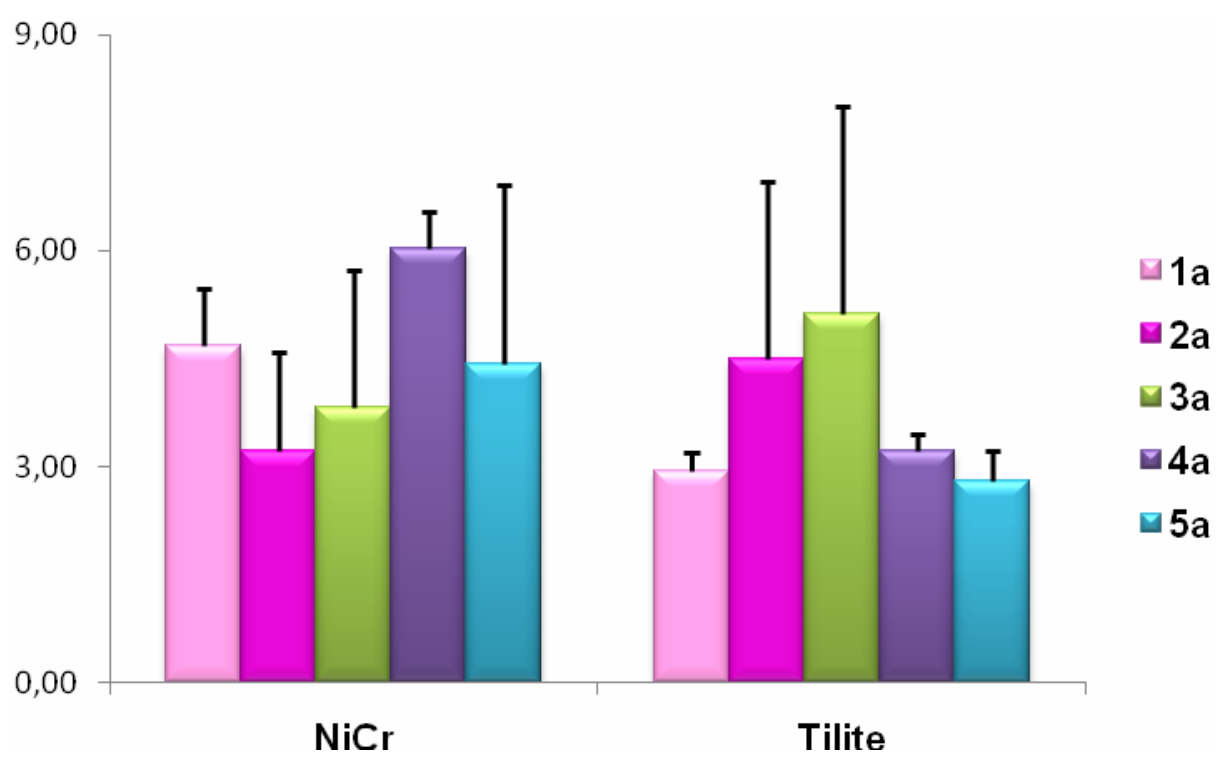

Figura 26 - Comparação entre as leituras de Liberdade Rotacional $\left({ }^{\circ}\right)$ para cada tipo de liga.

5.2.2 - Segunda etapa: comparação da Liberdade Rotacional entre as ligas NiCr e Tilite para cada tipo de situação

Após a verificação de que os dados são normais e homogêneos, foi aplicado o teste $\mathrm{t}$ (Student) não-pareado (amostras independentes) para comparar cada situação de liberdade rotacional (LR) entre as respectivas ligas estudadas (1- Ni-Cr e 2- Tilite) (Figura 27).

5.2.2.1 - Situação 1 - Comparação das médias, em graus, da liberdade rotacional entre os pilares calcináveis totalmente plásticos e calcináveis com a base usinada antes do processo de fundição associados a implantes, com ambos pilares e implantes, na condição de novos ou recém-adquiridos

Neste caso, as variâncias foram iguais ou homogêneas $(p>0,05)$ e a diferença observada entre os resultados dos pilares UCLA calcináveis plásticos e com a base usinada em Tilite foi estatisticamente significante. Ou seja, a LR dos pilares UCLA calcináveis plásticos $\left(4,684^{\circ} \pm 0,788^{\circ}\right)$ foi maior do que a média de valor dos pilares calcináveis com a base pronta $\left(2,923^{\circ} \pm 0,273^{\circ}\right)$ e esta diferença foi significativa $(p=0,002)$. 
5.2.2.2 - Situação 2 - Comparação das médias, em graus, da liberdade rotacional entre os pilares calcináveis totalmente plásticos e calcináveis com a base usinada, após processo de fundição em suas respectivas ligas ( $\mathrm{Ni}-\mathrm{Cr}$ e Tilite, respectivamente) associados a implantes, com ambos pilares e implantes, na condição de novos ou recém-adquiridos

Nesta situação, as variâncias foram homogêneas $(p>0,05)$ e não houve diferença estatisticamente significante $(p=0,332)$ entre os valores de $L R$ dos pilares fundidos em NiCr e em Tilite. Apesar da diferença entre os resultados e o fato de os pilares calcináveis com a base usinada e fundidos em Tilite apresentarem maior valor, em média, $\left(4,506 \pm 2,448^{\circ}\right)$ do que os pilares plásticos totalmente calcináveis fundidos em Ni-Cr $\left(3,210 \pm 1,370^{\circ}\right)$, ambos associados a implantes sem solicitação mecânica, esta não foi suficiente para produzir uma diferença significativa nos valores de LR.

5.2.2.3 - Situação 3 - Comparação das médias, em graus, da liberdade rotacional entre os pilares calcináveis totalmente plásticos e calcináveis com a base usinada, após processo de fundição em suas respectivas ligas ( $\mathrm{Ni}-\mathrm{Cr}$ e Tilite, respectivamente) associados aos implantes, com ambos pilares e implantes, após simulação de fadiga mecânica

$\mathrm{Na}$ situação 3 - pilares fundidos e ciclados + implantes ciclados - as variâncias foram homogêneas e não houve diferença significativa $(p=0,439)$ entre os valores encontrados de LR quando comparados entre a liga $\mathrm{NiCr}$ e a liga Tilite. A LR do pilares fundidos em Ni-Cr $\left(3,818 \pm 1,904^{\circ}\right)$ embora tenha sido numericamente menor do que a dos pilares fundidos em Tilite $\left(5,126 \pm 2,885^{\circ}\right)$, esta diferença não foi estatisticamente significativa.

5.2.2.4 - Situação 4 - Comparação das médias, em graus, da liberdade rotacional entre os novos pilares calcináveis totalmente plásticos e calcináveis com a base usinada, antes do processo de fundição, sem solicitação mecânica, associados aos implantes após já terem sido ciclados

Na situação 4 - novos UCLAs antes de fundir + implantes ciclados - o teste de homogeneidade da amostra verificou que as variâncias eram não-homogêneas e, os resultados de LR dos pilares calcináveis plásticos em relação aos calcináveis de 
base usinada em Tilite foram estatisticamente significantes $(p=0,000)$, ou seja, essa diferença se deve ao fato de os UCLAs calcináveis totalmente plásticos apresentarem maiores valores de LR antes do processo de fundição (6,029 \pm $\left.0,503^{\circ}\right)$ em relação aos os pilares calcináveis com a base usinada em Tilite $(3,229 \pm$ $\left.0,235^{\circ}\right)$.

5.2.2.5 - Situação 5 - Comparação das médias, em graus, da liberdade rotacional entre os pilares calcináveis totalmente plásticos e calcináveis com a base usinada, após processo de fundição em suas respectivas ligas ( $\mathrm{Ni}-\mathrm{Cr}$ e Tilite, respectivamente), ambos sem solicitação mecânica, associados aos implantes já ciclados

Nesta situação - novos UCLAs fundidos + implantes ciclados - o teste de homogeneidade revelou variâncias não homogêneas. Os valores de LR tanto para os pilares fundidos em NiCr como para os fundidos em Tilite, associados aos implantes ciclados, não apresentaram diferença estatística significativa entre si ( $p=$ $0,226)$. O grupo Tilite apresentou a média de $2,813 \pm 0,406^{\circ}$ e o grupo $\mathrm{NiCr}$, média de $4,421 \pm 2,499^{\circ}$.

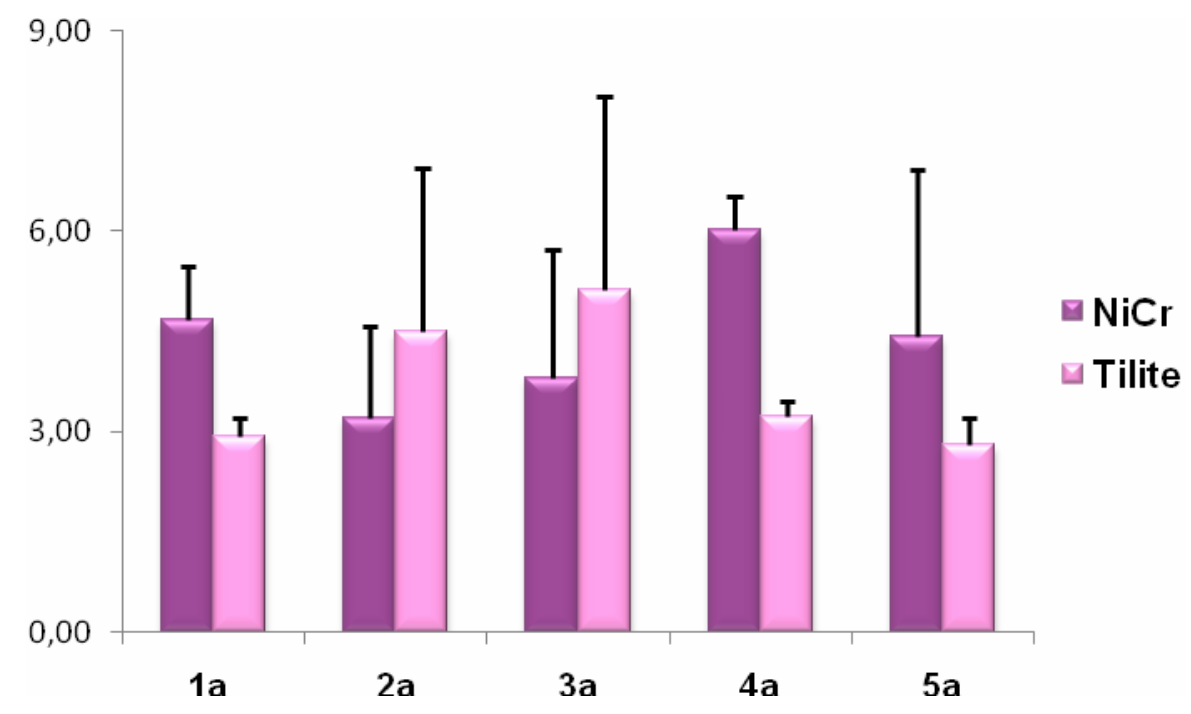

Figura 27 - Comparação da Liberdade Rotacional entre as ligas NiCr e Tilite para cada tipo de situação. 


\section{3 - Torque de afrouxamento ou destorque}

A análise de destorque foi realizada utilizando-se os valores de perda de torque $(\Delta)$. O cálculo foi feito da seguinte maneira: do valor do torque aplicado (32 $\mathrm{N} . \mathrm{cm}$ ), foi subtraído o valor do pico de torque de afrouxamento, registrado pelo torquímetro digital, resultando em valores de perda do torque. Em seguida, dos valores obtidos, foram calculadas as médias para cada grupo testado, grupo $\mathrm{NiCr}$ e grupo Tilite. Verificou-se que a amostra era normal e homogênea. Teste t de Student foi aplicado para comparação das médias de perda de torque entre as ligas estudadas.

O teste revelou que as médias foram estatisticamente iguais entre si e que, apesar da perda de torque do grupo Tilite ter sido maior $(13,72 \pm 7,36 \mathrm{~N} . \mathrm{cm})$ em relação ao grupo $\mathrm{NiCr}(13,26 \pm 4,32 \mathrm{~N} . \mathrm{cm})$, esta diferença não foi estatisticamente significativa $(p=0,90)$.

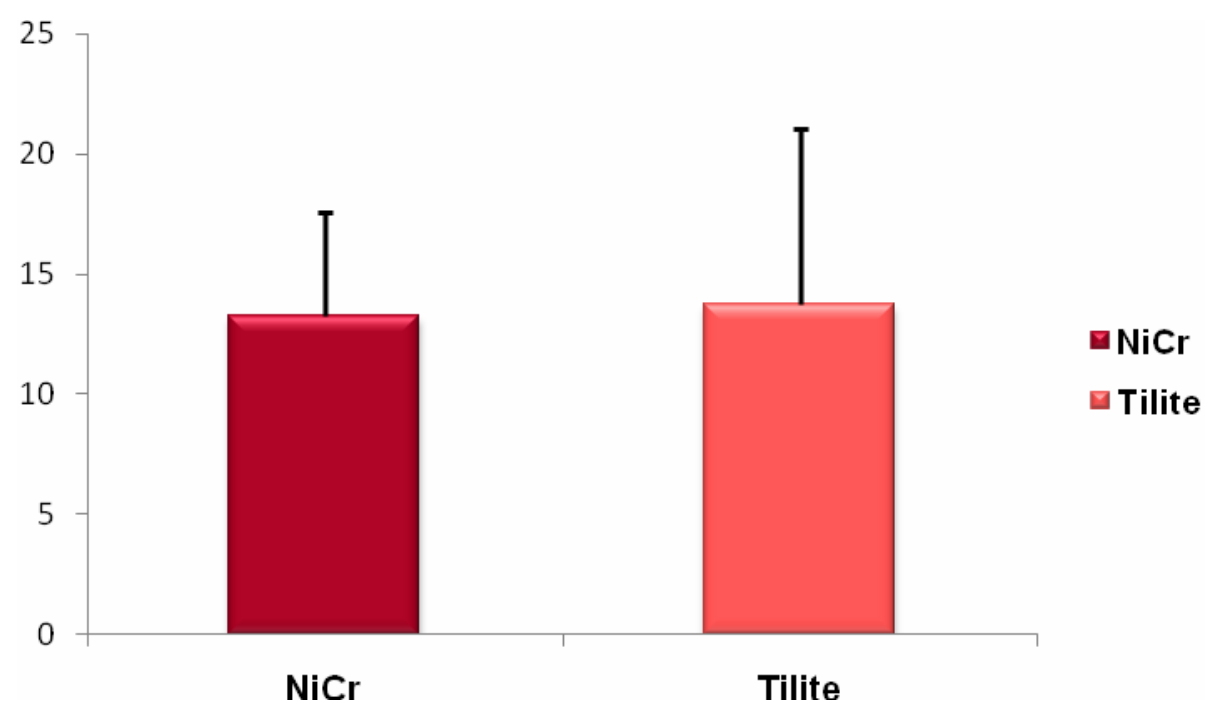

Figura 28 - Médias da perda de torque (N.cm) entre as ligas NiCr e Tilite. 
6-Díscussão 


\section{1 - Dimensões dos pilares UCLA}

Os pilares plásticos calcináveis, fixados diretamente sobre a cabeça dos implantes, foram desenvolvidos por pesquisadores da Universidade da Califórnia, Los Angeles, na década de 80 e, por isso, chamados de UCLA. Inicialmente, foram desenvolvidos para próteses múltiplas e utilizados em pacientes edêntulos, portanto, tratava-se de padrões lisos, sem mecanismo anti-rotacional, que deveriam ser encerados e fundidos em ligas metálicas. A principal característica verificada neste pilar é a eliminação do intermediário, por isso, tinham vantagens na correção de eventuais problemas de angulação, no posicionamento desfavorável dos implantes e na superação de problemas como a distância interoclusal limitada, além de permitir que a porcelana pudesse emergir através dos tecidos moles e adequado perfil de emergência fosse estabelecido. Todas essas características associadas a um baixo custo fizeram com que estes pilares fossem conhecidos por sua versatilidade (LEWIS et al., 1988a). Posteriormente, tiveram a incorporação de um desenho hexagonal na sua plataforma, para que pudessem ser utilizados em restaurações unitárias, ampliando ainda mais a utilização destes componentes (LEWIS et al., 1988b, 1989). Apesar da considerável melhoria dos componentes protéticos com a introdução da tecnologia CAD-CAM, os pilares calcináveis totalmente plásticos e com a base usinada ainda são as soluções mais amplamente utilizadas e difundidas, fato este, que está de acordo com a realidade brasileira quando fatores como baixo custo, facilidade de execução técnica e ampla aplicabilidade estão associados (MALAGUTI et al., 2009; VIGOLO et al., 2000).

Contudo, existem desvantagens deste tipo de pilar e elas estão relacionadas à sua adaptação com o implante, uma vez que as etapas clínicas e laboratoriais podem induzir a possíveis desajustes e distorções e, adaptação inadequada pode resultar em perda e/ou fratura dos parafusos e a possibilidade de perda e/ou fratura dos implantes (ARAMOUNI et al., 2010; VIGOLO et al., 2000). Além disso, outro questionamento importante a respeito da utilização deste componente é justamente a ausência de um segundo parafuso, como no caso dos componentes convencionais ad modum Brånemark, onde o parafuso protético tem a função de ser a parte mais fraca do sistema. Se forças desfavoráveis acontecerem como nos casos de pobre adaptação entre os componentes fundidos, discrepâncias oclusais ou traumas faciais na região dos implantes, o parafuso protético de ouro ou mesmo de outra liga 
entraria em fadiga e quebraria antes que algum dano ocorresse ao pilar (abutment) ou ao implante, desta forma, protegendo o sistema (LEWIS; LLAMAS; AVERA, 1992).

Os componentes que são expostos em sua completa estrutura ao processo de fundição, como os pilares UCLA, podem ter os valores de desajuste influenciados por procedimentos técnico-laboratoriais como: contração de fundição, técnica de inclusão, método de fundição, tipo de revestimento empregado, tipo de liga odontológica utilizada e sua contração e também o polimento, causando problemas que podem afetar diretamente a adaptação entre o componente e o implante e a função da restauração (ASSUNÇÃO et al., 2010; BYRNE et al., 1998; BONDAN, 2007; SILVA; MIRANDA; ALVES, 2010; DIAS; FERREIRA; REZENDE, 2003; KANO et al., 2007; VIGOLO; MAJZOUB; CORDIOLI, 2000). A literatura demonstra melhores resultados de adaptação dos pilares pré-fabricados ou com a base usinada de fábrica, sendo que, idealmente, esses componentes deveriam apresentar ajuste em toda a sua interface, o que caracterizaria uma adaptação passiva entre esses componentes (BYRNE et al., 1998; KANO et al., 2004, 2006; SARTORI, 1999). A tolerância de usinagem inerente aos componentes de implantes deve ser reduzida ao mínimo para garantir íntima adaptação entre as superfícies de união do pilar com o implante e, desta forma, impedir complicações mecânicas e biológicas (ARAMOUNI et al., 2010; BINON, 1995; MALAGUTI et al., 2009).

Como já foi dito anteriormente, a adaptação e precisão dos componentes são fatores importantes e também têm sido relacionados com a estabilidade da união implante / pilar (BINON, 1995, 1996; BINON; McHUGH, 1996; BYRNE et al., 1998; CARR; BRUNSKI; HURLEY, 1996; VIGOLO; MAJZOUB; CORDIOLI, 2000). Da mesma forma, variações na consistência da fabricação dos componentes podem levar a implicações clínicas de diferentes magnitudes. Exemplo importante tem-se no diâmetro da base do implante, que requer um tamanho previsível e consistente com mínimas variações, para poder encaixar na contraparte do pilar, uma vez que diferenças podem resultar na formação de um espaço ou fenda, o que possivelmente provocará uma invasão bacteriana, acúmulo de placa e uma resposta tissular adversa (ASAVANT; JAMESON; HESBY, 1988; BINON, 1995; NASCIMENTO, 2010; SONES, 1989). 
No presente trabalho, foram avaliadas as dimensões do hexágono interno dos pilares UCLA, em relação aos seus diâmetros e lados, antes e após fundição e também depois da simulação de fadiga mecânica.

Os pilares do Grupo $\mathrm{NiCr}$ apresentaram as seguintes medidas: a- em relação aos seus diâmetros: na condição de cilindros plásticos, anteriormente ao processo de fundição, apresentaram média de $3,23 \pm 0,033 \mathrm{~mm}$; b- em relação aos padrões fundidos 3,162 $\pm 0,034 \mathrm{~mm}$; c- pilares fundidos e também ciclados $3,122 \pm 0,011 \mathrm{~mm}$.

Para o grupo Tilite, as medidas foram: a- pilares antes do processo de fundição $(3,217 \pm 0,037 \mathrm{~mm})$; b- após fundição $(3,198 \pm 0,097 \mathrm{~mm})$; c- pilares fundidos e ciclados $(3,257 \pm 0,029 \mathrm{~mm})$.

Em relação às distâncias entre os lados dos pilares do grupo $\mathrm{NiCr}$, as médias encontradas foram: a- antes da fundição $(2,804 \pm 0,032 \mathrm{~mm})$; b- pós fundição $(2,755$ $\pm 0,039 \mathrm{~mm})$ e c- pós fundição e ciclagem mecânica $(2,713 \pm 0,005 \mathrm{~mm})$.

Da mesma forma, com o grupo Tilite, as medidas encontradas foram: a- antes da fundição $(2,784 \pm 0,032 \mathrm{~mm}) ; b$ - após serem fundidos em liga de Tilite $(2,786 \pm$ $0,082 \mathrm{~mm})$ e c- pilares que foram fundidos e ciclados $(2,839 \pm 0,027 \mathrm{~mm})$.

Tavarez, (2003) avaliou as alterações na interface implante-pilar de sistemas com conexão interna e externa associados a pilares pré-fabricados ou calcináveis, através das medidas de desadaptação, e a condição de torque e destorque dos parafusos de fixação quando submetidos a ensaios de fadiga. Os lados dos pilares UCLA variaram em: Grupo I - Implante HE + UCLA calcinável com base pronta em liga de prata/ paládio fundido na mesma liga e, posteriormente, após enceramento da coroa para cimentação, fundido em liga de NiCr: 2,70 \pm 0,01mm; Grupo IV Implante HE + pilares UCLA com base usinada em prata/ paládio e fundidos nesta mesma liga com coroa parafusada: 2,70 $\pm 0,01 \mathrm{~mm}$ e Grupo $\mathrm{V}$ - Implante HE + pilares CeraOne, para cimentação: $2,73 \pm 0,02 \mathrm{~mm}$, todos da marca Master Screw (Conexão). Os grupos II e III eram conexões internas associadas a pilares préfabricados em titânio para coroas cimentadas, sendo estas conexões $\mathrm{HI}$ e Ol, respectivamente.

Vigolo; Majzoub; Cordioli, (2000) fizeram um estudo em que as dimensões de pilares tipo UCLA calcináveis com a base usinada em liga de ouro (3i) e a liberdade rotacional dos conjuntos, foram medidas na condição inicial (recém-adquiridos), após fundição e após adição e cozimento da porcelana. As medidas dos lados (largura), profundidade (altura) do hexágono interno dos UCLA, bem como o diâmetro da 
plataforma foram mensuradas. As medidas dos lados do hexágono interno foram: tempo 0 - antes de serem fundidos - 2,712 \pm 0,014mm; tempo 1 - após fundição em liga de ouro e paládio de alta-fusão - 2,710 $\pm 0,16 \mathrm{~mm}$ e tempo 2 - após adição e cozimento da porcelana $-2,711 \pm 0,14 \mathrm{~mm}$. Os resultados indicaram que não houve mudança significativa nestes valores após os tratamentos utilizados e, os autores sugerem que seja seguido um protocolo de escolha adequada entre a combinação implante/ pilar com baixa tolerância de usinagem, seleção da liga de fundição e uso meticuloso de procedimentos clínico-laboratoriais. Da mesma forma, os valores do presente trabalho foram semelhantes quando se consideram os pilares do grupo $\mathrm{NiCr}$ fundidos e após terem sido ciclados, em comparação aos valores após adição e cozimento da porcelana. Todavia, em relação ao grupo Tilite, diferem pois, ao serem ciclados os pilares apresentaram mudança em seus valores de dimensão, demonstrado ter havido efeito da fadiga no tamanho original destes componentes.

Malaguti et al.,(2009) utilizaram em seu estudo, pilares UCLA com base usinada em liga de ouro, platina-paládio, que foram analisados antes e após fundição e pilares usinados em titânio. Para as medidas dos lados dos hexágonos internos dos pilares foi definido um valor nominal de 2,716 $\mathrm{mm}$ para os três os grupos e as médias das medidas encontradas foram: Grupo 1 - UCLA calcinável com base usinada, antes da fundição - 2,725 \pm 0,004mm; Grupo 2 - os mesmos pilares UCLA após fundição em liga de ouro, prata e cobre $-2,707 \pm 0,003 \mathrm{~mm}$ e, Grupo 3 - pilares usinados em titânio - 2,725 $\pm 0,003 \mathrm{~mm}$.

\section{2 - Dimensões dos implantes}

Em próteses unitárias a junção do pilar ao hexágono externo dos implantes é ainda mais crítica pelo fato de que uma adaptação precisa e passiva, além de um correto assentamento entre as peças precisa ser conseguida para que contatos interproximais possam ser reprodutíveis e ótimas características anti-rotacionais alcançadas (BINON, 1995, 2000a; KOHAVI, 1993). Isto significa que, as diferenças entre as dimensões dos hexágonos precisam ser mínimas, propiciando, desta forma, ajuste passivo entre os componentes e prevenindo a perda progressiva da tensão da condição de pré-carga do parafuso que pode causar afrouxamento e/ ou fratura, devido à desadaptação rotacional (BECKER; BECKER, 1995; BINON, 1995; BYRNE et al., 1998; WEINBERG, 1993). Daí também a importância da altura hexagonal e da 
distância entre os lados do hexágono do implante e do pilar na estabilidade da interface implante / pilar (BINON; McHUGH, 1996; BURGUETE et al., 1994; BYRNE et al., 1998; CIBIRKA et al., 2001).

Embora alcançar uma perfeita e passiva adaptação entre os componentes seja o ideal, isso é muito difícil de conseguir, uma vez que há uma somatória de distorções incorporadas nas restaurações durante as fases clínico-laboratoriais, que podem vir a causar desadaptações em diferentes níveis (KUNAVISARUT et al., 2002; TAN, 1995). Segundo Binon (2000a) a ausência de báscula é ainda mais importante do que o nível de adaptação passiva dos componentes, pois a presença de báscula favorece a micromovimentação entre os componentes permitindo o afrouxamento dos parafusos.

Componentes que não tenham uma adaptação precisa ou próxima do ideal podem influenciar, no sucesso longitudinal, no prognóstico dos implantes e em implicações clínicas que resultam desde o freqüente afrouxamento dos parafusos de fixação dos pilares, fraturas dos parafusos, instabilidade da prótese, fístulas, respostas adversas dos tecidos moles e até a perda da osseointegração (GROSS; ABRAMOVICH; WEISS, 1999).

A tolerância de usinagem dos implantes e seus componentes é outro fator importante a ser considerado, uma vez que menores valores podem resultar em menor rotação do sistema e assim, índices mais baixos de desaperto de parafusos (SCHULTE, 1994). O controle de fabricação é determinante nos limites de variação das dimensões dos implantes e seus componentes, minimizando os erros de processamento (ELIAS et al., 1999).

A aplicação de cargas cíclicas pode resultar em micromovimento e na fadiga do metal em próteses parafusadas que pareciam estáveis (ASSUNÇÃO et al., 2010; CIBIRKA et al., 2001; GRATTON; AQUILINO; STANDFORD, 2001). O teste de fadiga mecânica, com diferentes tolerâncias de adaptação, pode ser utilizado para avaliar a estabilidade da união parafusada hexagonal, além de avaliar o comportamento dessas conexões, uma vez que a fadiga e o assentamento que ocorre nos componentes podem ocasionar a instabilidade dessas junções e, conseqüentemente, a fratura ou afrouxamento dos parafusos em longo prazo. Alguns trabalhos, com metodologias variadas, utilizaram ensaios de fadiga para análise da estabilidade das conexões em prótese sobre implantes (BINON, 1996; BREEDING et al., 1993; CIBIRKA et al., 2001; DIXON et al., 1995; GRATTON; 
AQUILINO; STANDFORD, 2001; TAVAREZ, 2003). No presente trabalho, a aplicação de carga cíclica foi utilizada para avaliar o comportamento da união parafusada hexagonal externa, com diferentes pilares tipo UCLA, frente à desadaptação rotacional e da quantidade de destorque final.

Neste trabalho, a primeira parte da comparação se ateve em avaliar o efeito da ciclagem mecânica nas dimensões dos hexágonos externos dos implantes. Foi verificado que houve mudança significativa nos valores com redução dos mesmos, tanto para as dimensões dos diâmetros $(3,199 \pm 0,030 \mathrm{~mm} ; 3,093 \pm 0,064 \mathrm{~mm}$, respectivamente) quanto para os lados dos implantes $(2,776 \pm 0,025 \mathrm{~mm} ; 2,691 \pm$ 0,055mm, respectivamente). Portanto, pôde-se concluir que a quantidade de ciclos aplicada $\left(5,0 \times 10^{4}\right)$ foi suficiente para alterar a cabeça destes implantes de forma significativa.

Brosco, (2001) encontrou médias entre os lados do hexágono externo de 2,685, 2,697, 2,807 e, 2,699mm nos sistemas Dentoflex, Titanium Fix, Neodent, e Conexão (Master Screw) respectivamente. Os valores apresentados para os implantes de hexágono externo da empresa Neodent foram maiores do que os encontrados neste trabalho. Tavarez, (2003), obteve médias de 2,68 \pm 0,01mm, para os lados do hexágono externo do sistema estudado e, da mesma maneira, médias de 2,36 \pm 0,00mm e 2,50 \pm 0,01 mm nos sistemas Emfils de hexágono interno, e TMI de octágono interno respectivamente. A largura hexagonal da contraparte dos pilares teve médias de 2,70 $\pm 0,01 \mathrm{~mm}$, nos pilares tipo UCLA, e 2,73 $\pm 0,02 \mathrm{~mm}$ nos pilares tipo CeraOne. Nos pilares do sistema Emfils e do sistema TMl e 2,36 \pm $0,00 \mathrm{~mm}$ e 2,47 $\pm 0,01 \mathrm{~mm}$, respectivamente. Esses valores foram semelhantes ao encontrados no presente trabalho.

Para Neves (2000) é de grande importância a diferença entre o maior e menor valor das medidas $(\Delta)$ dos lados dos hexágonos externos dos implantes, para cada amostra e depois para cada grupo, pois, tal informação, indica a precisão de fabricação e, menores valores mostram a capacidade de produzir bem, associada a um adequado controle de qualidade. Em seu estudo, dentre as várias empresas avaliadas, destacou-se a empresa Neodent por ser a mesma utilizada neste trabalho. Os valores encontrados foram, em média de 2,688 $\mathrm{mm}(\Delta=0,0032)$ para os lados dos hexágonos externos dos implantes e interno dos intermediários de $2,736 \mathrm{~mm}(\Delta=0,0084)$. 
Nas plataformas Brånemark-compatíveis, as medidas dos hexágonos internos dos pilares devem sempre ser ligeiramente maiores do que os hexágonos externos dos implantes para permitir encaixe passivo entre os componentes para a montagem e desmontagem do sistema, sempre que necessário. Entretanto, esse mecanismo precisa ser cuidadosamente alinhado para assegurar estabilidade na interface e, desta forma, evitar maiores problemas de desadaptação (BINON, 2000; NEVES, 2000).

Malaguti et al., (2009) propuseram um novo protocolo para a tolerância dimensional das partes individuais da conexão implante/ pilar e sua precisão de montagem, baseada em medidas com ausência de contato entre as partes e processamento de dados estatísticos. Essa análise foi aplicada para pilares tipo UCLA usinados e calcináveis com a base usinada em liga de ouro, platina e paládio, bem como aos implantes de hexágono externo. Foram utilizadas cinco amostras para cada grupo. As medidas, em média, para os lados do hexágono externo dos implantes foi $2,680 \pm 0,004 \mathrm{~mm}$ e a medida nominal utilizada de $2,698 \mathrm{~mm}$. Para os UCLA calcináveis com base usinada do grupo 1 , a média foi de 2,725 $\pm 0,004 \mathrm{~mm}$, após fundição em liga de ouro, prata e cobre, constituíram os corpos-de-prova do grupo 2 com média de 2,707 $\pm 0,003 \mathrm{~mm}$. Já para os pilares usinados em titânio a média foi de $2,725 \pm 0,003 \mathrm{~mm}$. Os valores de referência para a distância entre os lados do hexágono interno de todos os pilares UCLA foi de $2,716 \mathrm{~mm}$.

DAVI (2006) em seu estudo sobre diferentes tipos de torque aplicados em implantes do sistema hexágono externo e interno, relatou que a média das medidas entre os lados do hexágono interno utilizada para os pilares (CeraOne e munhão personalizado) foi de 2,743mm. Para os implantes $\mathrm{HE}$, as médias foram: sem aplicação de torque - 3,084 \pm 0,009mm (diâmetro), 2,695 $\pm 0,006 \mathrm{~mm}$ (lados); torque de $45 \mathrm{~N} . \mathrm{cm}-3,078 \pm 0,015 \mathrm{~mm}$ (diâmetro), 2,696 \pm 0,007mm (lados); torque de 60 N.cm - 3,063 \pm 0,020mm (diâmetro), 2,686 $\pm 0,005 \mathrm{~mm}$ (lados); torque de 80 N.cm $2,861 \pm 0,073 \mathrm{~mm}$ (diâmetro), com esta quantidade de torque, os hexágonos externos deformaram-se a tal ponto que impossibilitou a leitura dos lados e prejudicou a leitura dos diâmetros (distâncias entre os vértices).

Em um estudo realizado por Binon (1995) as médias da largura hexagonal de 15 diferentes sistemas de implantes variou de 2,677 $\pm 0,0046 \mathrm{~mm}$ para STR a 2,707 $\pm 0,0015 \mathrm{~mm}$ para $3 \mathrm{i}, 2,707 \pm 0,0031 \mathrm{~mm}$ para NP e $2,707 \pm 0,0264 \mathrm{~mm}$ para 
SwedeVent. O maior valor registrado foi de 2,790mm para SwedeVent e o menor de 2,657mm para IMTEC.

$\mathrm{Na}$ segunda parte deste trabalho, avaliou-se o efeito da liga em que foram fundidas as coroas protéticas sobre a cabeça dos implantes, após simulação de fadiga mecânica. Para isso foi levado em conta o delta dos valores, ou seja, os valores utilizados foram resultados da subtração do valor inicial, antes da ciclagem mecânica, em relação ao valor final, depois da ciclagem mecânica. Na análise de comparação entre as ligas, verificou-se que para os diâmetros do hexágono externo dos implantes (NiCr- 0,141 \pm 0,042mm; Tilite- 0,063 \pm 0,061mm), embora não tenha havido diferença estatística significativa nas distâncias entre os vértices, houve um limite de significância $(p=0,057)$. Isto significa dizer que, provavelmente haveria diferença significante, se maior número de ciclos fosse aplicado.

Já para as medidas das distâncias entre os lados do hexágono externo dos implantes, essa comparação entre as ligas demonstrou diferença estatística significativa $(p=0,044)$, com maior valor, em média, para o grupo fundido na liga $\operatorname{NiCr}(0,114 \pm 0,031 \mathrm{~mm})$ em relação ao grupo sobrefundido na liga de Tilite $(0,049 \pm$ $0,049 \mathrm{~mm}$ ). Esta diferença pode ter ocorrido pelo fato da liga metálica Verabond II possuir maior módulo de elasticidade $(\mathrm{ME}=766 \mathrm{MPa})$ e, portanto ser mais rígida do que a liga Tilite (ME $\approx 690 \mathrm{MPa}$ ). Logo, por ser mais rígida, causou maior desgaste no hexágono. Outros estudos precisam ser feitos, adicionando-se análises de diferentes tipos de desajustes, com auxílio de análises por microscopia eletrônica de varredura, com maior quantidade de corpos-de-prova, para validar esta informação.

Durante a ciclagem mecânica do grupo Tilite um implante teve sua plataforma fraturada antes mesmo de completar os 500.000 ciclos, sendo que, o afrouxamento do parafuso foi verificado antes de completar 300.000 ciclos. Essa constatação se deu visualmente pela mobilidade da coroa protética. Uma desadaptação entre os componentes pode ter levado a uma significativa diminuição no valor da pré-carga, que foi acentuada com o carregamento cíclico, levando ao afrouxamento do parafuso do pilar e fratura do implante.

Byrne et al., (1998) realizaram um estudo no qual foram comparados pilares pré-usinados, plásticos totalmente calcináveis e pré-usinados modificados em laboratório, quanto à adaptação e ajuste marginal na interface implante/ pilar e o ajuste entre a parte inferior da cabeça do parafuso de ouro e a base do parafuso de pilar. Seis combinações de sistemas de hexágono externo foram testadas, parafusos 
de ouro usados, sendo que nos grupos 1, 2, 5 e 6 o torque dado foi de 32 N.cm e nos grupos 3 e 4 de 20 N.cm. Ainda os grupos 3, 4 e 5 receberam pilares do tipo UCLA, sendo os grupos 3 e 4 com pilares plásticos totalmente calcináveis e o grupo 5 com pré-fabricados, estes 3 grupos foram fundidos em liga de ouro/ paládio e também tiveram ciclo de queima da porcelana incluído. Os grupos 1 e 2 receberam pilares CeraOne e STR, respectivamente, sem queima da porcelana e os 5 e 6 ambos com UCLA pré-usinado, o primeiro com queima e o segundo sem queima da porcelana. Foram analisadas 5 amostras por grupo. Altos valores foram obtidos nos componentes fundidos, para isso os autores consideraram que a diferença de valores poderia ser devido à diferença de torque aplicado e também à borda arredondada dos componentes que foi considerada nas análises e que, segundo alguns autores, pode aumentar o desajuste vertical em até $52 \mu \mathrm{m}$. Altos desviospadrão foram observados nos grupos fundidos e sobrefundidos e isso, pode ser creditado à variabilidade inerente ao procedimento de fundição convencional utilizado na obtenção das amostras, enquanto que nos grupos usinados, pode indicar uma alta tolerância de usinagem utilizada pelos fabricantes. Para a avaliação do desajuste vertical, os valores variaram de 36 a $86 \mu \mathrm{m}$, sendo maior nos grupos fundidos. Para o desajuste horizontal, o grupo usinado apresentou a maior discrepância, sendo que o desajuste se apresentou na forma de subcontorno. Os autores concluíram que os pilares protéticos pré-fabricados, que são posteriormente sobrefundidos, possuem adaptação superior quando comparados aos componentes plásticos que são fundidos e, sugerem a necessidade de um maior controle de padronização para as fundições realizadas em laboratório.

Sartori, em 1999, comparou a estabilidade que se estabelece entre pilares protéticos de diversas empresas (Nobel Biocare, 3i e Conexão fabricados em ouro; e Conexão e Carbontec fabricados em plástico) e seus respectivos cilindros protéticos. A adaptação marginal, observada em microscópio ótico, encontrou medidas que variaram de 5,7 a 10,49 $\mu \mathrm{m}$ quando os cilindros eram fabricados em ouro e de 17,8 $\mu \mathrm{m}$ a aproximadamente $20 \mu \mathrm{m}$ quando fabricados em plástico. Após as leituras iniciais, os cilindros receberam enceramentos, foram incluídos e fundidos com ligas à base de ouro, de prata/paládio e de níquel/cromo, e novamente analisados. As medidas variaram de 5,8 a 20,4 $\mu \mathrm{m}$ quando os cilindros de ouro foram fundidos com as ligas de ouro e prata/paládio, e de 32,1 a $141 \mu \mathrm{m}$ quando os cilindros de plástico foram fundidos com a liga de níquel/cromo. Os resultados demonstraram que os 
pilares plásticos sofrem variabilidade de comportamento em relação à estabilidade dimensional das margens, em grau maior do que os pilares usinados em ouro.

\section{3 - Medidas de Liberdade (desadaptação) Rotacional da interface implante / pilar}

A era moderna da implantodontia foi iniciada na década de 60 , por Brånemark e equipe quando pelo modelo de sistema de implantes de hexágono externo, os primeiros pacientes foram tratados. A função inicial dos hexágonos externos dos implantes era servir como um mecanismo de transferência de torque rotacional durante a inserção cirúrgica do implante sendo, posteriormente, utilizada para um mecanismo anti-rotacional e de orientação dos pilares em próteses unitárias. Além disso, a configuração hexagonal também foi projetada para prevenir rotação do pilar sobre a superfície de encaixe do implante assegurando, desta forma, melhor estabilidade da união parafusada (ADELL et al., 1981; BINON, 1995, 2000a,b). Devido às altas taxas de sucesso nas reabilitações feitas com esses implantes em pacientes edêntulos, não tardou para que seu uso se estendesse a reabilitações parciais e unitárias (HASS et al., 1995; SCHMITT; ZARB, 1993). Embora estes implantes tenham sido não somente os mais comumente projetados e desenvolvidos por várias empresas no mundo todo, como também os mais estudados e relatados na literatura, possíveis falhas por fadiga ou sobrecarga podem ocorrer. Algumas das complicações biomecânicas mais relatadas são desapertos ou fraturas de parafusos de pilar e de próteses, bem como desadaptações rotacionais e fraturas de implantes (ADELL et al., 1981; SONES, 1989; HAAS et al., 1995; BINON, 1995, 1996, 2000b; BINON; McHUGH, 1996; BYRNE et al., 1998; CARRILHO et al., 2005; CIBIRKA et al., 2001; DIXON et al., 1995; ELIAS et al., 1999; GOODACRE et al., 1999; KHRAISAT et al., 2004; NEVES, 2000; VIGOLO; MAJZOUB; CORDIOLI, 2000; WIE, 1995). Fatores de risco como presença de hábitos parafuncionais estão associados à fratura de implantes e desaperto de parafusos, por gerarem carregamento de forças oclusais descontroladas e excessivas (BECKER; BECKER, 1995).

A altura hexagonal bem como a íntima relação entre os hexágonos externos dos implantes e internos dos pilares estão relacionadas com a estabilidade anti- 
rotacional da junção parafusada. Uma vez que o íntimo contato entre as peças esteja insuficiente, desadaptações resultantes criam um movimento potencial adicional na união entre implante/ pilar, o que faz com que efetiva pré-carga seja dissipada por vibrações e micromovimentos nesta junção, como consequência do carregamento funcional (ASAVANT; JAMESON; HESBY, 1988; BURGUETE et al., 1994).

Testes de fadiga com aplicação de carga cíclica que simulam os ciclos mastigatórios durante certo período de tempo têm sido aplicados para avaliar os desapertos ou fraturas de parafusos de pilar e de próteses (CIBIRKA et al., 2001; DAVI, 2006; KHRAISAT et al. , 2004).

A liberdade rotacional se refere à folga existente entre o hexágono externo do implante e o hexágono interno do pilar e, para Binon (1995) para que ótima estabilidade da união parafusada seja alcançada, é necessário que a liberdade rotacional do conjunto implante/ pilar seja menor do que $5^{\circ}$. Nesse mesmo estudo foram gerados índices compostos que indicam que, quanto menor seu valor, maior é a precisão e consistência dos componentes e menores são as tolerâncias de usinagem. Dados muito importantes, uma vez que podem resultar em um menor desajuste rotacional, tornando as conexões mais resistentes ao afrouxamento (BINON, 1996).

Uma vez que o desajuste rotacional entre os hexágonos na interface pilar/ implante tem sido considerado um fator significante na falha da junção parafusada (BINON, 1995, 1996, 2000b; BINON; McHUGH, 1996; VIGOLO; MAJZOUB; CORDIOLI, 2000; CARRILHO et al., 2005) foi de interesse deste estudo avaliar a liberdade rotacional em diferentes pilares tipo UCLA (plásticos totalmente calcináveis e calcináveis com a base usinada em Tilite), submetidos à ciclagem mecânica.

Neste trabalho, a análise foi dividida em duas etapas: na primeira, foram analisadas as diferentes situações de comparação de liberdade rotacional para cada tipo de liga, comparando-se duas a duas e, na segunda a comparação foi feita entre as ligas para a mesma condição de leitura da LR.

Embora não tenha havido nenhuma significância estatística nas comparações entre as diferentes leituras de LR, quando este comportamento foi avaliado para cada tipo de liga, algumas considerações e/ou peculiaridades precisam ser relatadas e, essas estão separadas por grupo. 
- Grupo NiCr: Embora tenha sido verificado a semelhança estatística entre as comparações das leituras de liberdade rotacional, verificou-se uma grande variação nas medidas destes pilares. Os pilares após fundição e também após terem sido ciclados apresentaram média inferior a $5^{\circ}$ de liberdade rotacional, dentro do período estudado de aproximadamente 1 ano e meio de simulação da mastigação. Isto significa que para esta quantidade de ciclos, estes conjuntos apresentam uma união estável. Maior quantidade de ciclos deve ser aplicada até que ocorra a falha da junção parafusada para avaliar o real efeito da ciclagem mecânica na liberdade rotacional nas diferentes etapas laboratoriais. Da mesma forma, uma amostra maior reflete melhor o que de fato acontece na realidade clínica cotidiana.

- Grupo Tilite: Para estes pilares, ocorreram variações acentuadas após o procedimento de fundição, com a presença de dois valores extremos, um muito baixo $\left(1,267^{\circ}\right)$ e o outro elevado $\left(8,13^{\circ}\right)$ e, também depois da ciclagem mecânica. Comparando-se os valores antes e após ciclagem, verificou-se que o pilar de extremo superior após fundição, teve seu valor aumentado após a ciclagem. Portanto, descartou-se a possibilidade de erro de medida e optou-se por deixar este pilar dentro da amostra, o que acarretou conseqüências para a mesma, com um grande aumento no valor da média e desvio-padrão nos valores de liberdade rotacional (LR), já que tal variação de valor não aconteceu para os outros pilares. Uma vez que o implante ainda não tinha sido submetido à ciclagem mecânica, não havia justificativa desse aumento ser devido ao amassamento dos seus vértices, causando aumento da LR. Ou seja, a única justificativa plausível poderia estar no procedimento de fundição, ocasionando mudanças no tamanho de seu hexágono interno. Devido a essa discrepância, a média destes pilares após ciclagem foi de $5,126^{\circ}$, valor que segundo Binon (1996) demonstra incapacidade da união parafusada em resistir à aplicação de cargas sem prejuízo à estabilidade da prótese. $\mathrm{Na}$ avaliação dos novos pilares antes e após fundição associados aos implantes ciclados, não houve esta divergência de valores, corroborando a afirmação de que algum erro de fundição possa ter ocorrido. 
Carrilho et al.,(2005) em um estudo piloto sobre a comparação da liberdade rotacional entre implantes de hexágono externo $(\mathrm{HE})$ com interno $(\mathrm{HI})$ da empresa Conexão Sistemas de Próteses, verificaram que $58,67 \%$ dos implantes HI apresentaram graus de liberdade entre 3 e 5 e, 41,33\% das combinações acima de $5^{\circ}$, com média geral de $5,5 \pm 1,9^{\circ}$ (menor valor de 3,5 e maior $11,0^{\circ}$ ). Para os implantes HE a média foi de $2,9 \pm 0,3^{\circ}$, sendo que $93,33 \%$ apresentaram valores menores do que $3^{\circ}$ (menor valor de $2,5^{\circ}$ e maior $3,5^{\circ}$ ).

Em um estudo realizado por Binon (1996) dez pilares usinados em titânio do tipo UCLA, tiveram suas dimensões aumentadas de forma incremental com aumentos de desadaptações rotacionais correspondentes que foram ciclados até ocorrer a falha da junção parafusada. Isso foi feito para avaliar o efeito da desadaptação rotacional na junção parafusada. A desadaptação rotacional entre o hexágono externo e o interno variou de $1,94^{\circ}$ até $14,87^{\circ}$, sendo a falha da união verificada, em média após 134.000 a $9,3 \times 10^{6}$ ciclos. A combinação hexagonal de implante e pilar que teve a melhor justeza ou adaptação falhou a uma média de $6,7 \times 10^{6}$ ciclos. Os resultados indicam uma correlação direta entre desadaptação rotacional na interface implante/ pilar e afrouxamento do parafuso. Segundo os autores, quanto maior for a discrepância entre a dimensão do pilar e do implante, maior será a desadaptação rotacional e, menor a área de contato entre os lados dos hexágonos na interface implante/ pilar, o que resultará em maior perda de pré-carga e consequentemente, menor rigidez da união. Isto significa que, quanto mais justa ou mais próxima for a adaptação entre o hexágono externo do implante e o interno do pilar, maior será o número de ciclos para causar falha da junção. Os autores verificaram que houve melhora significativa na estabilidade da união quando uma liberdade ou desadaptação rotacional foi menor do que $2^{\circ}$.

Binon e McHugh (1996) compararam a adaptação rotacional entre implantes com cinco tamanhos diferentes de hexágono externo e dois pilares tipo UCLA calcináveis com base usinada em ouro (grupo controle) e plásticos totalmente calcináveis, remodelados para encaixar nos distintos tamanhos de HE dos implantes e, fundidos em liga de ouro, prata/ paládio, submetidos a ensaio de fadiga mecânica, com aplicação de cargas axiais excêntricas. Os autores concluíram que em restaurações unitárias, para se conseguir uma união que apresente melhor resistência ao afrouxamento do parafuso, a liberdade rotacional entre os hexágonos precisa ser eliminada ou pelo menos reduzida a valores mínimos e, também que as 
tolerâncias de usinagem precisam ser melhoradas. De acordo com os autores, quanto maior for a liberdade (desadaptação) rotacional, maior deverá ser a quantidade de torque aplicada e também a pré-carga, necessárias por manter a junção parafusada intacta e estável.

O efeito do carregamento cíclico lateral em diferentes períodos $\left(0,25 \times 10^{6} \mathrm{e}\right.$ $0,5 \times 10^{6}$ ciclos) e posicionamento de aplicação da carga (cêntrica - aplicada perpendicularmente ao longo eixo do implante e excêntrica - aplicada a $4 \mathrm{~mm}$ de distância), no deslocamento rotacional do pilar sobre implante de hexágono externo, foi investigado por Khraisat et al., (2006). Ele verificou que o deslocamento rotacional hexagonal na interface implante/ pilar ocorreu de maneira significativa sob carregamento lateral excêntrico quando comparado ao cêntrico.

Kano et al., (2007) avaliou e comparou a liberdade rotacional entre diferentes pilares do tipo UCLA (plásticos totalmente calcináveis fundidos em liga de $\mathrm{NiCr}$; plásticos totalmente calcináveis fundidos em liga de $\mathrm{CoCr}$; calcináveis com base usinada em paládio e fundido em paládio e usinados em titânio). Os resultados encontrados foram: pilares pré-usinados e fundidos em paládio e os plásticos fundidos em NiCr obtiveram menos do que $2^{\circ}$ de liberdade rotacional e conseguiram boa estabilidade rotacional na junção parafusada; pilares plásticos fundidos em liga de $\mathrm{CoCr}$ excederam $2^{\circ}$ de desadaptação rotacional e foram contra-indicados quando uma boa estabilidade rotacional na união necessita ser alcançada; todos os pilares calcináveis demonstraram piores desadaptações rotacionais quando comparados aos usinados em titânio. Segundo os autores, embora os pilares fundidos em $\mathrm{NiCr}$ tenham tidos resultados equivalentes aos dos componentes usinados em titânio, o procedimento de fundição pode afetar a liberdade rotacional.

A inserção de implantes odontológicos é feita por meio de junções externas ou internas aplicando certo nível de torque, podendo ocorrer deformação da junção levando a complicações biomecânicas ao longo do tempo. A fragilidade do hexágono externo de alguns sistemas pode comprometer o futuro da prótese, caso ocorra deformação dos vértices do hexágono devido ao torque aplicado no montador de implante. Nestas situações, os ângulos de liberdade rotacional entre pilar e implante são aumentados, aspecto especialmente crítico em próteses unitárias (BINON; McHUGH, 1996; DAVI, 2006).

Segundo Binon (2000a) a região mais problemática dos hexágonos externos são seus cantos ou vértices quanto ao possível arredondamento durante seu 
processo de fabricação quando do assentamento e re-assentamento dos pilares em cima da cabeça do implante.

Vários outros autores também se utilizaram do método de mensuração da liberdade rotacional entre os hexágonos para avaliar as características da interface implante/ pilar (ARAMOUNI et al., 2010; BINON, 1995, 1996; BINON; McHUGH, 1996; CARRILHO et al., 2005; DAVI et al., 2008; VIGOLO; MAJZOUB; CORDIOLI, 2000).

As variações nas dimensões dos hexágonos, assim como as diferenças entre as medidas do implante e o pilar podem significar um maior ou menor ajuste, ou uma maior ou menor liberdade rotacional, o que pode influenciar o resultado de estabilidade da interface implante / pilar, após as cargas cíclicas (TAVAREZ, 2003).

Na segunda etapa de análise da liberdade rotacional entre implante e pilar, a comparação foi feita entre as ligas. As únicas diferenças estatísticas encontradas referem-se aos pilares antes da fundição. Nesta condição, os pilares plásticos calcináveis apresentaram os maiores valores de liberdade rotacional, provavelmente devido à memória elástica dos componentes plásticos, uma vez que, o contato entre metal e plástico, no momento da leitura da liberdade rotacional oferece menor rigidez. Já a conexão metal/ metal propicia maior fricção entre as partes, garantindo maior estabilidade da junção.

\section{4 - Medidas de destorque ou torque de afrouxamento}

A falha mecânica mais relatada na literatura é o afrouxamento e/ ou fratura do parafuso de retenção do pilar protético, fato mais comumente evidenciado em regiões de pré-molares e molares (BECKER; BECKER, 1995; DIXON et al., 1995). A presença de desadaptações e deformações preexistentes nos componentes aumentam as chances de afrouxamento do parafuso protético, isso é explicado pela ação de forças externas que sempre amplificam as mudanças dinâmicas que ocorrem nas junções parafusadas. Os parafusos afrouxam somente se o somatório de forças externas que agem na tentativa de separar as partes da união, superar a força que os mantém unidos (BINON, 1996; BYRNE et al., 1998). Na junção pilar/ implante, o torque de aperto inadequado associado à tolerância de adaptação entre o hexágono externo do implante e o interno do pilar, têm sido sugeridos como os dois maiores fatores atuantes na instabilidade da união (BINON, 1996). 
A pré-carga é uma tensão gerada no parafuso do pilar no momento em que é inserido o torque de aperto, sendo responsável por manter os componentes unidos ao gerar uma força de travamento entre eles (HAACK et al., 1995; MARTIN et al., 2001). O objetivo de apertar uma junção parafusada é conseguir uma ótima précarga que maximize a resistência à fadiga, ao mesmo tempo em que ofereça um grau de proteção razoável contra o afrouxamento do parafuso do pilar e estabilidade à união (BURGUETE et al., 1994; LANG; MAY; WANG, 1999). O sucesso da restauração de uma união parafusada está diretamente relacionado ao alongamento do parafuso do pilar ou à pré-carga conseguida a partir do torque de aperto e manutenção desta pelo tempo de função. Se o parafuso afrouxa e a pré-carga cai abaixo de um nível crítico, a estabilidade desta união estará prejudicada, podendo levar a sua falha clínica (CIBIRKA et al., 2001).

Assim como outros autores, assumiu-se neste trabalho que o valor do destorque medido ao desapertar os parafusos dos pilares, após a aplicação de carga cíclica é referente à pré-carga remanescente neles (CIBIRKA et al., 2001; KANO et al., 2006).

A análise de destorque foi realizada utilizando-se os valores de perda de torque $(\Delta)$, ou seja, do valor do torque aplicado (32 N.cm), foi subtraído o valor do pico de torque de afrouxamento, que indicava a quantidade de força que restava naquela junção parafusada e, desta forma, obtinha-se os valores de perda do torque. Verificou-se que, para comparação entre as ligas, as médias foram estatisticamente iguais entre si e que, apesar da perda de torque do grupo Tilite ter sido maior (13,72 \pm 7,36 N.cm) em relação ao grupo $\mathrm{NiCr}(13,26 \pm 4,32 \mathrm{~N} . \mathrm{cm})$, esta diferença não foi estatisticamente significativa $(p=0,907)$. Em outra palavras, significa dizer que os pilares fundidos em liga de NiCr perderam, em média, 41,44\% do torque aplicado e, que os pilares do grupo Tilite perderam 42,88\%. Essa perda de torque ocorreu provavelmente pela ação da ciclagem mecânica nestes conjuntos.

Os pilares fundidos em Tilite apresentaram maior valor de perda de torque, possivelmente porque, além de terem tido um implante com a plataforma fraturada e afrouxamento do parafuso antes de completar a quantidade de ciclos planejada, tiveram também um pilar com alto valor de liberdade rotacional, depois da fundição, condição que se estendeu também após ciclagem. Este achado está de acordo com a descrição do mecanismo de falha da junção parafusada de Bickford (1995), que diz que as forças externas abalam a pré-carga por causa da vibração do parafuso, 
desgaste das superfícies contactantes e relaxamento embutido. Quanto maior o micromovimento lateral do pilar, maior é a perda da pré-carga.

Para limitar o efeito de sedimentação e assim otimizar a pré-carga, recomenda-se reapertar o parafuso, com o mesmo valor de torque, 10 minutos após o torque inicial aplicado (BREEDING et al., 1993; DIXON et al., 1995). Isso também pode ter levado à divergência de alguns resultados, uma vez que o tempo esperado no presente trabalho foi de 2 minutos (ASSUNÇÃO et al., 2009, 2010).

A perda de torque pode apresentar várias causas: desajustes nas próteses (SONES, 1989; WEINBERG, 1993; BURGUETE et al., 1994; MAY et al., 1997), quantidade de pré-carga (BINON, 1996; KHRAISAT et al., 2004a), alteração no coeficiente de fricção entre as superfícies de contato (WEISS et al., 2000; MARTIN et al. 2001), deformação dos parafusos após a pré-carga, a união de implantes a dentes naturais, a extensão de longos cantilevers, concentração de estresse nos parafusos (BURGUETE et al., 1994) tipos de cargas aplicadas nas próteses (CIBIRKA et al., 2001) acabamento e fundição dos parafusos (KHRAISAT et al., 2004b), deformação plástica e relaxamento torsional das superfícies em contato (CANTWELL; HOBKIRK, 2004).

A ausência de adaptação entre os planos dos hexágonos dos implantes e pilares, associado ao fato de que forças geradas durante o carregamento cíclico podem forçar maior aproximação entre essas superfícies, acarretam a diminuição da pré-carga do parafuso com conseqüente redução do torque requerido para afrouxálos (DIXON et al., 1995). Essa falta de assentamento ou ajuste entre os componentes é um fator importante que atua negativamente na estabilidade dos parafusos. À medida que o torque é aplicado ao parafuso e os componentes são comprimidos, as micro-irregularidades existentes na parte inferior da cabeça do parafuso, na plataforma de assentamento do parafuso e nas superfícies de contato dos componentes começam a se deformar e acomodar, diminuindo a distância entre os componentes e promovendo uma folga entre eles, podendo resultar em afrouxamento dos parafusos (BINON, 2000a; BREEDING et al., 1993; BURGUETE et al., 1994; DIXON et al., 1995; HAACK et al., 1995).

Diversos fatores estão envolvidos na compressão exercida na junção de próteses parafusadas tais como: módulo de elasticidade dos materiais envolvidos, adaptação dos componentes, lubrificação, torque aplicado, temperatura do sistema, coeficiente de fricção entre as superfícies em contato, (BURGUETE et al., 1994; 
CANTWELL; HOBKIRK, 2004), além do desenho da cabeça do parafuso (KALLUSS; BESSING, 1994).

Segundo Carr, Brunski e Hurley (1996) a pré-carga é significativamente reduzida quando os componentes são submetidos à fundição, fato especialmente crítico quando componentes plásticos são utilizados e os procedimentos de acabamento e polimento na superfície de contato podem reduzir essa influência. Segundo estes autores, houve uma redução de cerca de $30 \%$ nos valores de précarga para componentes submetidos à fundição. Kano (2004) também relatou que os procedimentos protéticos podem produzir irregularidades e rugosidades nas superfícies de contato, aumentando a influência do processo de relaxamento e maior perda da pré-carga, e conseqüentemente, um menor valor de destorque inicial, isso acontece mesmo quando componentes pré-fabricados são utilizados.

Segundo Sakaguchi e Borgersen (1995), dentro de um mesmo lote de componentes protéticos pode haver diferença significante na pré-carga alcançada em função de fatores como coeficiente de fricção, sendo este, diretamente influenciado pela dureza do material das roscas, acabamento da superfície, quantidade e propriedades do lubrificante, e velocidade do apertamento. Para o mesmo valor de torque, quanto maior o coeficiente de fricção menor será a précarga (BURGUETE et al., 1994; SAKAGUCHI; BORGERSEN, 1995; MARTIN et al.,2001).

Os resultados de Carr, Brunski e Hurley (1996) também mostraram uma diferença significante na pré-carga entre componentes de diferentes fabricantes (Nobel Biocare x 3i) e, também antes e depois da sobrefundição para os componentes pré-fabricados com cinta metálica. Para os autores, esta diferença sugere que as propriedades dos materiais dos componentes utilizados podem ser alteradas durante os procedimentos de fundição, o que demonstra que seus comportamentos dependem de suas características. Portanto, pode-se dizer que componentes de diferentes fabricantes podem se comportar de maneira diferente.

Os resultados do presente trabalho diferem dos de Cibirka et al., (2001), Dixon et al., (1995) e Khraisat et al., (2004b).

Dixon et al., (1995) avaliaram os valores de destorque após a aplicação de carga e encontrou valores de $89,8 \%$ para os pilares usinados com hexágono externo e de $80,8 \%$ para os pilares com hexágono interno. Em seu trabalho, as amostras foram submetidas a apenas 16.667 ciclos. Já Khraisat et al., (2004a) observaram 
valores de destorque de $82,4 \%$ e $96,3 \%$ do torque aplicado para parafusos do intermediário CeraOne submetidos a 1 milhão de ciclos e carga de 0 a $50 \mathrm{~N}$.

Cibirka et al., (2001), fizeram um estudo onde as amostras foram submetidas a um número maior de ciclos de cargas (5 milhões de ciclos), os resultados dos valores de destorque após a aplicação de carga variaram de $45 \%(14,4 \mathrm{Ncm})$ a $51,2 \%(16,4 \mathrm{Ncm})$ do torque aplicado. O grupo com maior valor de destorque $(51,2 \%)$, com conexão tipo circular, também corresponde ao grupo cuja conexão apresenta a maior altura, fato este que pode ter contribuído para o melhor resultado deste grupo.

Segundo Falcão-Filho (2005), em concordância com dados apresentados na literatura os cilindros pré-usinados apresentam melhor acabamento das margens, possibilitando um assentamento mais preciso da prótese. Estes cilindros estão sujeitos a problemas relacionados à sobrefundição, que se não for bem executada pode induzir a erros tão relevantes quanto aos que apresentaram os cilindros calcináveis.

Khraisat et al. (2004a) analisaram por MEV parafusos de pilares que foram submetidos a cargas cíclicas e apresentaram perda de torque, observando ranhuras e bruniduras nas superfícies das roscas dos parafusos dos pilares submetidos ou não à carga. Afirmaram também que variações nos valores de perda de torque em amplitude considerável devem ocorrer devido a diferenças no acabamento, fundição e pré-carga dos parafusos individualmente e que os fabricantes deveriam levar isso em consideração e providenciar exatidão em sua produção.

Para Byrne et al. (1998) também os piores resultados ocorreram nos pilares fundidos.

Falcão-Filho (2005) verificou em seu estudo que as ligas testadas ( $\mathrm{Ni-Cr}$ e Tilite) não apresentam diferenças entre elas com relação a sua influência na perda de torque dos parafusos protéticos de titânio e à influência na ocorrência de desajustes nas interfaces pilar/ cilindro protético. Também encontrou que os cilindros pré-usinados apresentam melhores resultados quanto à ocorrência de desajustes nas interfaces pilar/ cilindro protético e, que defeitos de fundição podem influenciar nos níveis de desajustes. Em seus resultados foi verificado co-relação entre perda de torque em parafusos protéticos de titânio e desajustes verticais em infra-estruturas de próteses sobre implantes obtidas a partir de cilindros calcináveis e pré-usinados em Ni-Cr-Ti, fundidos em Ni-Cr e Ni-Cr-Ti. 
Para Falcão-Filho (2005), a perda de torque foi evidente em todos os parafusos testados, variando de 11 a $76 \%$, sendo a maior média de perda (\%) do grupo G3 (cilindro calcinável + fundição em Tilite - 52,09), seguido pelo grupo G4 (cilindro Tilite + fundição em Ni-Cr - 40,89), G1 (cilindro calcinável + fundição em NiCr - 30,52) e G2 (cilindro Tilite + fundição em Tilite - 21,83). No grupo G2, que apresentou os melhores resultados com relação à perda do torque, foram verificados alguns defeitos de fundição tanto no interior dos cilindros fundidos em Tilite como na porção externa deles, porém com menor freqüência e intensidade do que nos outros grupos. A combinação cilindro Tilite e fundição em Ni-Cr (grupo G4) também apresentou defeitos de fundição que, para o autor, possivelmente foram mais significativos para a perda de torque do que os defeitos do grupo G1 (cilindro calcinável + fundição em Ni-Cr). A diferença de percentual de perda de torque só não foi estatisticamente significante entre os grupos G3 e G4. Esta diferença na perda de torque pode ser considerada importante pois a combinação cilindro calcinável fundido em liga de Ni-Cr-Ti apresentou média de perda de torque superior a todos os outros grupos. Neste trabalho também o grupo que apresentou o pior valor de perda de torque foram os pilares fundidos em liga Tilite.

De acordo com Hoyer et al., (2001), o desajuste rotacional tem influência na resistência ao afrouxamento dos parafusos submetidos a cargas cíclicas. Avaliando pilares protéticos com a área do hexágono desgastada para aumentar o desajuste rotacional, observaram que essas amostras se comportaram de maneira diferente, apresentando maior abertura da interface e menor tempo para falha.

Kano, (2004) também observou que na comparação entre as conexões: o grupo A1 (hexágono externo + pilar usinado de titânio) com menor desajuste rotacional que o grupo B1 (hexágono interno + pilar usinado de titânio) apresentou maior destorque final. Entretanto o grupo A4 (implante $\mathrm{HE}+$ pilar fundido em $\mathrm{Co}-\mathrm{Cr}$ ) com desajuste rotacional superior ao grupo $A 1$ apresentou valor de destorque final igual ao mesmo. Seus resultados contrariam os estudos que demonstram a superioridade da estabilidade da conexão tipo hexágono interno, já que tanto para o desajuste rotacional como para o destorque final, os pilares usinados com hexágono interno apresentaram resultados inferiores aos pilares usinados com hexágono externo. Assim como também questiona a relação do desajuste marginal com a estabilidade da conexão, já que o grupo B1 (implante $\mathrm{HI}+$ pilar usinado de titânio) apresentou desajuste marginal inferior ao grupo. 
Em seu trabalho, Kano (2004) verificou que na comparação dos resultados entre pilares protéticos usinados, sobrefundidos e fundidos com diferentes tipos de ligas através das variáveis: profundidade de fenda, desajuste horizontal e vertical, liberdade rotacional, destorque inicial e final, os pilares fundidos foram comparáveis aos pilares usinados e sobrefundidos. Segundo a autora, esses resultados sugerem que, com uma boa técnica de fundição e pilares plásticos para fundição de qualidade, pode-se obter peças protéticas a um custo acessível sem comprometer a estabilidade da conexão. Muito embora os resultados obtidos em seu trabalho apontem favoravelmente para os componentes fundidos do ponto de vista mecânico, a autora sugere que seja feita uma análise biológica da utilização desses componentes, tanto em estudos in vitro, como in vivo, não apenas no que diz respeito às características físicas das interfaces (dimensões verticais, horizontais e profundidade de fenda, liberdade rotacional), mas também em relação aos diversos metais que podem ser utilizados, as características superficiais geradas pelo procedimento de fundição e aos possíveis efeitos locais e sistêmicos da combinação de diferentes metais.

Tavarez (2003) concluiu em seu estudo que houve redução estatisticamente significante da condição de torque dos grupos estudados após o ensaio de fadiga, sendo que a menor redução foi encontrada no grupo de hexágono interno com 5,3 N.cm $(17,67 \%)$ e a maior redução no grupo de hexágono externo que utilizou pilares UCLA parafusados com 20,5 N.cm (68,33\%). Os grupos com UCLA parafusado e cimentado tiveram afrouxamento total dos parafusos em quatro corpos de provas (dois em cada grupo), ao final do ensaio (500.000 ciclos). Segundo o autor, houve uma forte correlação entre a aplicação das cargas cíclicas e a diminuição da condição de torque. Uma possível justificativa para isso é que, ao tentar adaptar superfícies usinadas defeituosas pelo apertamento do parafuso, buscando-se aumentar o assentamento entre as peças, provoca-se danos nas roscas internas, afrouxamento do parafuso, possível fratura e potencial perda do implante. Da mesma forma, os procedimentos de fundição acabamento e polimento de pilares ou cilindros calcináveis têm um efeito deletério na produção da pré-carga no parafuso de fixação, fato este pelo qual o autor recomenda o uso de componentes préfabricados para que se consiga uma pré-carga ideal. Assim, existem limitações nos experimentos laboratoriais que devem ser consideradas ao se transferir os resultados encontrados à realidade clínica. No entanto, é de fundamental 
importância realizar trabalhos em que sistemas e componentes são testados, de forma que se possa contribuir de maneira efetiva na melhora e no avanço da tecnologia e da ciência odontológica.

Barbosa et al., (2007) observaram mudanças de valores negativos e positivos, demonstrando uma movimentação das infra-estruturas durante as etapas laboratoriais. Situação que pode gerar problemas mecânicos como o desaperto dos parafusos de pilar. Apesar de algumas destas mudanças serem consideradas como favoráveis (passar do valor negativo para o positivo - possibilitando uma melhor higienização, por exemplo), deve-se ter cautela nestas mudanças, devido a um possível estresse mecânico estar sendo gerado nos parafusos de retenção. A presença de regiões em que o pilar posiciona-se além do implante possibilita a retenção de placa, podendo gerar problemas biológicos. De acordo com os autores, as etapas laboratoriais de fundição e solda podem alterar o ajuste entre pilar e implante, independente do laboratório utilizado.

Quando objetos e/ ou alimentos mais duros são mastigados, forças localizadas e elevadas são produzidas. Além disso, o componente lateral das forças mastigatórias gera forças horizontais significativas no contato localizado. Isso parece mais danoso ao implante e seus componentes do que elevadas cargas axiais. Ademais, os contatos mastigatórios são gerados a uma freqüência de aproximadamente $2 \mathrm{~Hz}$, o que resulta em 350.000 contatos dente a dente por ano e, elevadas cargas, contatos excursivos laterais e repetidas cargas cíclicas contribuem para a propagação de trincas e fadiga dos componentes protéticos e implantes (BRUNSKI, 1988)

No trabalho de Nakamura (2005) houve diferença estatisticamente significante na comparação dos grupos submetidos e não-submetidos ao ensaio de ciclagem, sendo que todos os grupos submetidos ao ensaio apresentaram médias de torque de afrouxamento menores do que as médias dos grupos não-submetidos confirmando os resultados de Breeding et al. (1993), Hoyer et al. (2001).

A redução do torque requerido para afrouxar os parafusos ou também chamado de destorque não é necessariamente um fator ruim ou danoso, se isto não for progressivo e a força de travamento remanescente no conjunto for suficiente para prevenir a separação dos componentes da junção parafusada (DIXON et al., 1995).

O tamanho da amostra $(n=5)$ está de acordo com a US Food and Administration para testes de fadiga de implantes e pilares (QUEK et al., 2008). 
7-Conclusóes 
De acordo com a metodologia empregada e dentro das limitações deste estudo, pôde-se concluir que:

1- A quantidade de ciclos aplicada (500.000 ciclos) não foi suficiente para alterar de forma significativa a liberdade rotacional nos conjuntos implante/ pilar quando avaliados para cada tipo de liga.

2- Na comparação entre os pilares, antes do processo de fundição, foram encontrados melhores resultados de adaptação e liberdade rotacional para os pilares calcináveis com a base usinada em Tilite.

3- O processo de fundição não provocou alterações significativas nas medidas de liberdade rotacional, nas diferentes situações.

4- A quantidade de cargas cíclicas aplicadas foi suficiente para alterar as dimensões dos implantes, em relação aos seus diâmetros e lados.

5- Da mesma forma, a aplicação de cargas cíclicas foi suficiente para provocar $41,44 \%$ de perda do torque aplicado nos pilares fundidos em liga de $\mathrm{NiCr}$ e $42,88 \%$ nos pilares sobrefundidos em Tilite. Sendo que entre as ligas, não houve diferença estatística. 
Referências 
1. ADELL, R.; LEKHOLM, U.; ROCKLER, B.; BRANEMARK, P-I. A 15 -year study of osseointegrated implants in the treatment of the edentulous jaw. Int $\mathbf{J}$ Oral Surg, Copenhagen, v.10, n. 6, p. 387-416, Dec. 1981.

2. ADELL, R.; ERIKSSON, B.; LEKHOLM, U.; BRÅNEMARK, P-I; JEMT, T. Long-term follow-up study of osseointegrated implants in the treatment of totally edentulous jaws. Int J Oral Maxillofac Implants, Lombard, v. 5, n. 4, p. 347-359, Winter. 1990.

3. ALBREKTSSON, T. A multicenter report on osseointegrated oral implants. J Prosthet Dent, St. Louis, v. 60, n. 1, p. 75-84, Jul. 1988.

4. ARAMOUNI, P.; VIGOLO, P.; MAJZOUB, Z.; ZEBOUNI, E.; SALAMEH, Z.; ALMAS, K. Evaluation of rotational freedom of In-Ceram ceramic blank abutments before and after infiltration. Implant Dent, Baltimore, v. 19, n. 1, p. 50-56, Feb. 2010.

5. ASAVANT, S.; JAMESON, L. M.; HESBY, R. A. Single osseointegrated prostheses. Int J Prosthodont, Lombard, v. 1, n. 3, p. 291-296, 1988.

6. ASSUNÇÃO, W. G.; SANTOS, P. H.; DELBEN, J. A.; GOMES, E. A.; BARÃO, V. A. R.; TABATA, L. F. Effetc of misfit on preload maintenance of retention screws of implant-supported prostheses. J Mater Eng Perform, v. 18, n. 7, p. 935-938, Oct. 2009.

7. ASSUNÇÃO, W. G.; BARÃO, V. A. R.; DELBEN, J. A.; GOMES, E. A.; GARCIA Jr., I. R. Effect of unilateral misfit on preload of retention screws of implant-supportes prostheses submitted to mechanical cycling. J Prosthet Res, v. 4, June. 2010. In Press.

8. BARBOSA, G. A. S.; SIMAMOTO JÚNIOR, P. C.; FERNANDES NETO, A. J.; MATTOS, M. G. C.; NEVES, F. D. Desajuste do pilar UCLA processado por diferentes laboratórios. RGO, Porto Alegre, v. 55, n. 2, p. 127-131, abr./ jun. 2007.

9. BECKER, W., BECKER, B. E. Replacement of maxillary and mandibular molars with single endosseous implant restorations: a retrospective study. $\mathbf{J}$ Prosthet Dent, St. Louis, v. 74, n. 1, p. 51-55, Jul. 1995.

10. BRÅNEMARK, P-I, HANSSON, B. O.; ADELL, R.; BREINE, U.; LINDSTRÖM, J.; HALLÉN, O. Osseointegrated implants in the treatment of the edentulous jaw: experience from a 10-year period. Scand J Plast Reconstr Surg., v. 16, p. 1-132. 1977. Supplement. 
11.BRÅNEMARK P-I. Osseointegration and its experimental background. $\mathbf{J}$ Prosthet Dent., v. 50, p. 399-410. 1983.

12.BREEDING, L. C.; DIXON, D. L.; NELSON, E. W.; TIETGE, J. D. Torque required to loosen single-tooth implant abutment screws before and after simulated function. Int J Prosthodont, Lombard, v. 6, n. 5, p. 435-449, Sept./Oct. 1993.

13. BICKFORD, J. H. Introduction to design and behavior of bolted joints, ed 3. New York. Dekker, 1995

14. BINON, P. P. Evaluation of Machining Accuracy and Consistency of Selected Implants, Standard Abutments, and Laboratory Analogs. Int J Prosthodont., Lombard, v. 8, n. 2, p. 162-178, Marc./Apr. 1995.

15. BINON, P. P. Implants and Components: Entering the New Millennium. Int $\mathbf{J}$ Oral Maxillofac Implants, Lombard, v. 15, n. 1, p. 76-94, Jan.-Feb., 2000b.

16. BINON, P. P. The effect of implant/ abutment hexagonal misfit on screw joint stability. Int J Prosthodont, Lombard, v. 9, n. 2, p. 149-160, March-Apr. 1996.

17.BINON, P. P.; McHUGH, M. J. The effect of eliminating implant/ abutment rotational misfit on screw joint stability. Int J Prosthodont, Lombard, v. 9, n. 6, p. 511-519, Nov.-Dec., 1996.

18. BINON, P. P. Evaluation of the effectiveness of a technique to prevent screw loosening. J Prosthet Dent, v. 79, n. 4, p. 430-432, Apr. 1998.

19. BINON, P. P. The external hexagonal interface and screw-joint stability: a primer threaded fasteners in implant dentistry. Quintessence Dent Technol, Chicago, v.23, p. 91-105, 2000a.

20.BONDAN, J. L. Análise comparative da precisão de adaptação entre componentes UCLA e implante de um mesmo sistema. 2007. $104 \mathrm{f}$. Dissertação (Metrado em Materiais Dentários) - Faculdade de odontologia da Pontifícia Universidade Católica do Rio Grande do Sul, Porto Alegre.

21.BREEDING, L. C.; DIXON, D. L.; NELSON, E. W.; TIETGE, J. D. Torque required to loosen single-tooth implant abutment screws before and after simulated function. Int J Prosthodont, Lombard, v. 6, n. 5, p. 435-449, Sept./Oct. 1993. 
22. BROSCO, H. Precisão de adaptação de intermediários transmucosos unitários em sistemas nacionais de implantes compatíveis em hexágono externo. Bauru, 2001. 100p. Tese (Livre docencia) - Faculdade de Odontologia de Bauru, Universidade de São Paulo.

23.BRUSKI, J. B. Biomechanics of oral implants: Future research directions. J Dent Educ, Washington, v. 52, n. 12, p. 775-787, Dec. 1988.

24.BURGUETE, R. L.; JOHNS, R. B.; KING, T.; PATTERSON, E. A. Tightening characteristics for screwed joints in osseointegrated dental implants. J Prosthet Dent, St. Louis, v. 71, n. 6, p. 592-599, June. 1994.

25. BUTIGNON, L. E. Análise comparative do grau de rotação de parafusos para sistema UCLA em estruturas fundidas em monobloco provenientes de abutments calcináveis e com cinta de Cobalto-Cromo. 2007. 124 p. Dissertação (Mestrado em Reabilitação Oral) - Faculdade de Odontologia de Bauru, Universidade de São Paulo, Bauru, 2007.

26.BYRNE, D.; HOUSTON, F.; CLEARY, R.; CLAFFEY, N. The fit of cast and premachined implant abutments. J Prosthet Dent, St. Louis, v. 80, n. 2, p. 184-192, Aug. 1998.

27. CANTWELL, A.; HOBKIRK, J. A. Preload loss in gold prosthesis-retaining screws as a function of time. Int $\mathbf{J}$ Oral Maxillofac Implants, Lombard, v. 19, n. 1, p. 124-132, Jan. / Feb. 2004.

28. CARR, A.; BRUNSKI, J.; HURLEY, E. Effects of fabrication, finishing, and polishing procedures on preload in prostheses using conventional "gold" and plastic cylinders. International Journal of Oral and Maxillofacial Implants, Lombard, v. 11, n. 5, p. 589-598,Sep-Oct. 1996.

29. CARRILHO, G. P. B.; DIAS, R. P.; ELIAS, C. N. Comparison of external and internal hex implants'rotational freedom: a pilot study. Int J Prosthodont, Lombard, v. 18, n. 2, p. 165-166, Mar/ Apr. 2005.

30. CIBIRKA, R. M.; NELSON, S. K.; LANG, B. R.; RUEGGEBERG, F. A. Examination of the implant-abutment interface after fatigue testing. J Prosthet Dent, St. Louis, v. 85, n. 3, p. 268-275, Mar. 2001.

31. CRAIG, R. G. Restorative dental materials. 9th ed. St Louis: Mosby; 1993. p. 75-77. 
32. DAVI, L. R. Liberdade rotacional em implantes dentários avaliada pelos métodos experimental e analítico. 2006. 131 f. Dissertação (Mestrado em Reabilitação Oral) - Faculdade de Odontologia da Universidade Federal de Uberlândia, Uberlândia, 2006.

33.DAVI, L. R.; GOLIN, A. L.; BERNARDES, S. R.; ARAÚJO, C. A.; NEVES, F. D. In vitro integrity of implant external hexagon after aplication of surgical placement torque simulating implant locking. Braz Oral Res, São Paulo, v. 22, n. 2, p. 125-131, Apr. - June, 2008.

34.DIAS, R. P.; FERREIRA, C. F.; REZENDE, M. L. R. Revisão sobre a adaptação entre os implantes dentários e seus componentes protéticos. Rev. Bras. Implant, v. 9, n. 1, p. 16-22, jan./ mar. 2003.

35. DIXON, D. L. et al. Comparison of screw loosening, rotation, and deflection among three implant designs. J Prosthet Dent., St. Louis, v. 74, n. 3, p. 2708, Sept. 1995.

36. EKFELDT, A., CARISSON, G. E., BORJESSOM, G. Clinical evaluation of single tooth restorations supported by osseointegrated implants: a retrospective study. Int J Oral Maxillofac Implants, Lombard, v. 9, n. 2, p. 179-183, Mar./Apr. 1994.

37. ELIAS, C. N.; VIEIRA, L. H. A.; LIMA, J. H. C. Tolerâncias dimensionais em implantes dentários. RBO. v. 56, p. 234-238. 1999.

38. FALCÃO-FILHO, H. B. L. Avaliação da relação entre o desajuste vertical em interfaces pilar / cilindro protético fundido e sobrefundido e a perda de torque de parafusos protéticos de titânio. 2005. 134 f. Dissertação (Mestrado em Reabilitação Oral). Faculdade de Odontologia de Ribeirão Preto, Universidade de São Paulo, Ribeirão Preto, 2005.

39. GARINE, W. N.; FUNKENBUSCH, P. D.; ERCOLI, C.; WODENSCHECK, J.; MURPHY, W. C. Measurement of the rotational misfit and implant-abutment gap of all-ceramic abutments. Int J Oral Maxillofac Implants, Lombard, v. 22, n. 6, p. 928-938, Nov.- Dec. 2007.

40. GOODACRE, C. J.; BERNAL, G.; RUNGCHARASSAENG, K.; KAN, J. Y. K. Clinical complications with implants and implant prostheses. J Prosthet Dent., St. Louis, v. 90, n. 2, p. 121-132, Aug. 2003.

41. GRATTON, D. G.; AQUILINO, S. A.; STANFORD, C. M. Micromotion and dynamic fatigue properties of the dental implant-abutment interface. $J$ Prosthet Dent, St. Louis, v. 85, n. 1, p. 47-52, Jan. 2001. 
42. GROSS, M.; ABRAMOVICH, I.; WEISS, E.I. Microleakage at the abutmentimplant interface of osseointegrated implants: a comparative study. Int $\mathbf{J}$ Oral Maxillofac Implants, Lombard, v. 14, n. 1, p. 94-100, Jan-Feb. 1999.

43. HAACK, J. E.; SAKAGUCHI, R. L.; SUN, T.; COFFEY, J. P. Elongation and preload stress in dental implant abutment screws. Int $\mathbf{J}$ Oral Maxillofac Implants, Lombard, v. 10, n. 5, p. 529-536, Sept.-Oct. 1995.

44. HAAS, R.; MENSDORFF-POUILLY, N.; MAILATH, G.; WATZEK, G. Brånemark single tooth implants: a prelliminary report of 76 implants. J Prosthet Dent, St. Louis, v. 73, n. 3 , p. 274-79, Mar. 1995.

45.HOYER, S. A.; STANFORD, C. M.; BURANADHAM, S.; FRIDRICH, T.; WAGNER, J.; GRATTON, D. Dynamic fatigue properties of the dental implantabutment interface: Joint opening in wide-diameter versus standard-diameter hex-type implants. J Prosthet Dent, St. Louis, v. 85, n. 6, p.599-607, 2001.

46. International Organization for Standardization. ISO 14801: 2003, DentistryFatigue Test for Endosseous Dental Implants, Geneva, p. 1-9.

47.JEMT, T.; LEKHOLM, U.; GRONDAHL, K. A 3-Year Followup Study of Early Single Implant Restorations Ad Modum Brånemark. Int J Periodontics Restorative Dent, v. 10, n. 5, p. 341-349. 1990.

48. KALLUS, T.; BESSING, C. Loose Gold Screws Frequently Occur in Full-Arch Fixed Prostheses Supported by Osseointegrated Implants After 5 Years. Int J Oral Maxillofac Implants, Lombard, v. 9, n. 2, p. 107-125, Mar.- Apr. 1994.

49. KANO, S. C. Avaliação do desajuste e do destorque em pilares protéticos com conexão tipo hexágono externo e interno. 2004. 162 p. Tese (Doutorado em Reabilitação Oral) - Faculdade de Odontologia de Bauru, Universidade de São Paulo, Bauru, 2004.

50.KANO, S. C.; BINON, P.; BONFANTE, G.; CURTIS, D. A. Effect of casting procedures on screw loosening in UCLA-type abutments. J Prosthodont, Philadelphia, v. 15, n. 2, p. 77-81, Mar.- Apr. 2006.

51.KANO, S. C.; BINON, P. P.; BONFANTE, G.; CURTIS, D. A. The effect of casting procedures on rotational misfit in castable abutments. Int $\mathbf{J}$ Oral Maxillofac Implants, Lombard, v. 22, n. 4, p. 575-579, July- Aug. 2007. 
52. KOHAVI, D. Complications in the tissue integrated prostheses components: clinical and mechanical evaluation. J Oral Rehabil, Oxford, v. 20, n. 4, p. 413422, July, 1993.

53. KHRAISAT, A.; HASHIMOTO, A.; NOMURA, S.; MIYAKAWA, O. Effect of lateral cyclic loading on abutment screw loosening of an external hexagon implant system. J Prosthet Dent, St. Louis, v. 91, n. 4, p. 326-334, Apr. 2004a.

54. KHRAISAT, A.; ABU-HAMMAD, O.; AL-KAYED, A. M.; DAR-ODEH, N. Stability of the implant/abutment joint in a single-tooth external-hexagon implant system: clinical and mechanical review. Clin Implant Dent Relat Res, Hamilton, v. 6 , n. 4, p. 222-229, Dec. 2004b.

55. KHRAISAT, A.; BAQAIN, Z. H.; SMADI, L.; NOMURA, S.; MIYAKAWA, O.; ELNASSER, Z. Abutment rotational displacement of external hexagon implant system under lateral cyclic loading. Clin Implant Dent Relat Res, Hamilton, v. 8, n. 2, p. 96-99, 2006.

56. KUNAVISARUT, C.; LANG, L. A.; STONER, B. R.; FELTON, D. A. Finite element analysis on dental implant - supported prostheses without passive fit. J Prosthodont, Philadelphia, v. 11, n.1, p. 30-40, March. 2002.

57.LANG, L. A.; MAY, K. B.; WANG, R. F. The effect of the use of a countertorque device on the abutment-implant complex. J Prosthet Dent, St. Louis, v. 81n. 4, p. 411-417, Apr. 1999.

58. LEWIS, S.; BEUMER III, J.; HORNBURG, W.; MOY, P. The "UCLA" abutment. Int J Oral Maxillofac Implants, Lombard, v. 3, n. 3, p. 183-189, Fall, 1988a.

59. LEWIS, S.; BEUMER III, J.; PERRI, G. R.; HORNBURG, W.P. Single tooth implant supported restorations. Int J Oral Maxillofac Implants, Lombard, v. 4, p. 25-30, Feb. 1988b.

60. LEWIS, S.; AVERA, S.; BEUMER III, J.; ENGLEMAN, M. The restoration of improperly inclined osseointegrated implants. Int J Oral Maxillofac Implants, Lombard, v. 4, n.2, p. 40-49, Summer. 1989.

61.LEWIS, S. G.; LLAMAS, D.; AVERA, S. The UCLA abutment: A four-year review. J PROSTHET DENT, St. Louis, v. 67, n. 4, p. 509-515, Apr. 1992.

62. MA, T; NICHOLLS, J. I.; RUBENSTEIN, J. E. Tolerance measurements of various implant components. Int J Oral Maxillofac Implants, Lombard, v. 12, n. 3, p. 371-375. 1997. 
63. MALAGUTI, G.; DENTI, L.; BASSOLI, E.; FRANCHI, I.; BORTOLINI, S.; GATTO, A. Dimensional tolerances and assembly accuracy of dental implants and machined versus cast-on abutments. Clin Implant Dent Relat Res, Copenhagen, 2009. In Press. Publicado online em 3 Ago 2009.

64. MARTIN, W. C.; WOODY, R. D.; MILLER, B. H.; MILLER, A. W. Implant abutment screw rotations and preloads for four different screw materials and surfaces. J Prosthet Dent, St. Louis, v. 86, n. 1, p. 24-32, July. 2001.

65. MAY, K. B.; M. M.; EDGE, M. J.; RUSSELL, M. M.; RAZZOG, M. E.; LANG, B. $\mathrm{R}$. The precision of fit at the implant prosthodontic interface. J Prosthet Dent, St. Louis, v. 77, n. 5, p. 497-502, May, 1997.

66. MOHL, N.D.; ZARB, G.A.; CARLSSON, G.E.; RUGH, J.D. A textbook of occlusion. Chicago: Quintessence, p.143-52. 1988.

67. NASCIMENTO, C. Avaliação da infiltração bacteriana através da interface implante-conector protético sob aplicação de carga - avaliação in vitro pelo método DNA Checkerboard. 2010. 200 f. Tese (Doutorado em Reabilitação Oral) - Faculdade de Odontologia de Ribeirão Preto, Universidade de São Paulo, Ribeirão Preto, 2010.

68. NAKAMURA, L. H. Estudo comparativo do afrouxamento de diferentes parafusos de fixação de abutment em implantes de hexágono externo e interno, após o ensaio de ciclagem mecânica. 2005. 117 f. Dissertação (Mestrado em Reabilitação Oral) - Faculdade de Odontologia da Universidade de São Paulo, São Paulo, 2005.

69. NAKAMURA, L. H.; CONTIN, I.; PICHLER, E. F. Estudo comparativo do afrouxamento de diferentes parafusos de fixação de "abutment" em implantes de hexágono externo e interno, após o ensaio de ciclagem mecânica. Rev Pós Grad, São Paulo, v. 13, n. 1, p. 96-102, 2006.

70. NEVES, F. D. Estudo comparativo da adaptação entre componentes intermediários e implantes de sete sistemas diferentes. 2000. Tese (Doutorado em Reabilitação Oral) - Faculdade de Odontologia de Ribeirão Preto, da Universidade de São Paulo, São Paulo, 2000.

71. QUEK, H. C.; TAN, K. B.; NICHOLLS, J. I. Load fatigue performance of four implant-abutment interface designs: effect of torque level and implant system. Int J Oral Maxillofac Implants, Lombard, v. 23, n. 2, p. 253-262, Mar.- Apr. 2008. 
72. SAKAGUCHI, R. L., BORGERSEN, S. E. Nonlinear finite element contact analysis of dental implant components. Int J Oral Maxillofac Implants, Lombard, v. 8, n. 6, p. 655-661, Nov-Dec. 1993.

73. SAKAGUCHI, R. L., BORGERSEN, S. E. Nonlinear contact analysis of preload in dental in dental implant srews. Int J Oral Maxillofac Implants, Lombard, v. 10, n. 2, p. 253-262, Mar.- Apr. 2008.

74. SARTORI, I. Análise comparativa da interface intermediário estético/cilindro protético, torneados em ouro ou em plástico, antes e após as fundições. 1999. Dissertação Mestrado - Faculdade de Odontologia de Ribeirão Preto, Universidade de São Paulo, São Paulo.

75. SCHULTE, J. K. External hex manufacturing tolerances of six implant systems: pilot a study. Implant Dent, Baltimore, v. 3, n.1, p. 51-3, 1994.

76. SONES, A. D. Complications with osseointegrated implants. J Prosthet Dent, St. Louis, v. 62, n. 5, p. 581-585, Nov. 1989.

77.TAN, K. B.; NICHOLLS, J. I. Implant-abutment screw joint preload of 7 hextop abutment systems. Int J Oral Maxillofac Implants, Lombard, v. 16, n. 3, p. 367-377, May-June. 2001.

78. TAN, K. B. The clinical significance of distortion in implant prosthodontics: is there such a thing as passive fit? Ann Acad Med Singapore, v. 24, n. 1, p. 138-157, Jan. 1995.

79. TAVAREZ, R. R. J. Análise Comparativa das Interfaces de Implantes de Conexão Externa e Interna em Restaurações Unitárias Cimentadas e Parafusadas, Antes e Após Ensaios de Fadiga. 2003. 236 p. Tese (Doutorado em Reabilitação Oral) - Faculdade de Odontologia de Bauru, Universidade de São Paulo, Bauru, 2003.

80.SCHMITT, A.; ZARB, G.A. The longitudinal clinical effectiveness of osseointegrated dental implants for single-tooth replacement. Int $\mathbf{J}$ Prosthodont., Lombard, v.6, n. 2, p. 197-202, Mar-Apr, 1993.

81.SCHWARTZ-ARAD, D.; SAMET, N.; SAMET, N. Single tooth replacement of missing molars: a retrospective study of 78 implants. J Periodontol, Chicago, v. 70, n. 4, p.449-454, Apr. 1999. 
82. SILVA, J. M.; MIRANDA, J. E. S.; ALVES, B. P. Desajuste vertical na interface implantes/ pilares UCLA com cinta metálica. Revista Implant News, v. 7, n. 2, p. 203-210, mar./ abr. 2010.

83. VIGOLO, P.; MAJZOUB, Z.; CORDIOLI, G. Measurement of the dimensions and abutment rotational freedom of gold machined 3i UCLA-type abutments in the as-received condition, after casting with a noble metal alloy and porcelain firing. J Prosthet Dent, St. Louis, v. 84, n. 5, p. 548-553, Nov. 2000.

84. WEINBERG, L. A. The biomechanics of force distribution in implant-supported prostheses. Int J Oral Maxillofac Implants, Lombard, v. 8, n. 1, p. 147-165, Jan.-Feb. 1993.

85.WHITE, G. E. Osseointegrated Dental Technology. $1^{\text {st }}$ ed. London: Quintessence Publishing Company Ltd.; 1993: 82-83.

86.WIE, H. Registration of localization, occlusion and occluding materials for failing screw joints in the Branemark implant system. Clin Oral Impl Res., Copenhagen, v. 6, n.1, p. 47-53, Mar. 1995. 
Apêndices 
Apêndice A - Tabelas com os valores de liberdade rotacional, em graus, dos pilares do grupo Tilite.

\begin{tabular}{|c|c|c|c|c|}
\hline & \multicolumn{4}{|c|}{$1^{\circ}$ LIBERDADE ROTACIONAL } \\
\hline \multirow{2}{*}{ Conjuntos } & \multicolumn{3}{|c|}{ Posição } & \multirow[t]{2}{*}{ Média } \\
\hline & 1 & 2 & 3 & \\
\hline 1 & 2,7 & 2,887 & 2,887 & 2,824 \\
\hline 2 & 3,287 & 3,637 & 3,637 & 3,520 \\
\hline 3 & 3,3 & 2,762 & 2,762 & 2,941 \\
\hline 4 & 2,638 & 2,7 & 2,7 & 2,679 \\
\hline \multirow[t]{2}{*}{5} & 3,225 & 2,575 & 2,575 & 2,833 \\
\hline & \multicolumn{4}{|c|}{$2^{\circ}$ LIBERDADE ROTACIONAL } \\
\hline \multirow[t]{2}{*}{ Conjuntos } & \multicolumn{3}{|c|}{ Posição } & Média \\
\hline & 1 & 2 & 3 & \\
\hline 1 & 3,625 & 4,375 & 6,05 & 4,683 \\
\hline 2 & 3,938 & 3,913 & 4,05 & 3,967 \\
\hline 3 & 5,563 & 4,8 & 3,075 & 4,479 \\
\hline 4 & 1,063 & 1,113 & 1,625 & 1,267 \\
\hline \multirow[t]{2}{*}{5} & 8,3 & 8,25 & 7,85 & 8,133 \\
\hline & \multicolumn{4}{|c|}{$3^{\circ}$ LIBERDADE ROTACIONAL } \\
\hline \multirow[t]{2}{*}{ Conjuntos } & \multicolumn{3}{|c|}{ Posição } & Média \\
\hline & 1 & 2 & 3 & \\
\hline 1 & 6,013 & 6,1 & 5,863 & 5,992 \\
\hline 2 & 4,125 & 4,275 & 4,588 & 4,329 \\
\hline 3 & \multicolumn{4}{|c|}{ Implante fraturado } \\
\hline 4 & 1,350 & 1,663 & 1,963 & 1,658 \\
\hline \multirow[t]{2}{*}{5} & 8,438 & 8,8 & 8,338 & 8,525 \\
\hline & \multicolumn{4}{|c|}{$4^{\circ}$ LIBERDADE ROTACIONAL } \\
\hline \multirow[t]{2}{*}{ Conjuntos } & & Posição & & Média \\
\hline & 1 & 2 & 3 & \\
\hline 1 & 4,05 & 3,15 & 2,875 & 3,358 \\
\hline 2 & 3,088 & 3,013 & 3,025 & 3,042 \\
\hline 3 & \multicolumn{4}{|c|}{ Implante fraturado } \\
\hline 4 & 3,788 & 3,163 & 3,538 & 3,496 \\
\hline \multirow[t]{2}{*}{5} & 3,113 & 3,175 & 2,775 & 3,021 \\
\hline & \multicolumn{4}{|c|}{$5^{\circ}$ LIBERDADE ROTACIONAL } \\
\hline Conjuntos & \multicolumn{3}{|c|}{ Posição } & Média \\
\hline & 1 & 2 & 3 & \\
\hline 1 & 2,613 & 2,55 & 3,163 & 2,775 \\
\hline 2 & 2,400 & 2,650 & 3,100 & 2,717 \\
\hline 3 & \multicolumn{4}{|c|}{ Implante fraturado } \\
\hline 4 & 2,225 & 2,375 & 2,575 & 2,392 \\
\hline 5 & 3,413 & 3,5 & 3,188 & 3,367 \\
\hline
\end{tabular}


Apêndice B- Tabelas com o valores de liberdade rotacional, em graus, para os pilares do grupo $\mathrm{NiCr}$.

\begin{tabular}{|c|c|c|c|c|}
\hline \multirow{3}{*}{ Conjuntos } & \multicolumn{4}{|c|}{$1^{\circ}$ LIBERDADE ROTACIONAL } \\
\hline & \multicolumn{3}{|c|}{ Posição } & \multirow[t]{2}{*}{ Média } \\
\hline & 1 & 2 & 3 & \\
\hline 1 & 3,662 & 5 & 5,7 & 4,787 \\
\hline 2 & 5,8 & 5 & 4,6 & 5,133 \\
\hline 3 & 3,65 & 4,35 & 4,725 & 4,242 \\
\hline 4 & 4,95 & 5,113 & 6,875 & 5,646 \\
\hline \multirow[t]{2}{*}{5} & 3,587 & 3,25 & 4 & 3,612 \\
\hline & \multicolumn{4}{|c|}{$2^{\circ}$ LIBERDADE ROTACIONAL } \\
\hline \multirow[t]{2}{*}{ Conjuntos } & \multicolumn{3}{|c|}{ Posição } & Média \\
\hline & 1 & 2 & 3 & \\
\hline 1 & 3,175 & 4,7 & 6,025 & 4,633 \\
\hline 2 & 1,463 & 1,675 & 1,938 & 1,692 \\
\hline 3 & 3,15 & 2,813 & 3,138 & 3,033 \\
\hline 4 & 4,375 & 4,875 & 4,525 & 4,592 \\
\hline \multirow[t]{2}{*}{5} & 1,913 & 1,888 & 2,5 & 2,100 \\
\hline & \multicolumn{4}{|c|}{$3^{\circ}$ LIBERDADE ROTACIONAL } \\
\hline \multirow[t]{2}{*}{ Conjuntos } & \multicolumn{3}{|c|}{ Posição } & Média \\
\hline & 1 & 2 & 3 & \\
\hline 1 & 6,375 & 7,025 & 6,238 & 6,546 \\
\hline 2 & 2,150 & 1,563 & 1,925 & 1,879 \\
\hline 3 & 3,100 & 3,125 & 3,138 & 3,121 \\
\hline 4 & 5,5 & 4,575 & 4,800 & 4,958 \\
\hline \multirow[t]{2}{*}{5} & 2,737 & 2,375 & 2,650 & 2,587 \\
\hline & \multicolumn{4}{|c|}{$4^{\circ}$ LIBERDADE ROTACIONAL } \\
\hline \multirow[t]{2}{*}{ Conjuntos } & \multicolumn{3}{|c|}{ Posição } & Média \\
\hline & 1 & 2 & 3 & \\
\hline 1 & 5,5 & 5,725 & 6 & 5,742 \\
\hline 2 & 6,125 & 6,5 & 7,325 & 6,650 \\
\hline 3 & 5,5 & 5,85 & 5,075 & 5,475 \\
\hline 4 & 5,363 & 6,025 & 6,05 & 5,813 \\
\hline \multirow[t]{2}{*}{5} & 5,8 & 6,625 & 6,975 & 6,467 \\
\hline & \multicolumn{4}{|c|}{$5^{\circ}$ LIBERDADE ROTACIONAL } \\
\hline \multirow[t]{2}{*}{ Conjuntos } & \multicolumn{3}{|c|}{ Posição } & Média \\
\hline & 1 & 2 & 3 & \\
\hline 1 & 0,975 & 1,038 & 1,125 & 1,046 \\
\hline 2 & 6,375 & 6,5 & 6,088 & 6,321 \\
\hline 3 & 2,325 & 2,65 & 2,4 & 2,458 \\
\hline 4 & 7,15 & 7 & 5,25 & 6,467 \\
\hline 5 & 6,413 & 5,625 & 5,4 & 5,813 \\
\hline
\end{tabular}

